\title{
Solid-state photoelectrochemical hydrogen generation
}

Kingsley Odinaka Iwu

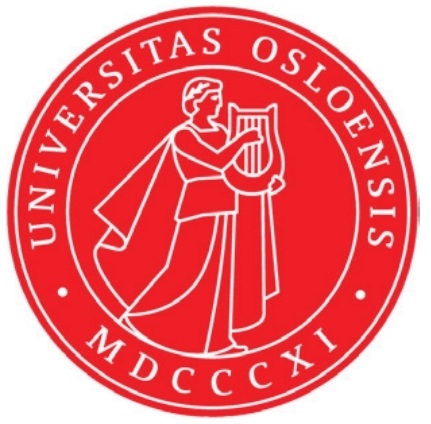

Dissertation for the Degree of Philosophiae Doctor

Department of Chemistry

Faculty of Mathematics and Natural Sciences

University of Oslo

2013 
(C) Kingsley Odinaka Iwu, 2013

Series of dissertations submitted to the

Faculty of Mathematics and Natural Sciences, University of Oslo No. 1406

ISSN 1501-7710

All rights reserved. No part of this publication may be

reproduced or transmitted, in any form or by any means, without permission.

Cover: Inger Sandved Anfinsen.

Printed in Norway: AIT Oslo AS.

Produced in co-operation with Akademika Publishing.

The thesis is produced by Akademika Publishing merely in connection with the thesis defence. Kindly direct all inquiries regarding the thesis to the copyright holder or the unit which grants the doctorate. 


\section{Preface}

This dissertation is the culmination of the research I have undertaken in fulfilment of the requirement for the award of the degree of Philosophiae Doctor $(\mathrm{PhD})$ at the Department of Chemistry, Faculty of Mathematics and Natural Sciences, University of Oslo. The project, led by Professor Truls Norby, was funded by the Research Council of Norway under the RENERGI scheme, from December 2009 to December 2012.

I would like to thank my supervisors Truls Norby and Andrej Yu. Kuznetsov for their guidance. Augustinas Galeckas, who worked as a PostDoc in the project, is appreciated for the time and effort he put into making my work a success. Members of the group for Solid State Electrochemistry are appreciated for providing a conducive work environment. I would like to particularly thank, Einar Vøllestad, Oddvar Dyrlie, and Andreas Løken for providing much needed support in those early days. The latter shared office with me at the beginning, and afterwards came Brian Wabende. They made the office environment pleasant, not least for being football fans, and supporters of the "wrong team" for that matter. Wen Xing and Ragnar Strandbakke are appreciated for all the time spent in trying to make sense of some experimental results. Ragnar and Camilla Vigen did their best to help me understand the simplicity of Norwegian language, as much as their busy schedules could allow.

All my friends near and far are acknowledged for their care and interest in what I have been doing.

Finally, I am grateful to members of my family for their support and love: my mother, sisters, brothers, and other relatives in Nigeria and the UK, and here in Norway, my mother-in-law, Amaka and Shylate.

Oslo, May 2013

Kingsley Odinaka Iwu 


\section{Contents}

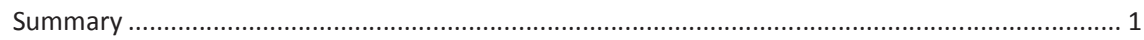

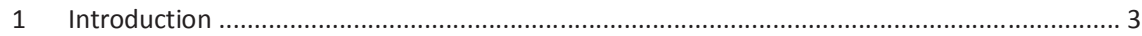

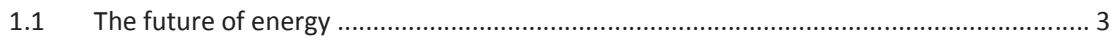

$1.2 \quad$ Energy from the sun ............................................................................................. 4

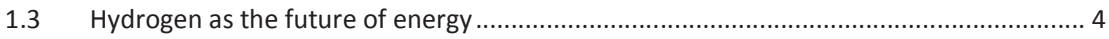

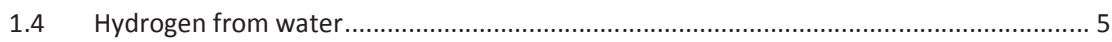

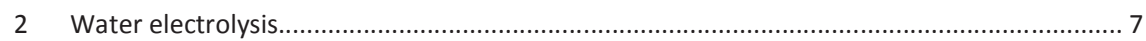

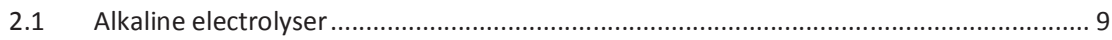

2.2 Polymer electrolyte membrane electrolyser ............................................................ 10

2.3 High temperature electrolyser................................................................................ 11

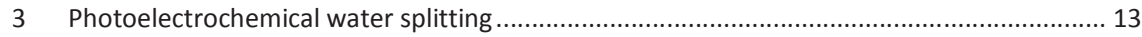

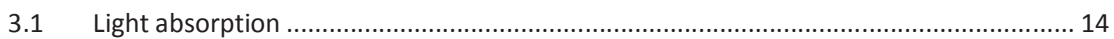

3.2 Materials stability and solar-to-fuel conversion efficiency .......................................... 16

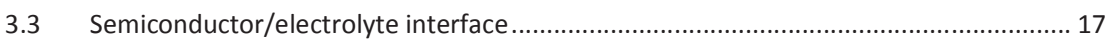

3.4 Charge transfer at the photoanode/electrolyte interface ............................................ 19

3.5 Investigating defects and charge carrier dynamics with photoluminescence................. 22

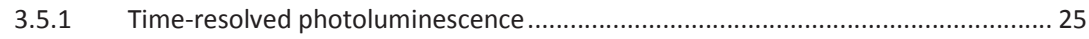

3.6 Solid electrolyte for photoelectrochemical hydrogen generation.................................. 25

3.7 Effect of temperature on photoelectrochemical hydrogen generation ......................... 26

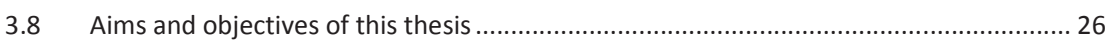

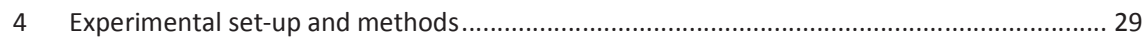

4.1 Photoelectrochemical set up and characterisation ..................................................... 29

4.1.1 Electrochemical impedance spectroscopy ……................................................. 33

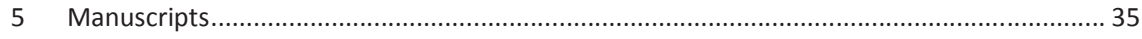

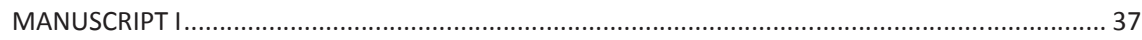

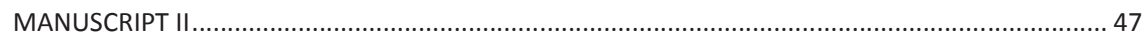

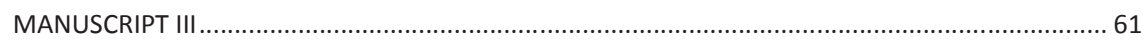

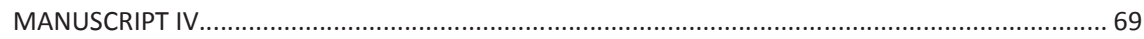

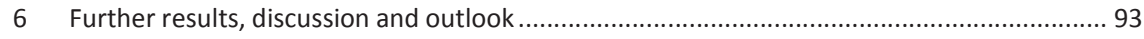

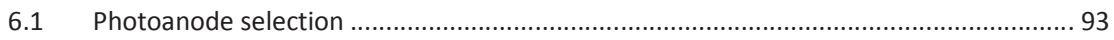

6.2 Nafion + inorganic composite proton conducting membrane..................................... 93

6.3 Carbon paper versus titanium-covered carbon paper ..................................................... 95 
6.4 Light-to-photocurrent conversion efficiency …………………………………......... 99

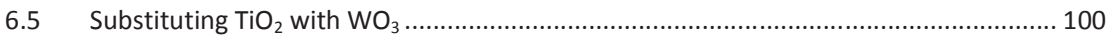

6.6 Photoanode/electrolyte/reactant triple phase boundary .................................................. 103

6.7 Suggestion for future improvements on solar-to-fuel conversion efficiency ................. 105

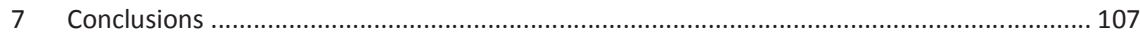

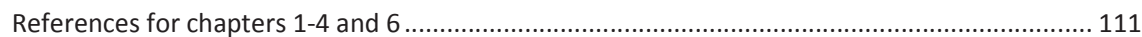

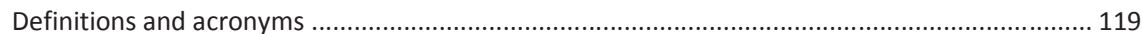

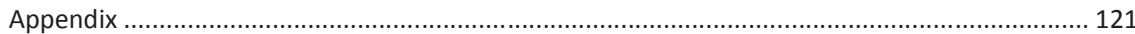




\section{Summary}

In the quest to derive all or the majority of the world's energy demand from renewable energy sources, photoelectrochemical hydrogen generation from aqueous electrolytes using nanostructured semiconductors as photocatalyst has attracted a lot of attention. The use of aqueous electrolytes both now and in future commercial devices implies the following limitations:

1. Almost all research is carried out at room or close to room temperature, precluding studies at higher temperatures where thermodynamics and electrode kinetics naturally favour electrolysis.

2. The need for post-production treatments of the produced hydrogen in order to purify, dry, and pressurise it.

3. The presence of gas bubbles which have the capacity to increase electrolyte resistance and impede mass diffusion at the electrodes.

Besides, the anode and cathode compartments in most of the current studies are not separated, leading to the mixing of the electrode gases. Integration of separate electrode compartments into photoelectrochemical hydrogen-generating devices is a vital step towards moving research in this area forward.

All-solid-state photoelectrochemical cells comprising oxide photoanodes, solid electrolytes based on polymer electrolyte membranes, and platinum-coated carbon cathodes were prepared and their performances evaluated in this thesis. The separation of the electrode compartments by a membrane meant that the gases produced at the two electrodes were prevented from mixing. The photoanode compartment was fed with water vapour or a gaseous mixture of water and methanol. The experimental work is presented in four manuscripts (chapter 5), and in part of chapter 6 .

In Manuscripts I and II, some of the materials used as photoanodes and solid electrolyte were prepared and characterised, with emphasis on nanostructuring, functionality, and optical properties. It was observed that the size of $\mathrm{WO}_{3}$ nanorods could be reduced, accompanied by the realisation of a phase pure hexagonal structure (elimination of an impurity monoclinic phase) and a red-shift in optical absorption. $\mathrm{WO}_{3} \cdot 1 / 3 \mathrm{H}_{2} \mathrm{O}$ with its molybdenum substituted version was particularly characterised for presence of adsorbed water molecules (in addition to the structural water) and presence of defect protons. These 
are considered important for its use in forming proton conducting composite membranes that are amenable to membrane electrode assembly by wet chemistry adhesion.

Photoelectrochemical cells with the $\mathrm{WO}_{3} \cdot 1 / 3 \mathrm{H}_{2} \mathrm{O}$-based composite membrane were prepared with Nafion ${ }^{\circledR}$ molecules as adhesive for membrane electrode assembly. They yielded much higher photocurrents than cells assembled by hot-pressing, which is a common method for making electrochemical cells based on polymer electrolyte membrane. Specifically, the Nafion ${ }^{\circledR}$ molecules enhanced the hydration of the photoanode particles, leading to a more efficient utilisation of photogenerated charge carriers.

For the cells prepared by hot-pressing, enhancement in photocurrent was obtained by increasing the temperature and conjugation of the photoanode $\left(\mathrm{TiO}_{2}\right)$ nanoparticles to an electro-active organic molecule. The organic molecules improved the lifetime of photogenerated charge carriers in $\mathrm{TiO}_{2}$ by a factor of about two. The optical absorption of $\mathrm{TiO}_{2}$ shifted to longer wavelength after hot-pressing. This was attributed to introduction of surface defect states near the conduction band of the photocatalyst, based on X-ray photoelectron spectroscopy. In general, voltammetry and impedance spectroscopy were used to identify the limitations to improving the efficiency of all photoelectrochemical cells.

Finally, comparisons in the performances of a $\mathrm{TiO}_{2}$ photoanode supported on carbon paper (the conducting substrate) and that on titanium-covered carbon paper are discussed in terms of photocurrent generation, stability and the photoanode/current collector interface. The performances of the studied photoelectrochemical cells are further analysed from the view point of active photoelectrochemical area. 


\section{Introduction}

\subsection{The future of energy}

Advances in energy production and utilisation have become the driving force for industrial and technological advancement in the history of humanity, leading to improvement in quality of life. This improvement however has come with mixed blessings in the long term, notably the pollution of the environment in which those whose lives have been purportedly improved live. There is yet another group of people whose lives have generally not improved significantly, but who instead have borne the brunt of the appetite of energy gulping societies in massive degradation of their land, air and water resources, and sometimes, in brutal conflicts.

Apart from environmental pollution, there is however another issue that concerns or should concern the two groups of people identified above. This is the fact that the commonest energy source - fossil fuels - is not limitless, both in terms of available and recoverable reserves. Fossil fuel as a primary energy source is reported to contribute about $80 \%$ of the total energy demand of the world, and this is expected to remain so up to 2030 [1]. The depletion of fossil fuels is not a threat in the short to medium term, but there should be no doubt that, should the current trend in the use of energy continue, a generation in the distant future will be left without enough energy sources to maintain a decent living standard.

In recent times, there have been increased efforts to tap into primary sources of energy that are renewable as a long term replacement for fossil fuels. This is also borne out of the desires to cut down on environmental pollution. Solar, hydro, geothermal, biomass, tidal and wind are examples of primary sources of renewable energy. Renewable energy sources (RES) accounted for about $2.6 \%$ of the world's primary energy sources in 2004, with the figure expected to reach $11.8 \%$ by 2030 [2]. A major problem with some RES, including the sun, is that they are not always there and must be used or stored when available. Energy storage more often than not entails conversion of energy from one form to another, and reconversion to a usable form when the energy is needed. The conversion processes lead to loss of energy, that is, less energy is available at the end than at the beginning. 


\subsection{Energy from the sun}

The sun is by far the biggest primary source of energy - with reference to RES or energy sources in general. The annual primary energy consumption of the world is 450 exajoules, while the solar radiation reaching the earth is 7,500 times that number [1]. The implication is that capturing just $0.1 \%$ of solar irradiance hitting the earth in a year would supply 7.5 times the current world energy demand. The problems with solar energy utilisation are firstly, the challenges of developing devices and materials that can harvest it at a reasonably high efficiency and cost effectiveness, and secondly, finding a way to efficiently store excess energy for use when the sun is not shining. The latter problem has not become a big issue yet but is something that must be addressed if we must hold on to the hope of seeing the sun replace fossil fuels as our dominant primary energy source.

The two most common ways of capturing energy from the sun are by photovoltaics and solar thermal collectors. While the former produces electricity directly, the latter produces heat which can be used directly for heating or for generating electricity in steam turbines. In this case, the heat can be stored, for example in a molten salt, until when electrical energy is needed.

\subsection{Hydrogen as the future of energy}

Hydrogen has been referred to as the energy of the future. It is not in itself an energy source but an energy carrier. Just like gasoline, it can be used as a chemical fuel in an internal combustion engine but the major attraction for it is its use in a fuel cell to generate electricity. A hydrogen economy in which hydrogen is used as the principal energy carrier has been envisaged. The challenge to this vision is that about $95 \%$ of the hydrogen produced today are used in chemical, petroleum and petrochemical industries for production of ammonia, methanol and processing of petroleum products [3].

Whether the energy stored in hydrogen is released by combustion or in a fuel cell, there is zero addition of the global warming gas, $\mathrm{CO}_{2}$, to the environment. Thus hydrogen is even better than the hydrocarbon with the lowest carbon footprint, methane. However, hydrogen is only as clean as the primary source of energy used in producing it. Figure 1.1 shows the primary sources of energy that can be used for hydrogen production, and they can be broadly divided into fossil fuels, nuclear energy and renewable energy sources. About $96 \%$ of current hydrogen production in the world comes from fossil fuels [4], mainly from 
hydrocarbon fuels reforming processes $[5,6]$. These processes have large carbon footprints. Only about $4 \%$ of current industrial hydrogen production comes through water electrolysis. Ramping up hydrogen production from hydrocarbon fuels to a level big enough to sustain a hydrogen economy will mean a more aggressive depletion of limited energy sources. The consequences will be more global warming and degradation of the environment. The future of a pollution-free hydrogen economy may therefore be hinged on using renewable energy sources for hydrogen production.

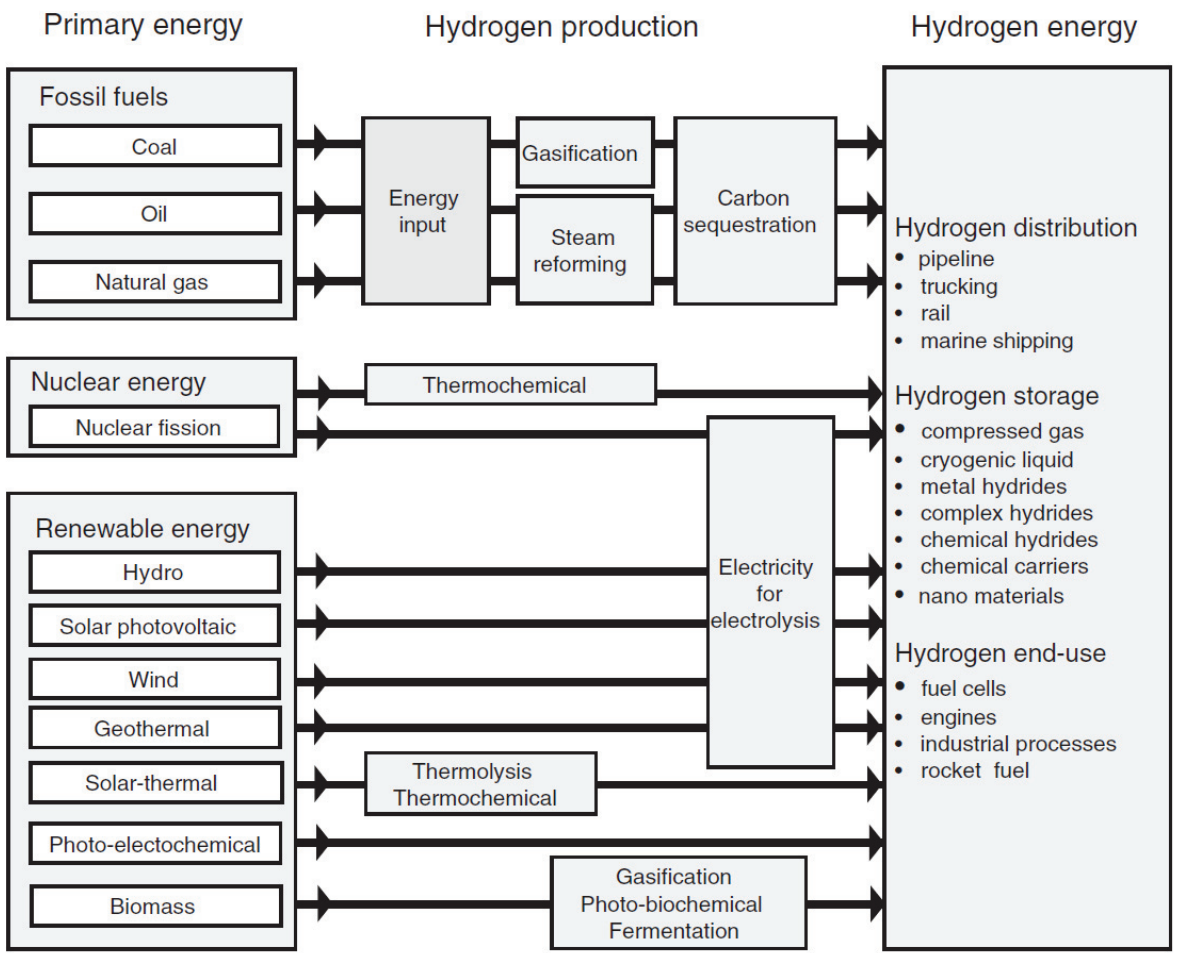

Figure 1.1: Primary sources of energy for hydrogen production for "a sustainable hydrogen economy" [2]

\subsection{Hydrogen from water}

Breaking the chemical bonds between oxygen and hydrogen atoms in water molecules will lead to the production of oxygen and hydrogen gases. The fact that about $70 \%$ of the earth surface is covered by water - streams, lakes, rivers, seas, oceans, etc. - makes this prospect particularly interesting for a hydrogen economy. This is especially true if the water splitting 
can be done without the need for purification of sea water for example, thereby eliminating a potential competition between water for domestic use and that for hydrogen production. High temperature splitting of water, otherwise known as thermolysis, is one of the ways of producing hydrogen from water. This can be accomplished by using solar concentrators or nuclear reactors to provide the enormous amount of heat energy needed for the process. The fact that the process requires operating temperatures of over $2000{ }^{\circ} \mathrm{C}$ imposes a problem of material limitation. In addition, the inherent inability of the process to separate the produced hydrogen from the product gas mixture introduces an additional difficulty in its practical implementation [7]. We shall now turn our attention to electrochemical splitting of water, which is the domain where this thesis lies and which is inherently capable of separating the produced oxygen and hydrogen. 


\section{Water electrolysis}

The electrolysis of water is a potential deal breaker in energy production and utilisation. A water electrolyser consists of two electrodes where the electrochemical reactions leading to gas evolution take place, and an electrolyte to facilitate the movement of ionic species from one electrode to the other. The biggest advantage of this method of water splitting and hydrogen production in general is that the product gases can be easily separated by putting an ion-conducting, gas-impermeable membrane between the two electrodes where oxidation (oxygen evolution reaction, OER) and reduction (hydrogen evolution reaction, HER) take place. The oxygen and hydrogen evolution terminal or electrodes are correspondingly called anode and cathode, and their particular half reactions leading to the evolution of the gases depend on the type of electrolyser, as will be shown later. The overall water splitting reaction is:

$\mathrm{H}_{2} \mathrm{O}(\mathrm{l})=\mathrm{H}_{2}(\mathrm{~g})+\frac{1}{2} \mathrm{O}_{2}(\mathrm{~g})$

The change in standard state Gibbs free energy, $\Delta \mathrm{G}^{\circ}$ for the reaction at $25{ }^{\circ} \mathrm{C}$ and 1 atmosphere is $237.178 \mathrm{~kJ} \mathrm{~mol}^{-1}$. The reversible potential $\left(\mathrm{E}^{\circ}\right)$ needed to drive the reaction can be calculated from:

$$
\Delta \mathrm{G}^{\circ}=-\mathrm{nFE}^{\circ}
$$

where $\mathrm{F}$ is Faraday's constant and $\mathrm{n}$ is the number of (moles of) electrons involved in the reaction. The value of $\mathrm{E}^{\circ}$ is $-1.23 \mathrm{~V}$, the negative sign implying that the reaction is non-spontaneous and would have to be run by application of electrical energy.

At present, the limitations to adopting water electrolysis as a large scale means of producing hydrogen are: 1) The energy needed for water splitting will have to come from somewhere, and 2) It takes more energy to split water than can be obtained when the reverse process, recombining hydrogen and oxygen in a fuel cell, is implemented ${ }^{1}$. Electrolysers typically operate at around $1.9 \mathrm{~V}$ and above [4], more than the reversible potential for water splitting

\footnotetext{
${ }^{1}$ In principle, reversing the water splitting reaction in a fuel cell should return the same energy (voltage) needed to split water in the first place. However, this is not the case because of energy losses due to resistive losses and overpotentials at the electrodes, just like in water electrolysis.
} 
because of ohmic (electrolyte, electrode and electrical connections resistive losses) and nonohmic (electrode polarisation) overpotentials.

The change in Gibbs free energy can be related to the total energy needed for water splitting and change in entropy by:

$\Delta \mathrm{G}=\Delta \mathrm{H}-\mathrm{T} \Delta \mathrm{S}$

where $\Delta \mathrm{H}$ is the change in enthalpy $\left(\mathrm{J} \mathrm{mol}^{-1}\right.$, endothermic in this case), $\mathrm{T}$ is temperature in Kelvin, and $\Delta \mathrm{S}$ is the change in entropy $\left(\mathrm{J} \mathrm{K}^{-1} \mathrm{~mol}^{-1}\right)$.

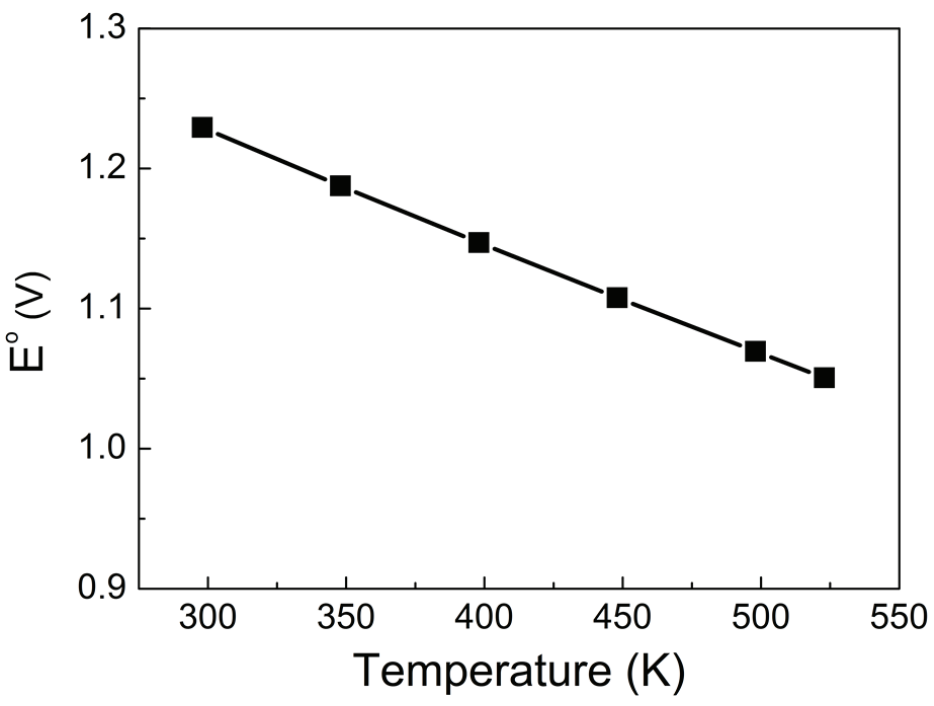

Figure 2.1: Plot of $\mathrm{E}^{\circ}$ vs. temperature at 1 atmosphere. The reversible potential was calculated based on equation 2.4. The negative sign on the potential is neglected for emphasis.

At 1 atmosphere, the reversible potential varies with temperature according to [8]:

$\mathrm{E}_{, \mathrm{t}}^{\circ}=1.5184-1.5421 \times 10^{-3} \mathrm{~T}+9.523 \times 10^{-5} \mathrm{~T} \ln \mathrm{T}+9.84 \times 10^{-8} \mathrm{~T}^{2}$

Figure 2.1 shows a plot of calculated potential versus temperature, indicating a decreasing reversible potential - and invariably a decreasing Gibbs free energy - with increasing temperature at a pressure of 1 atmosphere. In addition to reduced electrical energy input for 
electrolysis, electrode kinetics and the electrolyte conductivity (solid electrolyte in particular) are expected to improve with increasing temperature, further reducing the overall voltage requirement of an electrolyser. It has been stated that $\Delta \mathrm{H}$ for water electrolysis can be reduced from $284 \mathrm{~kJ} \mathrm{~mol}^{-1}$ for liquid water at $80{ }^{\circ} \mathrm{C}$ to $243 \mathrm{~kJ} \mathrm{~mol}^{-1}$ for steam at $130{ }^{\circ} \mathrm{C}$ $[9]$.

Further reduction in the cost of water electrolysis is dependent on using efficient electrolytes and electrodes. However, these improvements are not that straight forward as will be highlighted by briefly considering the major types of electrolysers.

\subsection{Alkaline electrolyser}

Alkaline electrolysis is the most common form of water electrolysis, and has been used industrially for several decades [10]. In this system, water is reduced to $\mathrm{H}_{2}$ and $\mathrm{OH}^{-}$at the cathode, and the hydroxide ion is conducted through the concentrated alkaline electrolyte to the anode where oxygen is evolved. Aqueous $\mathrm{KOH}$ ( 25 to $35 \mathrm{wt} \%$ ) is a common electrolyte, and the separator (between the electrodes) must possess such a porosity that allows the electrolyte to pass through while preventing mixing of the anode and cathode gases [4]. The half reactions taking place in this type of electrolyser are:

Anode: $2 \mathrm{OH}^{-}=\frac{1}{2} \mathrm{O}_{2}+\mathrm{H}_{2} \mathrm{O}+2 \mathrm{e}^{-}$

Cathode: $2 \mathrm{H}_{2} \mathrm{O}+2 \mathrm{e}^{-}=\mathrm{H}_{2}+2 \mathrm{OH}^{-}$

The main attractions of liquid alkaline water electrolysis lie in the high ionic conductivity of the electrolyte and the fact that cheaper materials can be used as electrode materials [11]. However, practical operation of an alkaline electrolyser [4] demands that bubbles - which reduce electrolyte conductivity - must be removed from the system, while continual injection of high purity water is needed to maintain the concentration of the electrolyte during operation. The use of a porous separator between the electrodes compartments can lead to problems such as product cross over (mixing of $\mathrm{H}_{2}$ and $\mathrm{O}_{2}$ )[10], which can be worse at higher temperatures (and invariably higher pressures) [12]. Shunt current occurrence [13] and use of even higher concentrated alkaline solution [14], with its attendant safety and materials degradation concerns, also complicate materials selection and cell design at higher temperatures and pressures. In the basic and less complex designs, the need for purification of the produced hydrogen and post-production gas compression make this type of 
electrolyser limited to mainly medium to large scale applications [11]. There is also a big concern for the safety of personnel operating an alkaline electrolyser plant due to the use of concentrated alkaline solution.

\subsection{Polymer electrolyte membrane electrolyser}

The electrolyte in a polymer electrolyte membrane (PEM) electrolyser is a solid, high acidity polymeric membrane which ensures effective separation of the electrode gases while at same time being very good in the conductivity of protons. A common membrane is the DuPont's product, Nafion $\AA$, which contains sulphonic acid terminal groups. These hydrophilic terminal groups are responsible for proton conductivity. Pure water is the only feedstock in this type of electrolyser and the electrode catalysts are supported on the membrane, leading to a more robust and compact design as shown in Figure 2.2. The cell half reactions are:

Anode: $\mathrm{H}_{2} \mathrm{O}=\frac{1}{2} \mathrm{O}_{2}+2 \mathrm{H}^{+}+2 \mathrm{e}^{-}$

Cathode: $2 \mathrm{H}^{+}+2 \mathrm{e}^{-}=\mathrm{H}_{2}$

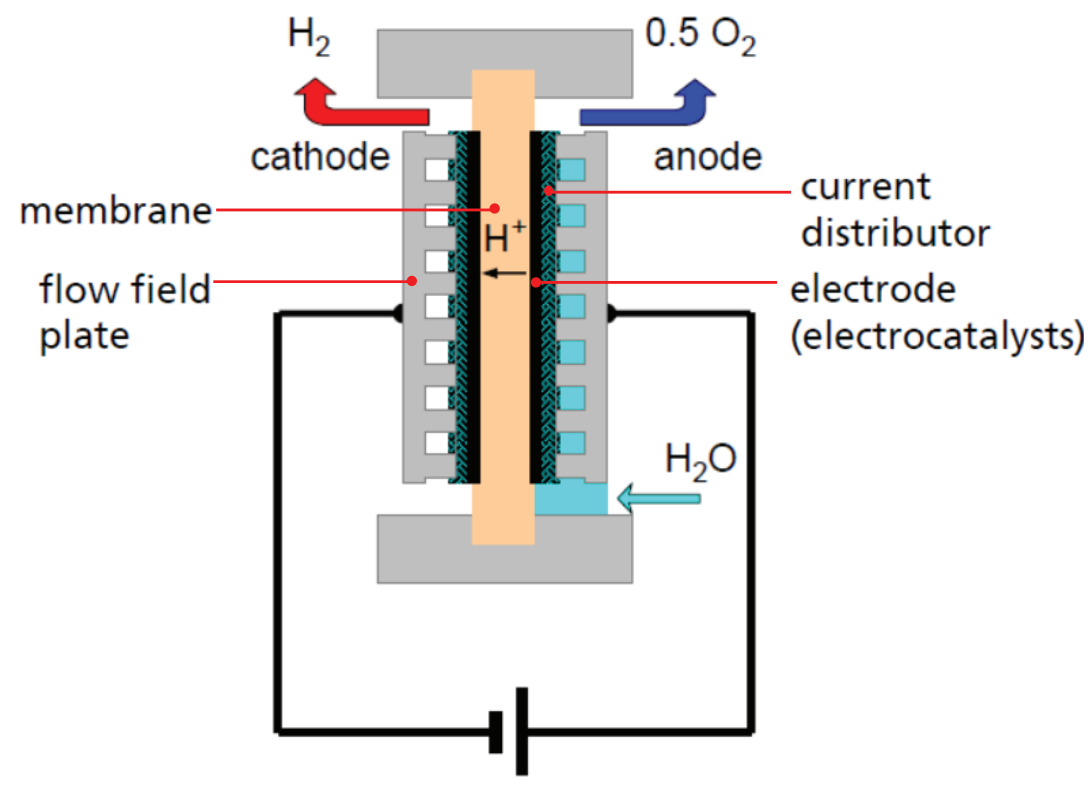

Figure 2.2: Schematic of a PEM electrolysis cell [15] 
It should be noted that protons are conducted in PEM mainly as $\mathrm{H}_{3} \mathrm{O}^{+}$, that is, they are carried on the back of water molecules - the vehicle mechanism. The major advantages of PEM electrolysis over liquid alkaline electrolysis include: [9] (a) higher purity of produced $\mathrm{H}_{2}$, (b) higher $\mathrm{H}_{2}$ production rate, (c) operation at higher pressures in order to make compressed $\mathrm{H}_{2}$ directly, and (d) easier to operate at higher temperature - steam electrolysis. Operating PEM electrolyser at higher pressures of 30-45 bar requires less power input than electrolysis at lower pressure followed by $\mathrm{H}_{2}$ compression [11].

The obvious superiority of PEM electrolysers notwithstanding, their wide scale adoption as a viable means of $\mathrm{H}_{2}$ production is still limited by their high costs, mainly due to expensive parts such as the membrane, flow field plates and current collectors/distributors [16], and the noble metal catalyst needed for stable operation at the highly acidic cell conditions [10]. As the costs of PEM electrolyser units are reduced, their use is expected to become more widespread. This cost reduction is expected to benefit from intense research in the PEM fuel cell, which is basically the same as a PEM electrolyser but with operation in reverse mode.

Another possibility in membrane-based water electrolysis is to combine the merits of liquid alkaline and PEM electrolysers by replacing the acidic PEM with a more tolerable basic $\left(\mathrm{OH}^{-}\right.$conducting) membrane. This will allow the use of cheaper and abundant electrode catalysts like in the classical liquid alkaline electrolysis. Recent works [10, 17] indicate that this direction is promising, but is limited by availability of hydroxyl conducting membranes with comparable stability and conductivity as their proton conducting counterparts.

\subsection{High temperature electrolyser}

The need to exploit the favourable thermodynamics and electrode kinetics of high temperature electrolysis is the driving force for the development of electrolysers operating at temperatures much higher than PEM electrolysis can withstand. The most studied type of high temperature electrolysers are those employing oxygen ion conducting solid-oxide as electrolyte. They are typically operated in the 700 to $1000{ }^{\circ} \mathrm{C}$ range, with the state of the art nickel/yttria stabilised zirconia cermet cathode (Ni/YSZ), stabilised zirconia electrolyte and conducting perovskites anode [12, 18-20]. The expensive noble metal catalysts used in PEM electrolysers are not needed for their operation. Operating a high temperature electrolyser at as high as $1000{ }^{\circ} \mathrm{C}$ (better for electrolyte conductivity) is common but lowering the temperature to between $500-750{ }^{\circ} \mathrm{C}$ can offer better flexibility in some aspect of materials selection. The only challenge in this case is getting the electrode kinetics to be as good as 
when operating at higher temperatures [18]. The half cell reactions taking place in this type of electrolyser are:

Anode: $\mathrm{O}^{2-}=\frac{1}{2} \mathrm{O}_{2}+2 \mathrm{e}^{-}$

Cathode: $\mathrm{H}_{2} \mathrm{O}+2 e^{-}=\mathrm{H}_{2}+\mathrm{O}^{2-}$

A different type of high temperature electrolyser uses proton conducting solid oxide, for example doped $\mathrm{BaZrO}_{3}$, with operating temperatures of $700{ }^{\circ} \mathrm{C}$ [21] and $800{ }^{\circ} \mathrm{C}$ [22]. It can be regarded as the high temperature variant of PEM electrolysis, since it has the same half cell reactions as PEM electrolysis. This implies that the produced hydrogen is dry (see equation 2.7), in contrast to oxygen ion conducting high temperature electrolysis in which water is mixed with hydrogen at the cathode (equation 2.9). Besides, the fact that proton conducting oxides can be operated at $700{ }^{\circ} \mathrm{C}$ and below, even down to $400{ }^{\circ} \mathrm{C}[23,24]$, makes material selection easier. Their proton conductivity is based on protons from water or hydrogen dissolving in them, and moving by hopping from one oxygen atom to another - the so called Grotthuss mechanism. This means that electrolysers based on them can produce drier hydrogen than PEM electrolysers in which the vehicle mechanism dominates. 


\section{Photoelectrochemical water splitting}

Converting electrical energy to chemical energy by water electrolysis and re-converting back to electrical energy when the need arises can be a rather wasteful route, except in the case of cheap and abundant electrical energy. Storing electrical energy in batteries and capacitors can be described as a medium scale solution at best, and may be insufficient for a future energy consumption scheme without fossil fuels. If the source of the electrical energy for water electrolysis is the Sun (through photovoltaic and solar thermal systems), another potential way exists for circumventing electricity production and directly converting solar energy to hydrogen, and that is by photoelectrochemical (PEC) water splitting.

In PEC water electrolysis, one or both of the electrocatalysts of an electrolysis cell are replaced by semiconductor materials $[25,26]$; the electrodes are then appropriately referred to as photoanodes and photocathodes. Thus, a PEC hydrogen generating cell could be a combination of a photoanode and a photocathode, a photocathode and an electrocatalyst anode, or a photoanode and an electrocatalyst cathode. The latter is the more widely researched of the three and is the focus of this thesis. PEC hydrogen production at a cost competitive with the price of petroleum based fuels is considered the holy grail of electrochemistry, and in recent times has become the subject of intense research aimed at overcoming its present low energy conversion efficiency.

In a typical PEC cell for water splitting shown in Figure 3.1, shining light of appropriate wavelength on the n-type photoanode leads to generation of electrons and holes. If the charge carriers can be separated ${ }^{2}$, with the electrons getting to a current collector (substrate of the n-type semiconductor film), and the holes migrating to the semiconductor-electrolyte interface, the latter will react with water to produce oxygen and protons:

$$
\mathrm{H}_{2} \mathrm{O}+2 \mathrm{~h}^{+}=2 \mathrm{H}^{+}+\frac{1}{2} \mathrm{O}_{2}
$$

while the electrons flowing through an external circuit meet and reduce the protons to hydrogen gas at the cathode:

$$
2 \mathrm{H}^{+}+2 \mathrm{e}^{-}=\mathrm{H}_{2}
$$

\footnotetext{
${ }^{2}$ Generation and separation of electron hole pairs are given a more in depth treatment in section 3.3.
} 


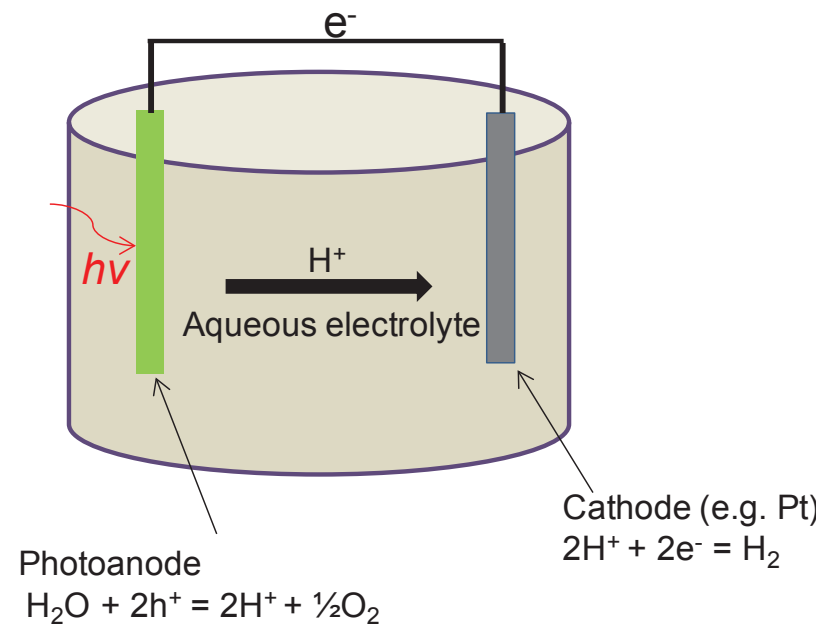

Figure 3.1: Schematic of a photoelectrochemical water splitting cell. The electron-hole pairs generated at the photoanode by light $(h v)$ absorption carry out the half reactions.

PEC hydrogen production has a number of limitations that have to be addressed in order to bring the process to a point where commercial application can be considered. The most important of these limitations are discussed below.

\subsection{Light absorption}

In order to split water photoelectrochemically, a semiconductor with a bandgap higher than $1.23 \mathrm{eV}$, typically around $1.9 \mathrm{eV}$, is needed to accommodate the thermodynamic requirements and overpotential losses [26]. This in turn places the entire spectral region of solar radiation with the wavelengths longer than $\sim 650 \mathrm{~nm}$ out of use. Figure 3.2 shows the solar irradiance reaching the earth (AM1.5) as a function of wavelength, also indicating the part of the spectrum that can be absorbed by an ideal semiconductor with a band gap of about $2 \mathrm{eV}$. Among the variety of semiconductor materials, only a few appear suitable for direct conversion of solar energy needed to sustain photoelectrochemical splitting of water as shown in Figure 3.3. This is further complicated by the problem of materials stability as will be discussed next. PEC cells comprising tandem (series) arrangement of three photoanodes absorbing at different parts of the solar spectrum have been devised as a way of maximising light absorption and utilising light with wavelength longer than $650 \mathrm{~nm}[27,28]$. 


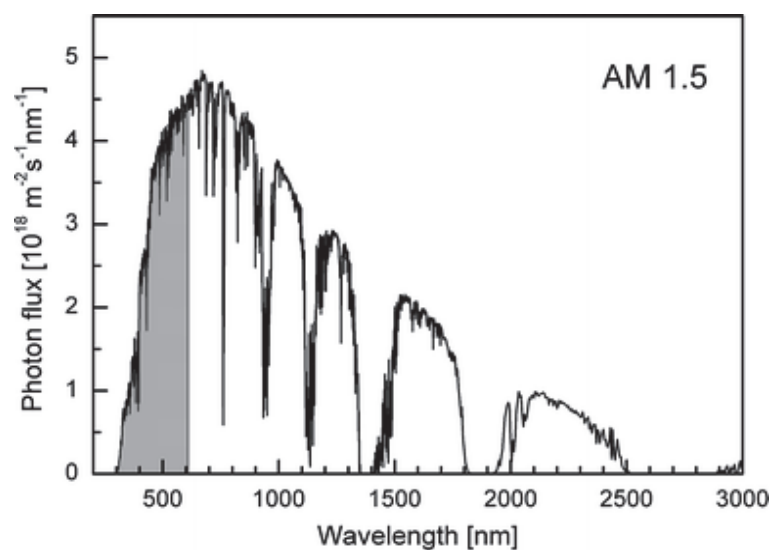

Figure 3.2: Solar irradiance as a function of wavelength for AM 1.5 conditions. The grey area indicates the part of the spectrum that can be absorbed by an ideal semiconductor with a band gap of about $2 \mathrm{eV}[26]$.

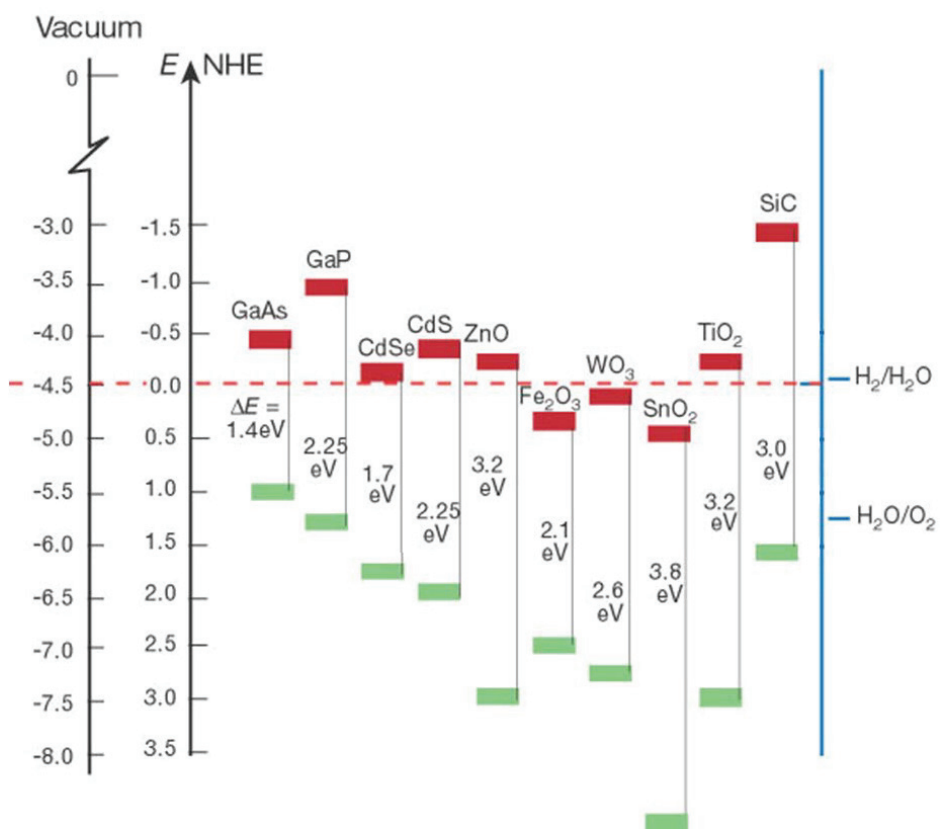

Figure 3.3: Conduction (red) and valence (green) bands edges, and band gaps of selected semiconductors in aqueous electrolyte of $\mathrm{pH} 1$. On the right-hand side, the standard potentials for water oxidation and reduction are indicated [29]. 


\subsection{Materials stability and solar-to-fuel conversion efficiency}

A PEC photoanode needs to be resistant to corrosion in the aqueous - often acidic or basic solutions in which they are operated. When this is juxtaposed against the need for significant visible light absorption, a problem with selecting the right material arises. The reason is that, in general, semiconductors with strong absorption in the visible range (mainly non oxide semiconductors) are vulnerable to corrosion while the ones that are stable (mainly oxide semiconductors) have wide band gaps $[26,29]$. Thus the latter - for example $\mathrm{TiO}_{2}$ and $\mathrm{ZnO}$ absorb mainly in the ultraviolet (UV) region and are therefore able to convert less than $4 \%$ of solar irradiance to hydrogen [30]. With a band gap of 2 to $2.2 \mathrm{eV}[31,32], \alpha-\mathrm{Fe}_{2} \mathrm{O}_{3}$ (hematite) can utilise about $40 \%$ of incident solar irradiance[33], but the material is troubled by a very short hole diffusion length [32] and low electron mobility [30], leading to high recombination rate of photogenerated charge carriers. Nanostructuring is being used to address these limitations for $\alpha-\mathrm{Fe}_{2} \mathrm{O}_{3}$ [34] and also for generally enhancing light absorption and efficient use of photogenerated charge carriers in semiconductors [29].

In addition to low cost and stability, a photoanode needs to convert a reasonable amount of incident solar flux to hydrogen in order to move PEC hydrogen production towards the path of commercialisation. The commercial target set by the United States Department of Energy (DOE) is a solar-to-hydrogen conversion efficiency greater than $10 \%$, which translates to a photocurrent density of $8.1 \mathrm{~mA} / \mathrm{cm}^{2}$ with a solar irradiance of $100 \mathrm{~mW} / \mathrm{cm}^{2}$ (AM 1.5) [28]. The conversion efficiency, $\eta$, is normally determined from the relationship [27, 28].

$$
\eta(\%)=\left(\frac{1.23 \times \mathrm{J}}{\mathrm{L}_{\text {irr }}}\right) \times 100
$$

where $\mathrm{J}$ is the photocurrent density and $\mathrm{L}_{\mathrm{irr}}$ is the light intensity per unit area. This formula assumes that the entire photocurrent is due to hydrogen production and that there are no side reactions. In the case of some of the photocurrent coming from reactions that do not lead to hydrogen production, the actual percentage of the photocurrent corresponding to hydrogen evolution should be used. In addition, if an external bias voltage $\left(V_{\text {ext }}\right)$ is used to help the PEC process, 1.23 in the equation should be replaced by $1.23-\mathrm{V}_{\text {ext }}$ [26]. It has been suggested that if photovoltaic is the source of the external bias, then the subtraction of the applied voltage from 1.23 is not appropriate (applied bias is assumed to be zero) [35]. 
The need for application of an external bias during PEC hydrogen production can be due to the fact that a photoanode needs to have its conduction and valence band energy levels overlapping the reduction and oxidation potentials of water [26], and/or the need to simply increase the rate of $\mathrm{H}_{2}$ production. From Figure 3.3, the band energy levels requirement is met by non-oxide semiconductors like $\mathrm{SiC}, \mathrm{CdS}$ and $\mathrm{CdSe}$ and the oxide semiconductors. As stated earlier, the non-oxide semiconductors can suffer from instability during PEC operation. The valence band edges of the oxide semiconductors all meet the energy level requirement but only $\mathrm{ZnO}$ and $\mathrm{TiO}_{2}$ have their conduction band edges at energies more positive (with respect to the vacuum level) than the reversible $\mathrm{H}_{2} \mathrm{O} / \mathrm{H}_{2}$ (or $2 \mathrm{H}^{+} / \mathrm{H}_{2}$ ) potential. This implies that some positive bias voltage is needed when using $\mathrm{Fe}_{2} \mathrm{O}_{3}$ or $\mathrm{WO}_{3}$ as a photoanode for example.

Equation 3.3 describes the efficiency of a photoanode over the entire wavelength range of an incident light. Sometimes it may be useful to find out how each individual wavelength is contributing to the PEC process. In that case, incident photon-to-current efficiency (IPCE) parameter is used. It is expressed as a percentage of the irradiance at a given wavelength which is converted to photocurrent [30] and is thus a useful way of knowing how much of the absorbed light at each wavelength actually leads to hydrogen generation.

\subsection{Semiconductor/electrolyte interface}

The Fermi level $\left(\mathrm{E}_{\mathrm{F}}\right)$ of an n-type semiconductor is usually higher than the redox potential of an aqueous electrolyte. Therefore, when an n-type semiconductor comes in contact with an electrolyte, electrons are transferred to the electrolyte until the two energy levels are equilibrated. This effectively leads to accumulation of positive charges in the depletion region - the region close to the semiconductor surface from where electrons move away, also called a space charge region (SCR). This is in contrast to the bulk of the semiconductor which is still charge neutral. The presence of positive charges in the SCR is balanced by accumulation of negatively charged ions from the electrolyte at the Helmholtz layer of the electrolyte. Upward bending of the conduction and valence band edges $\left(E_{C}\right.$ and $E_{V}$ respectively) of the semiconductor occurs as a result of this interfacial electron transfer. The reverse would be the case for a p-type semiconductor with a Fermi level typically located below the redox potential of the electrolyte - electrons move into the semiconductor from the electrolyte and the band edges of the semiconductor are bent downwards. There is no charge transfer and hence no band bending at a potential called the flat band potential $\mathrm{V}_{\mathrm{fb}}$, which is 
the potential at which the Fermi level of the semiconductor is equal to the redox potential of the electrolyte $[4,29,36,37]$. With applied potential less than $\mathrm{V}_{\mathrm{fb}}$, the n-type semiconductor begins to act like a p-type semiconductor. These phenomena are illustrated in Figure 3.4a-d.
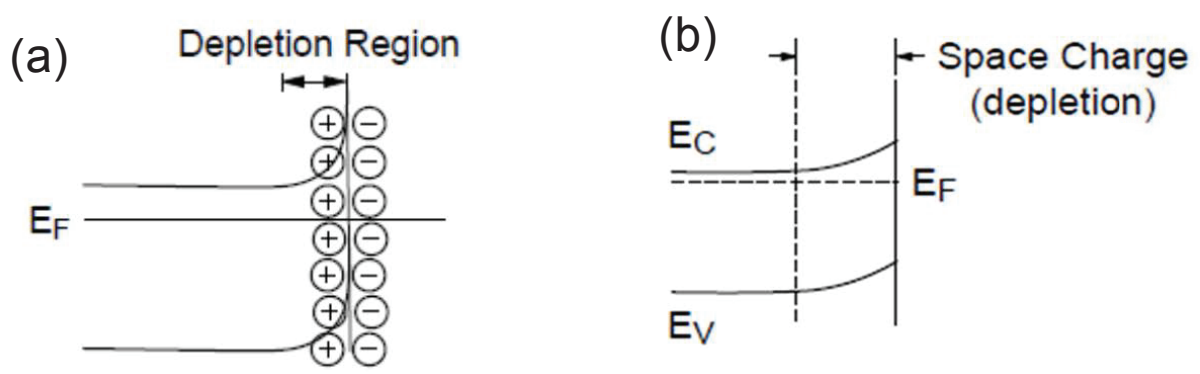

(C)

(d)

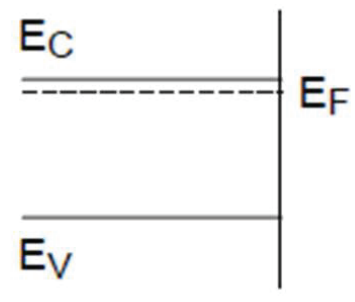

Electrode Solution

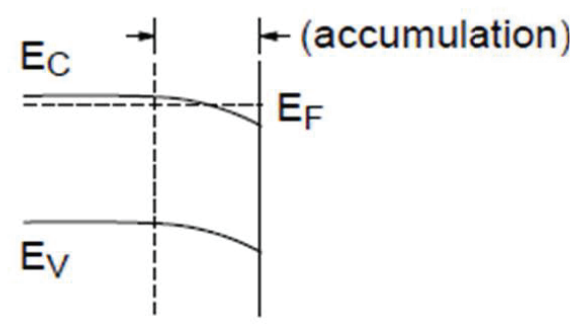

Electrode
Solution

Figure 3.4: Energy diagrams for a n-type semiconductor in contact with an electrolyte [37] (a) depiction of charge distribution across the semiconductor/electrolyte interface leading to the development of a depletion region in a n-type semiconductor. The situation in the cases of applied potential $\mathbf{V}>V_{\mathrm{fb}}(\mathrm{b}), \mathrm{V}=\mathrm{V}_{\mathrm{fb}}$ (c) and $\mathrm{V}<\mathrm{V}_{\mathrm{fb}}$ (d). In the latter case, an accumulation layer forms in the space charge region and the n-type photoanode acts like a photocathode (ptype semiconductor).

The SCR in the n-type semiconductor thus has an electric field at a potential above the $V_{\mathrm{fb}}$, and it is this field which is responsible for separating the electron hole pairs generated upon illumination of the photoanode. The holes are driven towards the semiconductor-electrolyte interface and the electrons move into the interior of the photoanode, onto the conducting substrate [37]. This is illustrated in Figure 3.5. Therefore, only electron-hole pairs generated within the electric field of the SCR can be separated and utilised in a PEC process. For this reason nanostructuring of semiconductor materials is very important for enhancing the performances of $\mathrm{H}_{2}$ generating PEC cells [34]. This is due to the fact that the electrolyte can 
percolate and surround the nanostructure, such that majority of the area of the material where light absorption is taking place is within the electric field of a SCR. Besides, nanostructuring provides shorter travel distances to the semiconductor electrolyte interface for photogenerated holes. Enhanced light absorption as a result of light trapping is also achieved through nanostructuring [38, 39].

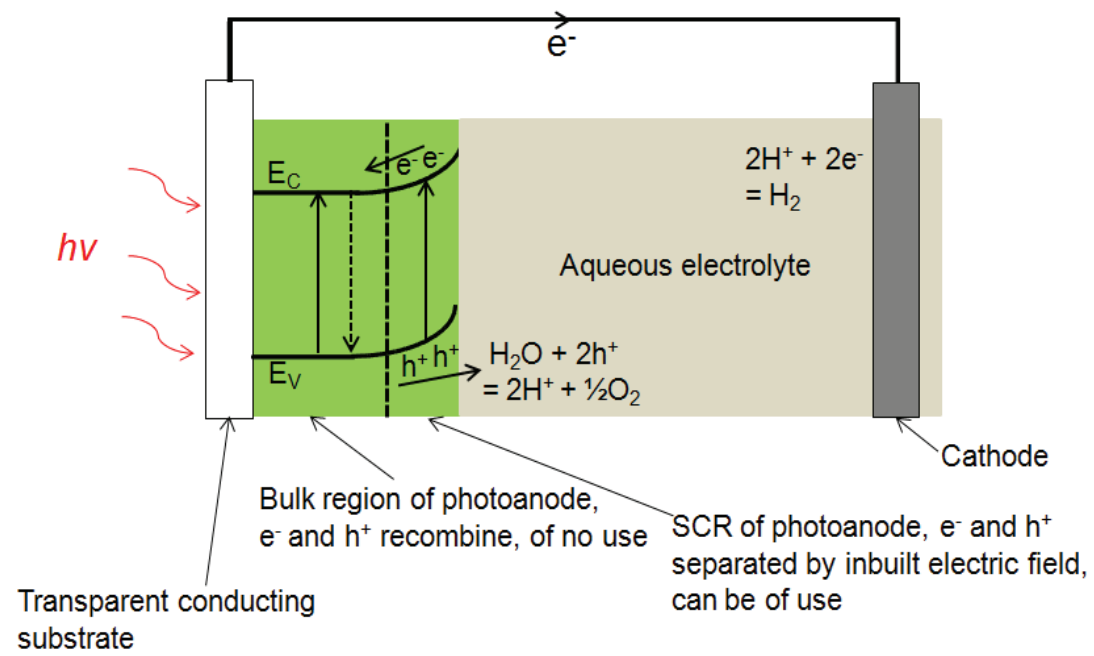

Figure 3.5: A photoanode (green) illuminated with light (hv) of energy greater or equal to its band gap, causing electrons to be excited (black, upward pointing arrows) from the valence band to the conduction band, and creating holes in the valence band. The electron-hole pairs created in the bulk region recombine (broken, downward pointing arrow), while the ones created in the SCR can be separated for redox reactions.

The SCR model is built on the presence of a neutral bulk region of the semiconductor. Once the characteristic dimensions of the semiconductor material - nanoparticle diameter, wall thickness of nanoplates or nanotubes for example - becomes too small to support both bulk and SCR regions, the SCR model can no longer apply. In that case, utilisation of photogenerated charge carriers will depend on how fast the charge carriers can be transferred to redox species on the semiconductor surface [29].

\subsection{Charge transfer at the photoanode/electrolyte interface}

Irrespective of whether hole transfer at a photoanode surface is mediated by a SCR, surface kinetics or even both, the ability to effectively utilise photogenerated charge carriers for the sole purpose of $\mathrm{O}_{2}$ evolution from water oxidation (invariably accompanied by a 
stoichiometric $\mathrm{H}_{2}$ evolution) is a challenge. This is because the kinetics of the OER ${ }^{3}$ at a photoanode is slow and therefore may have a competitor in some side reactions, such as formation of peroxo species on the photoanode surface, for example in $\mathrm{TiO}_{2}[40]$ and $\mathrm{WO}_{3}$ [41]. These peroxo species, which can also be formed by $\mathrm{TiO}_{2}$ conduction band electrons, can further complicate things by acting as electron traps [40] or leading to photodecomposition of the photoanode over time [41]. In addition to the formation of peroxo species, trapping of photogenerated electrons by defect sites of a photoanode has also been reported to diminish PEC performance by enhancing recombination of electrons and holes [42]. Trapped electrons have been reported to be discharged in the dark to give anodic current (presumably for $\mathrm{H}_{2}$ evolution at the cathode) [43]. However, there is the possibility of such discharging electrons participating in reductions reactions at the anode [44].

Apart from nanostructuring, which decreases the distance photogenerated holes have to travel before getting to the surface of a photoanode, a number of strategies for enhancing the utilisation of photogenerated holes for oxygen evolution at a photoanode have been employed. At negative bias, $\mathrm{TiO}_{2}$ trap sites were filled with electrons, charge compensated by intercalation of cations from the electrolyte. When the electrochemically treated $\mathrm{TiO}_{2}$ was used for PEC test, it yielded a threefold increase in photocurrent in comparison with $\mathrm{TiO}_{2}$ without the prior electrochemical treatment [42]. A cobalt based OER catalyst [45] has been used to suppress electron hole recombination and enhance the performance of some photoanodes [41, 46-48], and has been shown to particularly suppress peroxo species formation and its consequent decomposition effect on a $\mathrm{WO}_{3}$ photoanode [41].

Yet another way of reducing the recombination rate of photogenerated electron-hole pairs is the use of organic additives in the aqueous electrolyte solution. Small organic molecules (SOM) like methanol, glycerol, and ethylene glycol can enhance PEC hydrogen production by reducing recombination of electron hole pairs. It is also thought that the energy levels of an aqueous electrolyte solution is modified by introduction of such molecules, while the extent of the reduction in the recombination rate of electrons and holes varies from one molecule to another [49], likely due to the nature of the interaction (adsorption) of a molecule with the photocatalyst [50]. Other SOM such as acetone and acetophenone have however been reported to decrease photocurrents [51]. Furthermore, it has been reported that the enhancement in photocurrent with addition of glycine is mainly limited to short

\footnotetext{
${ }^{3}$ OER in general is the more challenging and difficult of the two half reactions involved in water electrolysis, PEC water splitting being no exception.
} 
wavelength region $(<330 \mathrm{~nm})$, and that the enhancement factor can be 0-, 2-, or 7-fold for single crystalline (rutile), polycrystalline (anatase) and porous nanocrystalline (anatase) $\mathrm{TiO}_{2}$ films, respectively [52].

The general consensus on the mechanism of SOM photocurrent enhancement is that of fast scavenging of photogenerated holes. However, the reaction kinetics is still being debated. With methanol for example, the PEC photocurrent enhancement could proceed via the following anodic reactions [53]:

$$
\mathrm{CH}_{3} \mathrm{OH}+\mathrm{h}^{+}=\mathrm{H}^{+}+\mathrm{CH}_{3} \mathrm{O}^{*}
$$

A photogenerated hole is directly captured by methanol which gets oxidised to a proton and a methoxy radical. The radical then reacts with water:

$$
\mathrm{CH}_{3} \mathrm{O}^{*}+\mathrm{H}_{2} \mathrm{O}=\mathrm{CO}_{2}+5 \mathrm{H}^{+}+5 \mathrm{e}^{-}
$$

The HER at the cathode (bearing in mind there is one available electron from the electron hole pair) becomes:

$$
6 \mathrm{H}^{+}+6 \mathrm{e}^{-}=3 \mathrm{H}_{2}
$$

A different set of reaction pathways have been proposed elsewhere [54]. It was argued that the first interaction of photogenerated holes in an aqueous solution of methanol is with water because of the preferential adsorption of water over methanol on $\mathrm{TiO}_{2}$. Therefore the likely anodic reactions could be:

$$
\begin{aligned}
& \mathrm{H}_{2} \mathrm{O}+\mathrm{h}^{+}=\mathrm{H}^{+}+\mathrm{OH}^{*} \\
& \mathrm{CH}_{3} \mathrm{OH}+\mathrm{OH}^{*}=\mathrm{H}_{2} \mathrm{O}+\mathrm{CH}_{2} \mathrm{O}+\mathrm{H}^{+}+\mathrm{e}^{-}
\end{aligned}
$$

Formaldehyde $\left(\mathrm{CH}_{2} \mathrm{O}\right)$ can then go through a series of reactions comprising intermediates, water, holes and hydroxyl radicals to yield $\mathrm{CO}_{2}$ and protons, with the possibility of another electron being donated to the conduction band of the photoanode. By whichever route the enhancement of PEC splitting is accomplished, it should be noted that direct PEC water splitting still goes on. 
Direct methanol photo-oxidation (essentially similar to a direct methanol fuel cell[55]) involving no radicals or donation of electrons to the photoanode conduction band can also occur via:

$$
\mathrm{CH}_{3} \mathrm{OH}+\mathrm{H}_{2} \mathrm{O}+6 \mathrm{~h}^{+}=\mathrm{CO}_{2}+6 \mathrm{H}^{+}
$$

With a PEM electrolyser utilising noble metals as electrode catalysts, an electrolysis onset voltage of $0.45 \mathrm{~V}$ has been reported for a $4 \mathrm{M}$ aqueous solution of methanol in comparison to $1.4 \mathrm{~V}$ for pure water [56].

\subsection{Investigating defects and charge carrier dynamics with photoluminescence}

Light emission occurs when species - e.g. electrons - in an excited state return to a stable energy level (e.g. ground state, GS), giving off some of the energy used in promoting them to the excited state (ES) as electromagnetic radiation. This phenomenon, generally called luminescence ${ }^{4}$, is commonly subdivided into several types according to specific origin of the excitation energy. Examples include excitation with electromagnetic radiation (photoluminescence), high energy electrons (cathodoluminescence), electrical voltage (electroluminescence), mechanical action (triboluminescence) and energy of a chemical reaction (chemiluminescence) [57]. We shall henceforth talk of photoluminescence (PL) as it is the method used in this thesis.

Usually, the emitted light is of lower energy (longer wavelength) than the excitation energy. This is because the ground and excited states (valence and conduction bands respectively for a semiconductor) consist of sub energy levels arising from lattice vibrations. Excitation will normally occur from the lowest vibrational energy level of the GS to the highest vibrational level of the ES. Thereafter, the excited species relax to an equilibrium energy level (lower vibrational levels) in the ES, giving off energy as heat to the lattice. Radiative transition, that is a transition accompanied by light emission, then proceeds from the equilibrium level in the ES to the highest vibrational level in the GS. These processes are illustrated in Figure 3.6a, and further simplified for a semiconductor in Figure 3.6b.

\footnotetext{
${ }^{4}$ Depending on how long the emission lasts, luminescence can also be divided into fluorescence (short lived, typically nanoseconds life time) and phosphorescence (long lived, milliseconds to several seconds life time). Fluorescence however is commonly used to erroneously refer to both processes.
} 
(a)

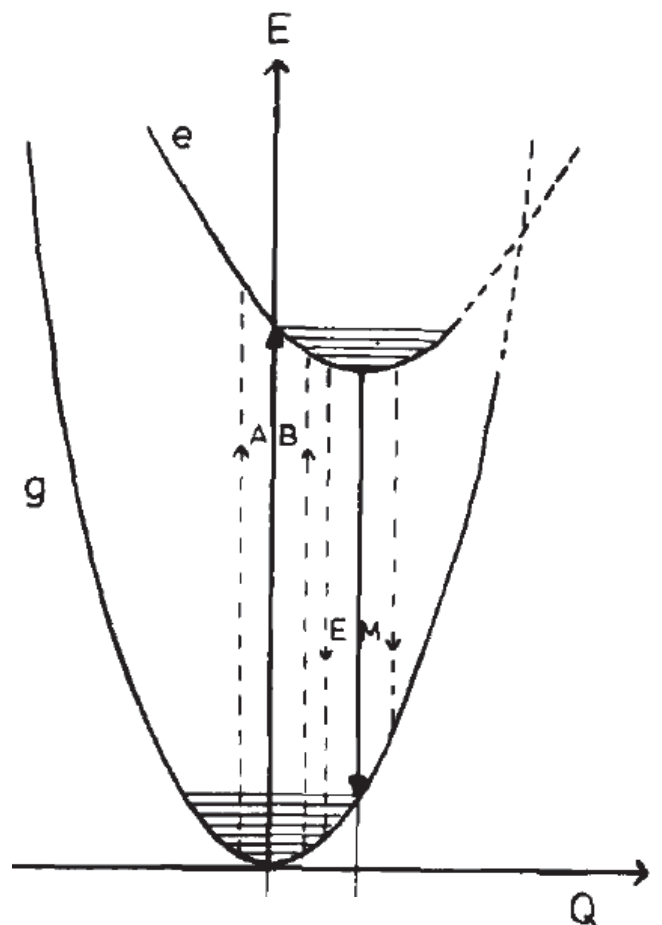

(b)

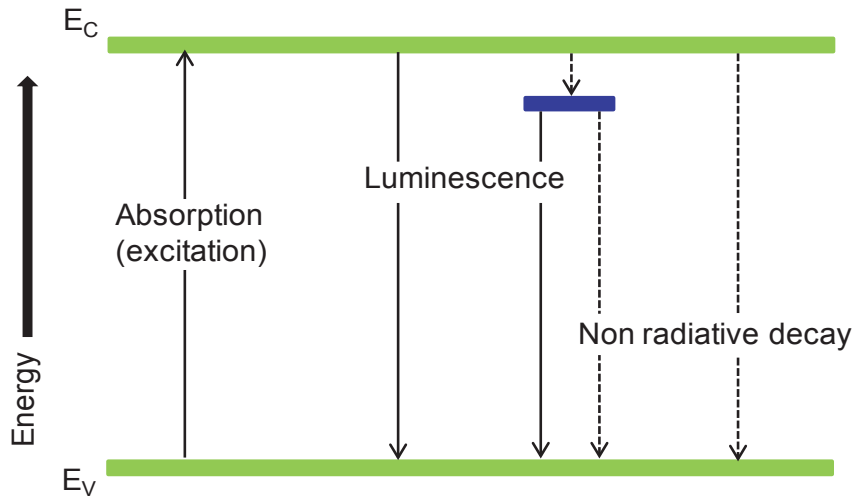

Figure 3.6: (a) Plot of Energy (E) vs. configurational coordinate (Q) for ground (parabola g) and excited (parabola e) states of an emitting centre. $Q$ describes a symmetrical vibration of the lattice while the horizontal lines in the parabolas represent vibrational energy levels. The three lines (including the solid one) with arrows pointing up (AB) and down (EM) indicate possible pathways for excitation and emission, respectively [58]; (b) Illustration of absorption in a semiconductor and resultant band-to-band and shallow defect level (blue bar) mediated transitions which can be radiative (luminescent) or non radiative. The excited electrons can first decay non-radiatively to the defect level before transition to $E_{V}$. 
Other possible routes during excitation and emission are possible but they more often than not involve some form of relaxation (energy loss) among vibrational energy levels so that at the end, the excited species emit light at wavelength longer than the absorption wavelength. This phenomenon is referred to as Stokes shift [58]. An exception to Stokes shift, called antiStokes shift, occurs in the so called up-converting phosphors where one shorter wavelength visible light emission is caused by absorption of at least two longer wavelength photons, aided by intra molecular energy transfer between two emitting centres [59].

In semiconductors, the GS and ES are referred to as valence and conduction band, respectively. Upon absorption of the photon energy, electrons are promoted from the valence to the conduction band from where they can become useful in PEC or photovoltaic processes. They can also radiatively or non radiatively return to the GS through band-toband transition, or via defect states in the band gap as shown in Figure 3.6b. Intrinsic defects like oxygen vacancies [60] and hydrogen [61] are typical examples of omni present defects in oxide semiconductors. They can introduce donor states in the band gap of semiconductors. Oxygen vacancies have been reported to lead to high-lying (in the conduction band) and low-lying (in the valence band) resonant states in $\mathrm{WO}_{3}$ [62], as well as deep-lying band gap state in $\mathrm{ZnO}$ [63]. Due to overlap between their energy levels and the conduction band of the intrinsic material - specifically vibrational levels in the conduction band - these defect states can be luminescent centres, that is centres from which photogenerated electrons undergo radiative decay to a ground state $[64,65]$. In addition, visible light emission has been attributed to the deep-lying oxygen vacancies in $\mathrm{ZnO}$ which act as recombination centres for electron hole pairs [63].

It is important to note that excitation to a higher energy level does not always lead to light emission. This is especially the case at high temperatures when the lattice vibrational levels of the excited and ground states are close enough, such that the excited species can return to the ground state via non-radiative transitions [58]. For this reason, photoluminescence studies are preferably conducted at low temperatures, usually cryogenic temperatures, in order to minimise the non-radiative transitions. This is particularly true for indirect band gap semiconductors which typically do not have strong luminescence. 


\subsubsection{Time-resolved photoluminescence}

Time-resolved photoluminescence (TRPL) is a common technique used to investigate the recombination dynamics of photogenerated charge carriers. This technique can help distinguish the normally fast decay associated with band-to-band transition from the longer lived decays due to trapping by defect states [63]. In this technique, the material is excited with a pulsed light source, and the excitation is stopped. The duration of the pulse should be shorter than that of recombining charge carriers, so the recombination of charge carriers can be studied after the pulsed light source has been stopped [66]. The simplest case of singleexponential decay of the photogenerated charge carriers with time can be expressed as:

$$
\Delta \mathrm{p}_{\mathrm{n}}(\mathrm{t})=\Delta \mathrm{p}_{\mathrm{n}}(0) \exp \left(\frac{-\mathrm{t}}{\tau}\right)
$$

where $\Delta \mathrm{p}_{\mathrm{n}}$ is the increase in charge carriers with excitation, and $\tau$ is the lifetime of the charge carriers. Zero time is counted from the time the light source is cut off, or in the case of varying decay rates, the time corresponding to the beginning of each decay profile. At $t=$ $\tau$, equation 3.10 becomes

$$
\Delta \mathrm{p}_{\mathrm{n}}(\tau)=\Delta \mathrm{p}_{\mathrm{n}}(0) \exp (-1)=0.37 \Delta \mathrm{p}_{\mathrm{n}}(0)
$$

Therefore, $\tau$ is defined as the time it takes the concentration of the photogenerated charge carriers to decrease to $37 \%$ of their initial value [67].

\subsection{Solid electrolyte for photoelectrochemical hydrogen generation}

The main focus of the numerous studies on PEC water splitting has been on the use of aqueous electrolytes, often without separating the two electrode compartments. This implies that when and if the time for commercialisation comes, the process will encounter the same limitations enumerated for alkaline water electrolysis (section 2.1). Even when PEM proton conductors have been used as a separator for the photoanode and cathode compartments similar to a PEM electrolyser design - aqueous electrolytes [53, 54, 68] or liquid water [68, 69] were still supplied to the photoanodes. An all solid state PEC hydrogen generating device utilising the vapour of $10 \mathrm{wt} \%$ aqueous solution of ethanol at the photoanode has been demonstrated, but with no demonstration of the effect of temperature on performance [70]. In addition, a similar design for PEC decomposition of organics in air has been implemented [71-73]. In general however, there is very little work on the use of a solid 
electrolyte for PEC hydrogen generation with gaseous reactants supplied to the oxygen evolving photoelectrode.

\subsection{Effect of temperature on photoelectrochemical hydrogen generation}

Since most of the effort in PEC hydrogen generation has been concentrated on the use of aqueous electrolyte, it naturally follows that studies on the effect of temperature on the PEC processes will be very few. Stuart Licht has used theoretical studies to show that sub bandgap light can be used to heat up a PEC cell, thereby lowering the thermodynamic energy requirement for PEC water splitting with a semiconductor [74, 75] while Katakis et al. reported that the efficiency of water splitting on a photocatalyst particles in aqueous solution increased 3-fold from 20 to $70{ }^{\circ} \mathrm{C}[76]$. S. J. Bell[77], in his doctoral dissertation, provided evidence of enhancement of photocurrent of a PEC water splitting cell at higher temperatures, reporting an increase in photocurrent of about 2.5 times with about $78{ }^{\circ} \mathrm{C}$ increase in temperature. However, the use of liquid electrolyte limited his studies to $100{ }^{\circ} \mathrm{C}$ and below.

\subsection{Aims and objectives of this thesis}

This thesis is geared towards accomplishing the following:

(a) Investigation, preparation and characterisation of suitable materials for use as solid proton conducting membranes and photoanodes. For a solid electrolyte, a PEM or high temperature proton conducting solid oxide are of interest in order to have a wider temperature area for investigation.

(b) Integration of the above materials into an all-solid-state device - PEM or high temperature electrolyser type design - for photoelectrochemical water splitting experiments using only gaseous reactant at the photoanode. The gaseous reactant could be water vapour or a mixture of water and methanol vapours.

(c) Enhancing light-to-current conversion efficiency by improving electrode kinetics and solid electrolyte conductivity through the application of heat. In this regard it is also of interest to maximise the electrode/electrolyte/reactant triple phase boundary, especially at the photoanode.

(d) Surface modification of the photoanode nanoparticles in order to enhance the lifetime of photogenerated charge carriers and invariably, photocurrent. 
(e) Use of electrochemical measurements and $\mathrm{H}_{2}$ sensing to evaluate the workability and limitations to an all-solid-state $\mathrm{PEC}_{2}$ generating device. 


\section{Experimental set-up and methods}

The experimental techniques used in this thesis include hydrothermal synthesis, X-ray diffraction, scanning electron microscopy, transmission electron microscopy, voltammetry, chronoamperometry, electrochemical impedance spectroscopy and optical techniques Fourier transform infrared spectroscopy, Raman spectroscopy, diffuse reflectance spectroscopy and photoluminescence (including time resolved photoluminescence). Diffuse reflectance spectroscopy is an essential tool for measuring the optical absorption profiles of non-transmitting samples, and together with scanning electron microscopy, was particularly useful in providing quick feedback information necessary for deciding to continue, modify or discard a particular material preparation route. We shall take a somewhat in-depth look at the PEC set-up and electrochemical impedance spectroscopy in order to enhance understanding of their use in subsequent chapters.

\subsection{Photoelectrochemical set up and characterisation}

A conceptual design for a typical PEC cell presented in Figure 4.1 shows a porous, nanostructured photoanode which allows water vapour to diffuse into it. With illumination, the electron-hole pairs are generated, the holes oxidising water to $\mathrm{O}_{2}$ and $\mathrm{H}^{+}$, and the electrons travelling through an external circuit to reduce the protons (which have passed through the solid proton conductor) to hydrogen at the cathode. The cathode is also a porous structure, allowing for easy diffusion of hydrogen gas. Dilute methanol vapour $\left(\mathrm{H}_{2} \mathrm{O}+\right.$ methanol) can also be used on the anode side, which implies evolution of $\mathrm{CO}_{2}$, besides $\mathrm{O}_{2}$. This is in principle similar in design and implementation to conventional PEM or high temperature proton conducting solid-oxide electrolysis. 


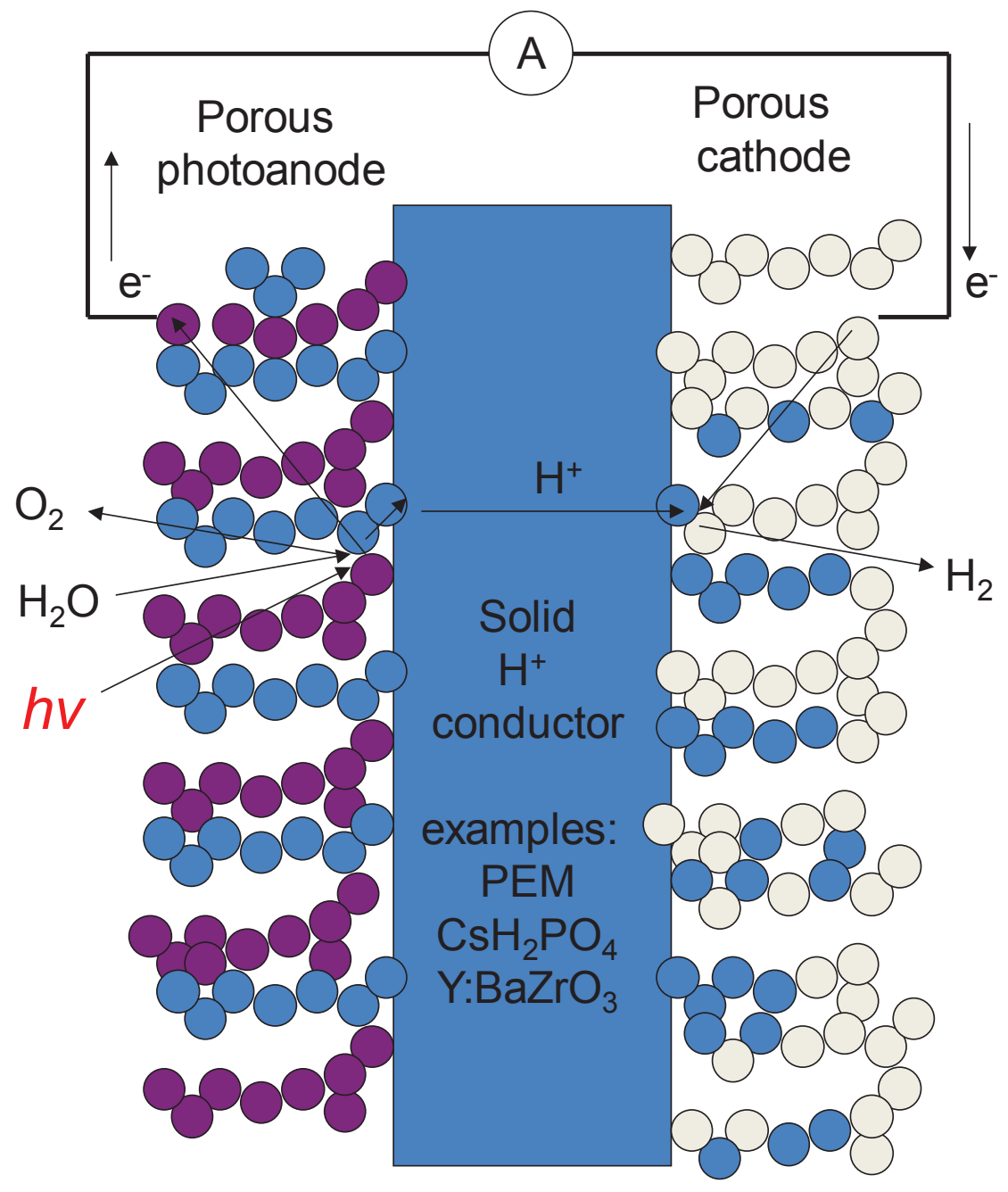

Figure 4.1: Schematic of a solid-state photoelectrochemical cell showing gas diffusion in porous electrode layers separated by and attached to a solid proton conductor. With illumination (hv) gas evolution takes place at the electrodes (courtesy of Prof. T. Norby). 
(a)

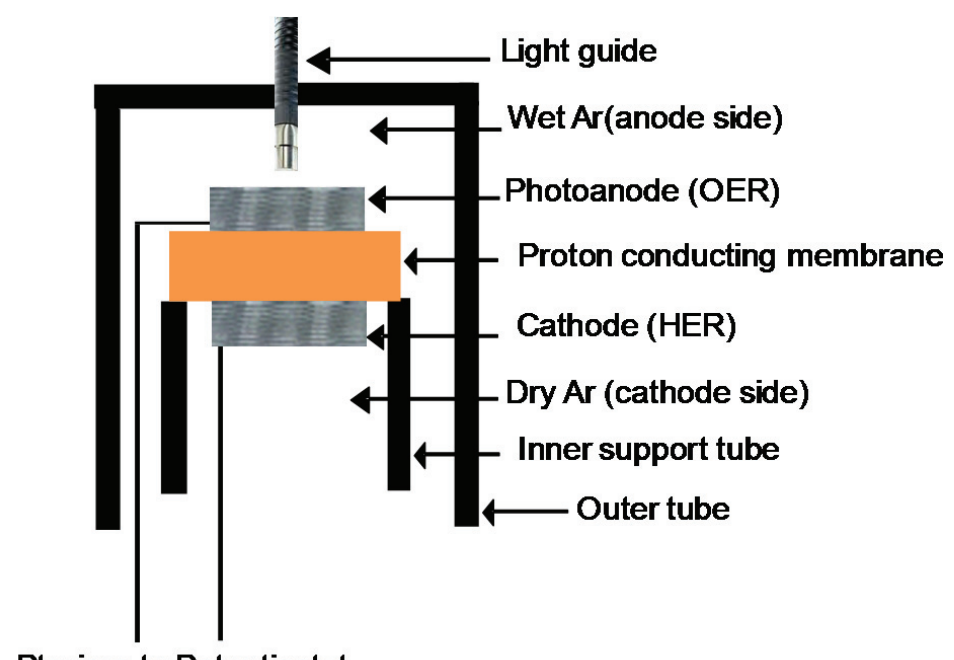

Pt wires to Potentiostat

(b)

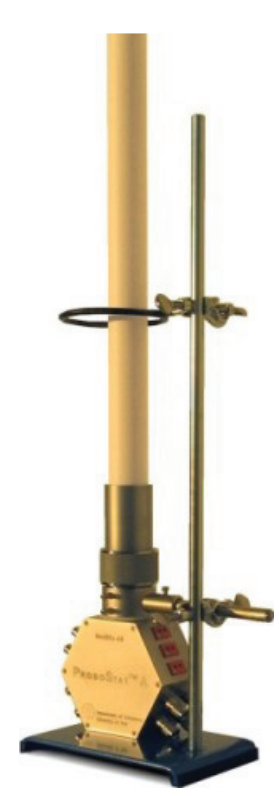

Figure 4.2: (a) Schematic of a PEC cell consisting of a photoanode, proton conducting membrane and a HER cathode mounted on a ProboStat ${ }^{\mathrm{TM}}$ measurement cell. The PEC cell is securely supported on the inner support tube by a spring load (not shown), (b) A ProboStat ${ }^{\mathrm{TM}}$ measurement cell (courtesy of NorECs AS) mounted on a retort stand. The light guide is coupled to the cell at the top open end. 
For PEC measurements, the PEC cell was mounted on the inner support tube of a ProboStat $^{\mathrm{TM}}$ sample holder cell (NorECs AS, Norway) as shown in Figure 4.2. Ar was bubbled through pure water or aqueous 1 molar $\mathrm{CH}_{3} \mathrm{OH}$ and supplied to the anode side (upper electrode, outer tube compartment) while dry Ar was supplied to the cathode side (lower electrode, inner tube compartment). Both compartments have their separate gas outlets (gas tubes not shown). The photoanode was illuminated from the top of the assembly with an Omnicure S2000 UV-visible lamp spanning the wavelength region of 320-500 nm (Figure 4.3). Details of the lamp irradiance on the photoanode are presented in the appendix. The electrodes are electrically connected to a PARSTAT 2273 potentiostat in a twoelectrode set up, making it possible to run linear voltammetry (current-voltage sweep in one direction), chronoamperometry (current-time at a fixed applied voltage) and impedance spectroscopy measurements. The reliability of using the potentiostat in a two-electrode setup was confirmed by running a current-voltage experiment for a $4 \mathrm{M} \Omega$ resistor; the resulting resistance from both manual and linear fitting calculation of the experimental data was also 4 $M \Omega$ (see the appendix).

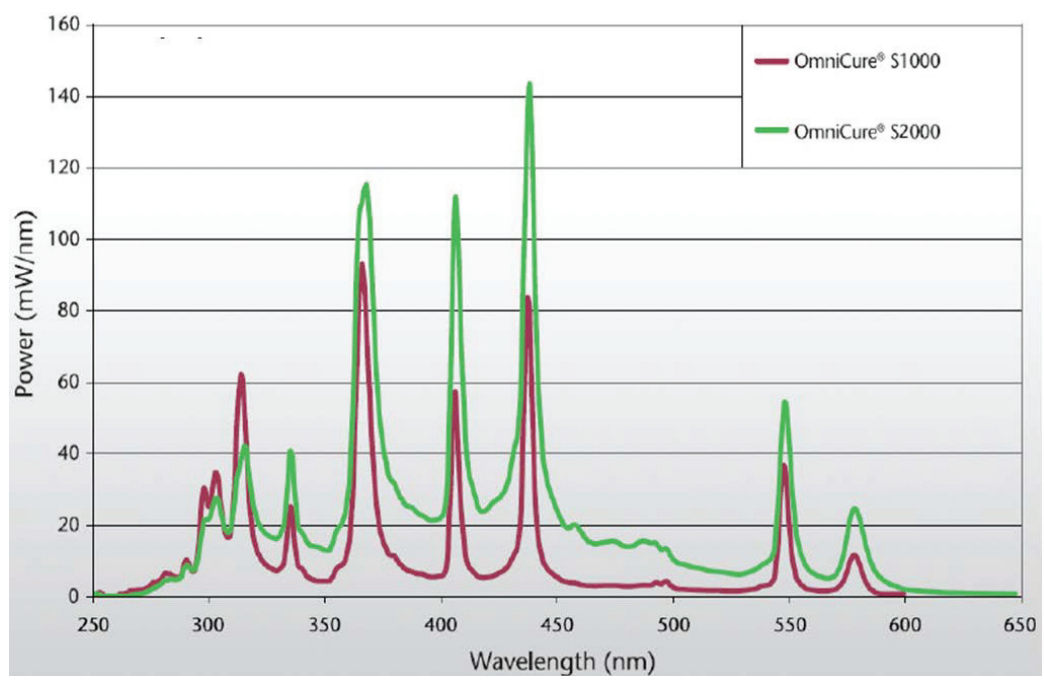

Figure 4.3: Spectral plot of Omnicure S2000 lamp (in green) used in the experiment. An installed filter cut off light outside the $320-500 \mathrm{~nm}$ wavelength range. The lamp can be tuned from 100 to $0 \%$ output intensity (courtesy of Lumen Dynamics) 


\subsubsection{Electrochemical impedance spectroscopy}

This discussion on electrochemical impedance spectroscopy (EIS) is based on the book, "Electrochemical Impedance Spectroscopy" by M. E. Orazem and B. Tribollet [78], and the journal article "Electrochemical Impedance Spectroscopy for better Electrochemical Measurements" by S-U Park and J-S Yoo [79]. EIS is a vital tool because of its ability to distinguish between electrolyte and electrode processes. If more than one physical process is involved at the electrolyte or electrodes (as is usually the case), it can also identify them separately. This is due to the different physical processes - e.g. mass diffusion of electroactive species, charge transfer at electrode/electrolyte interface, electrolyte resistance, and electrolyte grain boundary resistance, etc - possessing different time constants. During EIS, a small AC current (galvanostatic mode) or voltage (potentiostatic mode) is imposed on an electrochemical system with or without a DC bias, and the electrochemical impedance of the system is recorded over a frequency range. The result can be graphically represented in a Nyquist plot (imaginary, out of phase impedance vs. real, in phase impedance) or Bode plot (absolute impedance or phase angle vs. frequency). Only the Nyquist plot will be used in this thesis.

The behaviour of an electrochemical system can be likened to that of an electrical circuit (called equivalent circuit) comprising resistors, capacitors and inductors, thereby providing a model for fitting and analysing EIS results. The capacitor represents the imaginary part of this impedance to current flow in an electrochemical cell. A simple and common equivalent circuit used for modelling EIS signals of an electrochemical cell is presented in Figure 4.4. It consists of the resistance of the electrolyte $\left(R_{S}\right)$ in series with a parallel combination of the electrode resistance $\left(R_{P}\right)$ and capacitance $\left(C_{P}\right)$.

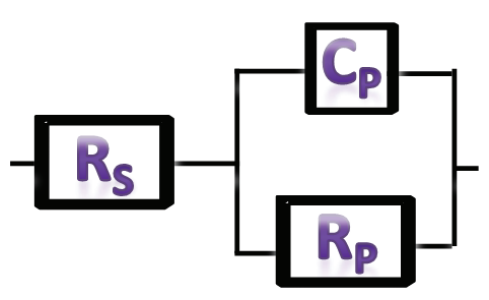

Figure 4.4: An equivalent circuit consisting of the resistance of an electrolyte $\left(R_{S}\right)$ in series with a parallel combination of electrode resistance $\left(R_{P}\right)$ and capacitance $\left(C_{P}\right)$. 
For the model circuit In Figure 4.5, the time constant for the electrode electrochemical process is given as

$$
\tau_{\mathrm{p}}=\mathrm{R}_{\mathrm{p}} \mathrm{C}_{\mathrm{p}}
$$

Equation 4.3 assumes a fixed time constant for the electrode reaction, which is often not the case. Variation in the time constant for an electrode process can arise due to differences in reactivity, current and potential distribution across the electrode. A constant phase element (CPE), which is based on a simplified assumption of a specific distribution of time constants for any given system, is used to model this non-homogeneity of time constant and therefore substitutes the capacitance in the equivalent circuit. The impedance of a CPE is given by

$$
\mathrm{Z}_{\mathrm{CPE}}=\frac{1}{\mathrm{Y}_{0}(\mathrm{j} \omega)^{\mathrm{n}}}
$$

$\mathrm{j}$ and $\omega$ stand for imaginary number and angular frequency, respectively. The pseudocapacitance can be calculated from [80]

$$
\mathrm{C}_{\mathrm{p}}=\mathrm{Y}_{0}^{1 / \mathrm{n}} \mathrm{R}_{\mathrm{p}}^{(1-\mathrm{n}) / \mathrm{n}}
$$

where $\mathrm{Y}_{0}$ and $\mathrm{n}$ are parameters of the CPE which can be obtained by fitting experimental data to a circuit model. 


\section{Manuscripts}

\section{Manuscript I}

One-dimensional $\mathrm{WO}_{3}$ and its hydrate: One-step synthesis, structural and spectroscopic characterization

Journal of Solid State Chemistry 185 (2012) 245-252

K. O. Iwu, A. Galeckas, P. Rauwel, A. Yu. Kuznetsov, T. Norby

\section{Manuscript II}

Optical characterisation of nanostructured $\mathrm{WO}_{3} \cdot 1 / 3 \mathrm{H}_{2} \mathrm{O}$ : Effects of synthetic route, Mo substitution, hydrogen isotope exchange and temperature

To be submitted

K. O. Iwu, A. Galeckas

\section{Manuscript III}

Solid-state photoelectrochemical $\mathrm{H}_{2}$ generation with gaseous reactants

Electrochimica Acta 97 (2013) 320-325

K. O. Iwu, A. Galeckas, A. Yu. Kuznetsov, T. Norby

\section{Manuscript IV}

Effects of temperature, triazole and hot-pressing on the performance of $\mathrm{TiO}_{2}$ photoanode in a solid state photoelectrochemical cell

Submitted to Electrochimica Acta

K. O. Iwu, A. Galeckas, S. Diplas, F. Seland, A. Yu. Kuznetsov, T. Norby 


\section{MANUSCRIPT I}

One-dimensional $\mathrm{WO}_{3}$ and its hydrate: One-step synthesis, structural and spectroscopic characterization 


\section{MANUSCRIPT II}

Optical characterisation of nanostructured $\mathrm{WO}_{3} \cdot 1 / 3 \mathrm{H}_{2} \mathrm{O}$ : Effects of synthetic route, Mo substitution, hydrogen isotope exchange and temperature 


\section{MANUSCRIPT III}

Solid-state photoelectrochemical $\mathrm{H}_{2}$ generation with gaseous reactants 


\section{MANUSCRIPT IV}

Effects of temperature, triazole and hot-pressing on the performance of $\mathrm{TiO}_{2}$ photoanode in a solid state photoelectrochemical cell 


\title{
Effects of temperature, triazole and hot-pressing on the performance of $\mathrm{TiO}_{2}$ photoanode in a solid-state photoelectrochemical cell
}

\author{
Kingsley O. Iwu ${ }^{\mathrm{a}}$, Augustinas Galeckas ${ }^{\mathrm{b}}$, Spyros Diplas ${ }^{\mathrm{a}, \mathrm{c}}$, Frode Seland ${ }^{\mathrm{d}}$, \\ Andrej Yu. Kuznetsov ${ }^{\mathrm{b}}$ and Truls Norby*a \\ ${ }^{a}$ Department of Chemistry, University of Oslo, Centre for Materials Science and Nanotechnology, \\ FERMiO, Gaustadalleen 21, NO-0349 Oslo, Norway \\ ${ }^{b}$ Department of Physics, University of Oslo, Centre for Materials Science and Nanotechnology, P.O. Box \\ 1048 Blindern, NO-0316 Oslo, Norway \\ ${ }^{c}$ SINTEF Materials and Chemistry, P.O. Box 124, Blindern, NO-0314 Oslo, Norway \\ ${ }^{d}$ Department of Materials Science and Engineering, Norwegian University of Science and Technology, \\ NO-7491 Trondheim, Norway
}

*email: truls.norby@kjemi.uio.no

\begin{abstract}
The photocurrent of hydrogen generating solid-state photoelectrochemical cell utilising a polybenzimidazole proton-conducting membrane and gaseous anode reactants has been enhanced by operation at higher temperatures. With a bias of $0 \mathrm{~V}$ for example, photocurrent increased from 15 to $30 \mu \mathrm{A} / \mathrm{cm}^{2}$ on moving from $25{ }^{\circ} \mathrm{C}$ to $45{ }^{\circ} \mathrm{C}$. The increase in photocurrent, which was limited by the dehydration of the cell, was shown to have contribution from improved electrode kinetics. Modification of $\mathrm{TiO}_{2}$ surface with triazole, a conjugated heterocyclic compound, led to significant increase in photocurrent - up to 4 fold increase at $0 \mathrm{~V}$ and $25{ }^{\circ} \mathrm{C}$. This was attributed to improved separation of photogenerated charge carriers, as confirmed by correspondingly increased carrier lifetimes from 50 ns to 90 ns for triazole-
\end{abstract}


modified $\mathrm{TiO}_{2}$. Assembly of the photoelectrochemical cell by hot-pressing induced a $0.3 \mathrm{eV}$ red shift in optical absorption edge of $\mathrm{TiO}_{2}$, in agreement with a shift of its valence band maximum to higher binding energy.

Keywords: Solid-state; photoelectrochemical; XPS; carrier lifetime; triazole.

\section{Introduction}

Efficient direct conversion of solar to chemical energy will help make solar energy an alternative to fossil fuels. Among the many possibilities are the conversion of $\mathrm{CO}_{2}$ to gaseous and liquid fuel [1-5], and hydrogen production from aqueous solutions [6-10]. The latter is sometimes accomplished with organic additives like methanol in order to reduce charge carrier recombination and boost solar-to-chemical conversion efficiency [10]. In these mentioned processes, there are basically two approaches: photocatalytic conversion and use of photoelectrochemical (PEC) cells. Both approaches rely on absorption of photon energy by a semiconductor photocatalyst to generate electrons and holes. In photocatalytic conversion, the chemical processes leading to product formation take place on the surface of photocatalyst nanoparticles. Since both the photogenerated holes and electrons are active in the same region, complications can arise when only one particular reaction is desirable, for example reduction to yield $\mathrm{H}_{2}$ or hydrocarbons. Undesirable side reactions sometimes limit the efficiency of the preferred reactions $[4,5]$ and/or lead to production of mixtures of oxidising and reducing gases [7-9] (e.g. $\mathrm{O}_{2}$ and $\mathrm{H}_{2}$ ). The second approach is based on the use of PEC cells and allows reduction and oxidation reactions to take place at two different and spatially separated electrodes. Here, it is possible to not only separate the products at the electrodes but also to modify the conditions at one electrode in order to enhance the half reaction there without negatively affecting the half reaction at the other electrode [11].

The majority of PEC hydrogen generation studies involve the use of aqueous electrolyte as both the electrolyte and the photoanode reactants, and among them are very few attempts to separate the two half reactions compartments with a proton conducting membrane [11-13] as is the case in polymer electrolyte membrane (PEM) electrolysis. Recently, we have been investigating the use of gaseous reactants at the photoanode of a PEC hydrogen generating cell, similar in design to a PEM water electrolysis cell [14]. This approach is expected to benefit from the advantages 
of using a solid polymer over aqueous electrolytes, namely, operation at higher temperatures in order to improve electrode kinetics and reduce the thermodynamic energy requirement for electrolysis [15], pressurising the system to produce compressed $\mathrm{H}_{2}$ directly [16] and absence of gas bubbles which can increase electrolyte resistance and impede reactions at the electrode surfaces [17]. The use of a gaseous mixture of ethanol and water for PEC hydrogen generation with a PEM electrolyser type cell has been reported [18], while a similar cell design has been utilised for PEC degradation of organics in air $[19,20]$. However, there is little or insufficient information on the effects of surface characteristics and temperature on the electrode and electrolyte processes of such a system.

In this work, we study the effect of temperature on the performance of a solid-state PEC hydrogen generating cell comprising a $\mathrm{TiO}_{2}$ photoanode, $\mathrm{Pt}-\mathrm{C}$ cathode, and a $\mathrm{H}_{3} \mathrm{PO}_{4}$-doped polybenzimidazole (PBI) proton conducting membrane. The effects of hot-pressing on the optical properties of $\mathrm{TiO}_{2}$, and triazole- $\mathrm{TiO}_{2}$ conjugation on the photocurrent of the assembled cell, are also analysed.

\section{Experimental}

Nafion ${ }^{\circledR}$ perfluorinated resin solution $(20 \mathrm{wt} \%)$ and $1 H-1,2,3$-triazole $(97 \%$, hereafter referred to as triazole) were obtained from Sigma Aldrich. Carbon paper (190 $\mu \mathrm{m}$ thick) and platinum coated carbon, Pt-C (Pt/Vulcan XC-72R, 10 wt \% Pt) were obtained from Quintech, Germany. PBI membrane (40 $\mu \mathrm{m}$ in dry condition) was sourced from Danish Power Systems. It was aciddoped by immersing the dry membrane in $85 \% \mathrm{H}_{3} \mathrm{PO}_{4}$ for at least 5 days to ensure high doping level. All dilutions were made with isopropanol.

The procedures for preparation of $\mathrm{TiO}_{2}$ photoanode (Degussa P25) and Pt-C cathode layers on carbon paper support, and PEC experiments are the same as in our earlier publication on an all-solid-state PEC hydrogen generating cell [14], except for a few modifications. The photoanode layer was either $\mathrm{TiO}_{2}$ with $20 \mathrm{wt} \% \mathrm{Nafion}^{\circledR}\left(\mathrm{n}-\mathrm{TiO}_{2} / \mathrm{C}\right)$ or $20 \mathrm{wt} \%$ of Nafion ${ }^{\circledR}+$ triazole $\left(\mathrm{nt}-\mathrm{TiO}_{2} / \mathrm{C}\right)$. The Nafion ${ }^{\circledR}+$ triazole solution was obtained by stirring their mixture (weight ratio of 7:3 in favour of Nafion ${ }^{\circledR}$ ) for $1 \mathrm{~h}$. The Pt-C electrocatalyst was saturated with $\mathrm{H}_{3} \mathrm{PO}_{4}$ by dripping $20 \mu \mathrm{l}$ of $10.6 \mathrm{wt} \% \mathrm{H}_{3} \mathrm{PO}_{4}$ aqueous solution. $\mathrm{H}_{3} \mathrm{PO}_{4}$ is needed to maintain good proton conductivity at higher temperatures when the proton conductivity of $\mathrm{Nafion}^{\circledR}$ drops 
off due to dehydration [21-23]. That was also one of the reasons for adding triazole to the anode side [21]. $\mathrm{H}_{3} \mathrm{PO}_{4}$ was intentionally not used in the anode side to avoid introduction of particulates which may interfere with light absorption and electronic conductivity. The photocatalyst and Pt-C loadings were each approximately $1.5 \mathrm{mg} / \mathrm{cm}^{2}$.

The catalyst layers were placed on opposite side of the PBI membrane and hot-pressed at 160 ${ }^{\circ} \mathrm{C}$ for 4 minutes under a pressure of $35 \mathrm{~kg} / \mathrm{cm}^{2}$ to get the PEC cell [11]. Non-hot-pressed $\mathrm{TiO}_{2}$ /organic samples, nt- $\mathrm{TiO}_{2} / \mathrm{G}$ (nt- $\mathrm{TiO}_{2}$ dropcast on glass), and $\mathrm{n}-\mathrm{TiO}_{2} / \mathrm{G}$ (n- $\mathrm{TiO}_{2}$ dropcast on glass), were also prepared for optical studies. We have recently studied the performances of PEC cells assembled with and without hot-pressing, and found that the non-hot-pressed cell - in which membrane electrode assembly was implemented by using Nafion as adhesive - gave a superior performance, despite possessing a larger cell resistance. The superior performance was attributed to better hydration of the non-hot-pressed cell [14]. However, the latter is not used in this work because dehydration at higher temperatures affects it strongly and masks any positive effect of increasing temperature on its photocurrent.

Diffuse reflectance spectroscopy (DRS) was carried out with a Thermo Scientific EVO-600 UVVIS spectrophotometer. The band gap energies were thereafter determined using standard Kubelka-Munk and Tauc treatment of the DRS spectra. Photoluminescence (PL) measurements were performed using a $325 \mathrm{~nm}$ line of $\mathrm{cw}$ He-Cd laser $(10 \mathrm{~mW})$ for excitation and fiber-optic spectrometer (Ocean Optics, USB4000) for analysis. Temperature-dependent PL was performed using a closed-cycle He-cryostat operating in the range 10-300 K. Time-resolved photoluminescence (TRPL) was carried out at $10 \mathrm{~K}$ by employing a $372 \mathrm{~nm}$ wavelength $50 \mathrm{ps}$ pulsed laser (PicoQuant, 2mW@40MHz). The spectral region of interest was filtered out from the total PL signal using an imaging spectrograph (HORIBA Jobin Yvon, iHR320), and then the corresponding PL decay transient was analysed by time-correlated single photon counting system (PicoQuant, TimeHarp200) with overall time resolution of $\sim 50$ ps.

X-ray photoelectron spectroscopy (XPS) was performed on a KRATOS AXIS ULTRA ${ }^{\text {DLD }}$ using monochromatic $\mathrm{Al} \mathrm{K} \alpha$ radiation $(\mathrm{h} v=1486.6 \mathrm{eV})$. The spectra were acquired at zero angle of emission, $\theta=0^{\circ}$ (normal emission) with the lenses in hybrid mode (i.e. both the magnetic and electrostatic lenses were used). The samples were not conducting, and charge neutralisation was 
applied to compensate for the charging effects. This was achieved with the use of low energy electrons driven by a magnetic field towards the sample surface. In practice, overcompensation takes place and this manifests in a shift of all peaks to lower binding energies. The spectra were energy corrected by initially placing the Ti $2 \mathrm{p}$ position at $458.8 \mathrm{eV}$ [24] and then by correcting the $\mathrm{C} 1 \mathrm{~s}$ spectra of hot-pressed samples so that their C-F peaks coincide with those of the nonhot-pressed ones.

The $\mathrm{Pt} / \mathrm{C}$ electrode functioned as both the counter and reference electrode in a standard twoelectrode configuration. Any effects from the cathode (hydrogen electrode) have been neglected, thus assuming that the impact from cathode kinetics and double layer capacitance are very small compared to the photoanode. The potential was controlled by a PARSTAT 2273 potentiostat. Linear sweep voltammetry was performed from 0 to $1 \mathrm{~V}$ cell voltage during light and dark conditions. Current transients during periodic conditioning (light on, light off) were recorded as well as electrochemical impedance spectroscopy (EIS). EIS was monitored from $500 \mathrm{kHz}$ to 50 $\mathrm{mHz}$ with a $10 \mathrm{mV}_{\mathrm{RMS}}$ a.c. perturbation at a selection of d.c. biases. The impedance data were fitted to various equivalent circuits using ZSimpWin 3.22 with modulus weighting. The PEC cell was mounted on a ProboStat ${ }^{\mathrm{TM}}$ sample holder cell (NorECs AS, Norway) as shown in Fig.1. The UV-visible $(320-500 \mathrm{~nm})$ irradiance at the surface of the cell was $85 \mathrm{~mW} / \mathrm{cm}^{2}$ and the sample holder was heated with a heating tape, maintained at a given temperature for 30 minutes before commencement of measurement. 

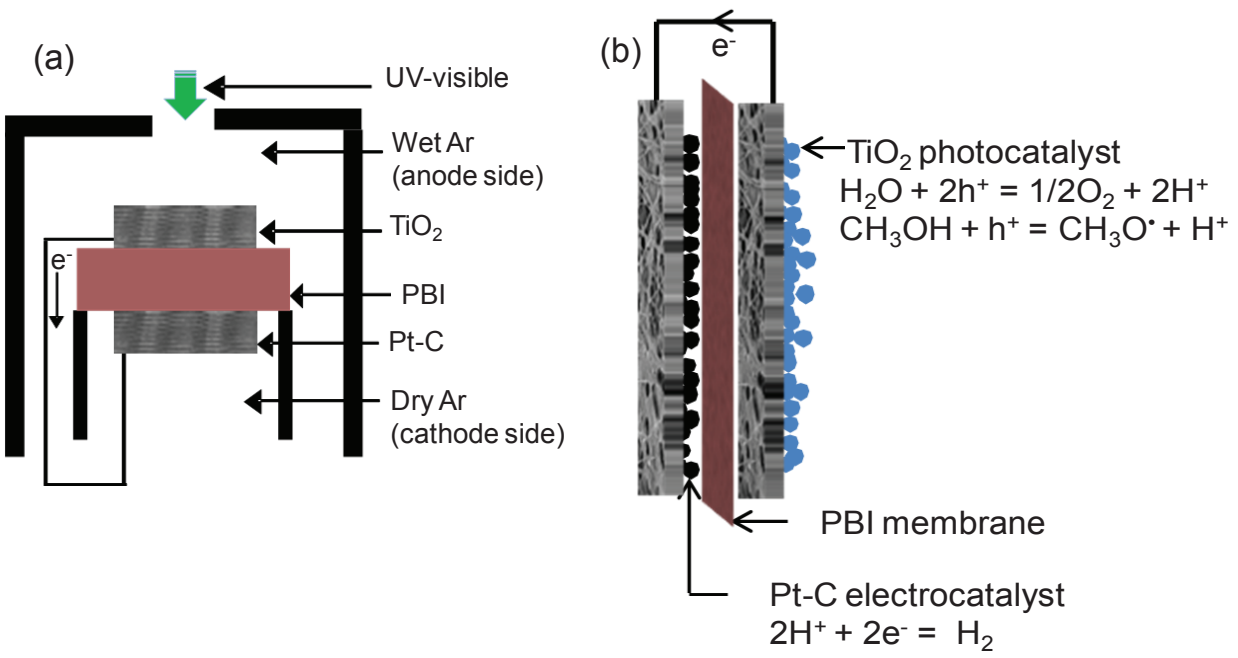

Fig. 1: (a) Schematic of a PEC cell on a ProboStat ${ }^{\mathrm{TM}}$ sample holder, (b) an enlarged view of the cell indicating some of the reactions going on at the electrodes. The methoxy radical produced at the photoanode can undergo further reaction to produce more $\mathrm{H}^{+}$, electrons and $\mathrm{CO}_{2}$ [12].

\section{Results and discussion}

\subsection{Optical characterisation: Band gap, photoluminescence and charge carrier lifetime}

The optical characterisation included diffuse reflectance spectroscopy (DRS) and photoluminescence (PL) measurements of hot-pressed samples (nt- $\mathrm{TiO}_{2} / \mathrm{C}$ and $\mathrm{n}-\mathrm{TiO}_{2} / \mathrm{C}$ ), nonhot-pressed samples (nt- $\mathrm{TiO}_{2} / \mathrm{G}$ and $\mathrm{n}-\mathrm{TiO}_{2} / \mathrm{G}$ ), as well as of pure $\mathrm{P} 25 \mathrm{TiO}_{2}$ powder and a

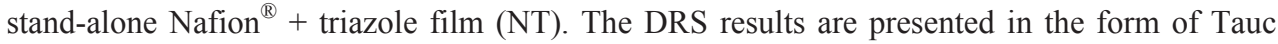
plots in Fig. 2a, indicating an apparent $(\sim 0.3 \mathrm{eV})$ red-shift of the absorption edge for the hotpressed samples with respect to the non-hot-pressed ones and pure $\mathrm{TiO}_{2}$. The absorption thresholds of the non-hot-pressed samples and of the pure $\mathrm{TiO}_{2}$ (not shown) are found to be matching at around $3.4 \mathrm{eV}$. In turn, this band gap values implies the mainly anatase structure of $\mathrm{P} 25 \mathrm{TiO}_{2}[25,26]$, also indicating that no band gap modification occurs upon embedding $\mathrm{TiO}_{2}$ into the organic matrix. Regarding the latter, the absorption threshold for a stand-alone NT film is found far into the UV region, at around $5.4 \mathrm{eV}$, suggesting total transparency of the organic compound matrix throughout the spectral range relevant to PEC operation. Although hotpressing has been used to prepare PEM-electrolyser type $\mathrm{PEC}$ cells utilising $\mathrm{TiO}_{2}$ as photoanode $[11,18,27]$, we are not aware of any report on the modification of the optical absorption of 
$\mathrm{TiO}_{2}$ by the hot-pressing process. Further studies, for example incident-photon-to-current efficiency $[28,29]$, are needed to determine if the gain in absorption with hot-pressing translates to improved PEC efficiency.

(a)

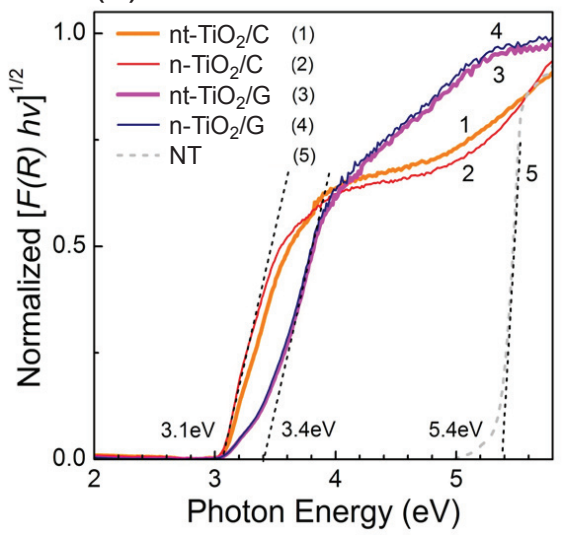

(b)

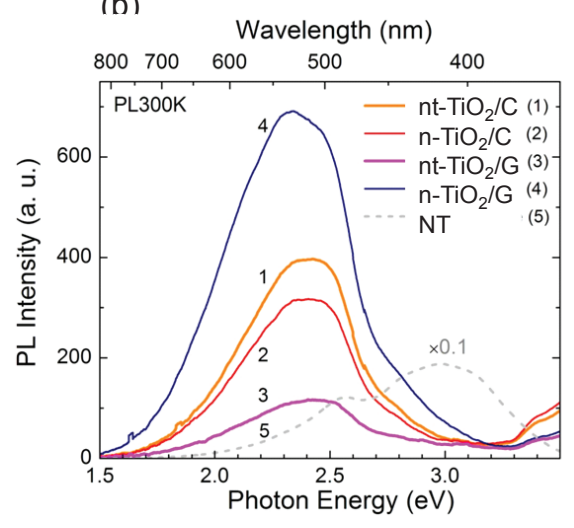

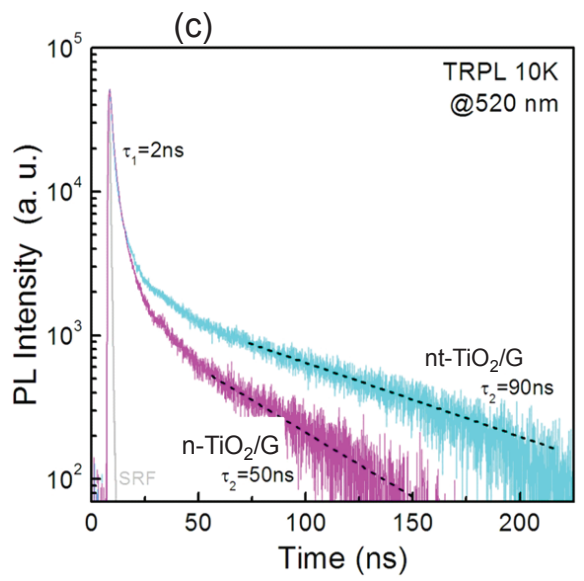

Fig. 2: Diffuse reflectance spectra (a) steady-state photoluminescence spectra at $300 \mathrm{~K}$ (b) and time-resolved PL decay transients measured at $10 \mathrm{~K}$ (c). 
The optical emission properties of the samples were examined to get an insight into the charge carrier transport and recombination processes. Fig. $2 \mathrm{~b}$ summarises time-integrated photoluminescence (PL) spectra obtained at room temperature, in all the cases dominated by a characteristic red luminescence of anatase $\mathrm{TiO}_{2}$, which is commonly attributed to the radiative recombination of self-trapped excitons [30]. The generally low PL efficiency observed for all samples is consistent with the indirect-type of $\mathrm{TiO}_{2}$ bandgap, also inferring that photo-generated carriers for the most part recombine non-radiatively via surface defect traps and mid-bandgap states. The variable density of such defects in the samples is mirrored by corresponding changes of the PL efficiency, which therefore can be considered as a measure of non-radiative losses. As can be seen in Fig. 2b, the two extremes of most luminous and most quenched PL are represented by $n-\mathrm{TiO}_{2} / \mathrm{G}$ and $\mathrm{nt}-\mathrm{TiO}_{2} / \mathrm{G}$ samples, respectively.

Time-resolved photoluminescence (TRPL) was employed to evaluate the charge carrier lifetimes in the above-mentioned $n t-\mathrm{TiO}_{2} / \mathrm{G}$ and $\mathrm{n}-\mathrm{TiO}_{2} / \mathrm{G}$. The carrier dynamics in $\mathrm{TiO}_{2}$ is usually non-exponential due to distribution of the recombination rates up to microsecond time scale. As a first approximation, the influence of the triazole on the carrier recombination rate can be deduced from the comparison of asymptotic lifetime parameters at a fixed delay time as shown in Fig. 2c, and implying by a factor of two higher recombination rate in $\mathrm{n}-\mathrm{TiO}_{2} / \mathrm{G}$ as compared to $\mathrm{nt}-\mathrm{TiO}_{2} / \mathrm{G}$. The longer lifetimes observed for structures modified with triazole is most likely a result of reduced surface leakage, i.e. suppressed surface recombination at the interface of $\mathrm{TiO}_{2}$ particle and surrounding matrix. 

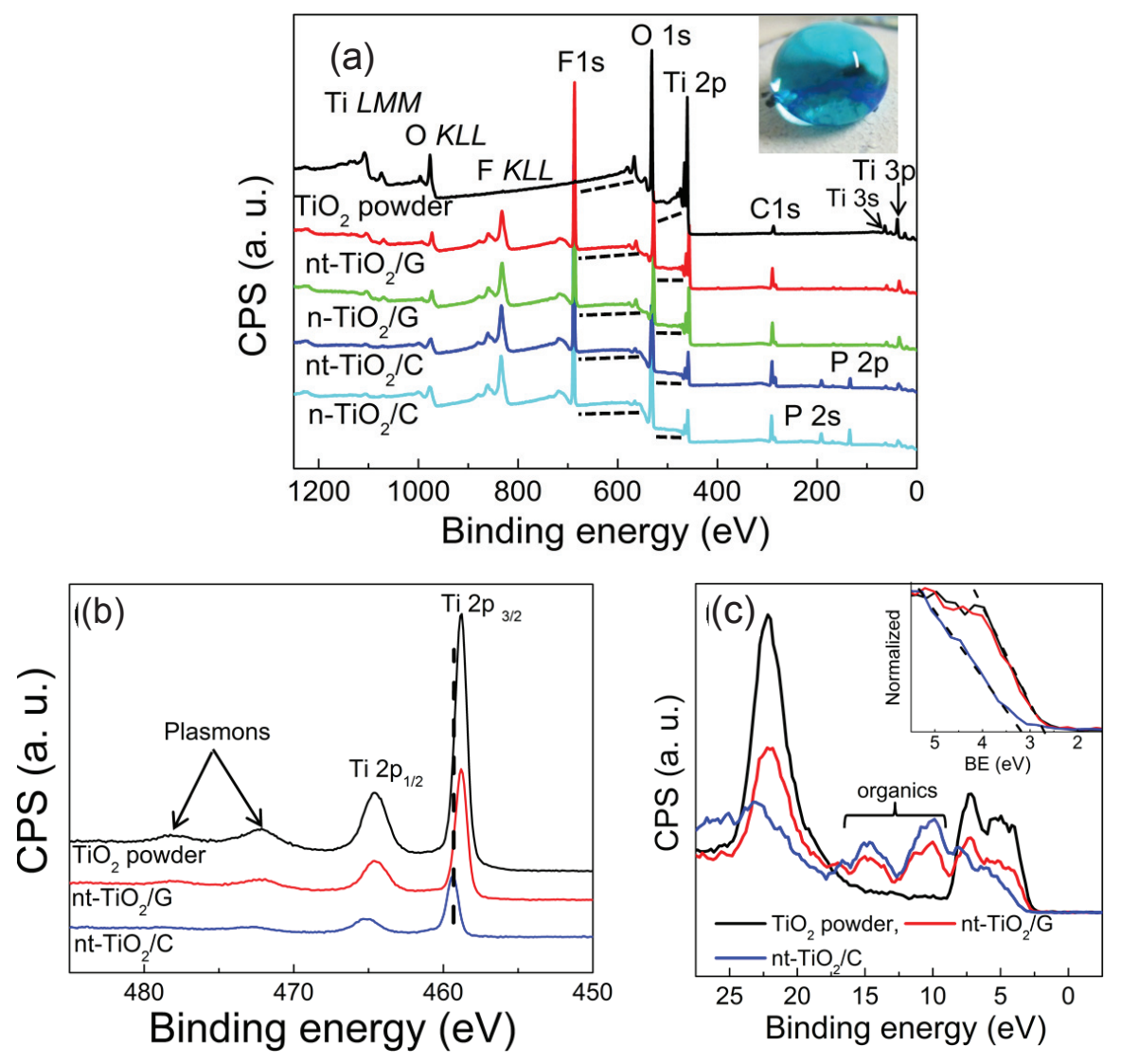

Fig. 3: XPS survey scan (a), high resolution spectra of Ti 2p peaks (b), and valence band spectra (c) of samples. The inset in (a) is an image of a droplet of aqueous methylene blue solution on a dropcast film of $\mathrm{Nafion}^{\circledR} / \mathrm{TiO}_{2}$. The extra peaks in (c) are attributed to states owing to the presence of organic matter while its inset is a magnification of the shift in binding energy seen for hotpressed samples. The spectra for $n t-\mathrm{TiO}_{2} / \mathrm{C}$ and $\mathrm{nt}-\mathrm{TiO}_{2} / \mathrm{G}$ in (b) and (c) are representative of n$\mathrm{TiO}_{2} / \mathrm{C}$ and $\mathrm{n}-\mathrm{TiO}_{2} / \mathrm{G}$, respectively.

\subsection{XPS analysis}

The XPS survey scans of the samples are presented in Fig. 3a. The post peak background slopes for $\mathrm{O} 1 \mathrm{~s}$ and $\mathrm{Ti} 2 \mathrm{p}$ peaks of all samples with Nafion ${ }^{\circledR}$ (highlighted with dashed lines) indicate that the $\mathrm{O} 1 \mathrm{~s}$ and $\mathrm{Ti} 2 \mathrm{p}$ photoelectrons are attenuated compared with pure $\mathrm{TiO}_{2}$ standard. This is indicative of the presence of an outermost layer around $\mathrm{TiO}_{2}$; the unmarked post peak background slopes of F 1s are higher than the corresponding ones for $\mathrm{O} 1 \mathrm{~s}$ and Ti $2 \mathrm{p}$. The same 
conclusion is drawn from the Ti 2 p spectra in Fig. $3 \mathrm{~b}$ and also from that of $\mathrm{O} 1 \mathrm{~s}$ (shown in Fig. $\mathrm{S} 1$ in the supporting information ${ }^{*}$ ). The reduction of spectral intensities from top to bottom is due to the increased attenuation of the photoelectrons. In acidic environment, the surface of $\mathrm{TiO}_{2}$ will become positively charged $[31,32]$, which will make the deprotonated sulphonic acid end group (negatively charged) in Nafion $\left.{ }^{(}\right)$interact with it [33]. The hydrophobic fluorinated end groups and backbone of $\mathrm{Nafion}{ }^{\circledR}$ will then form an outer layer around $\mathrm{TiO}_{2}$ nanoparticles. This is in agreement with the attenuation of Ti $2 p$ and $\mathrm{O} 1$ s post peak background slopes in the samples with $\mathrm{Nafion}^{\circledR}$, and also with the observation that the drop cast $\mathrm{TiO}_{2} / \mathrm{Nafion}$ film surface appears superhydrophobic (inset of Fig. 3a). The stronger attenuation of photoelectrons in n$\mathrm{TiO}_{2} / \mathrm{C}$ and nt- $\mathrm{TiO}_{2} / \mathrm{C}$ (hot-pressed) compared with $\mathrm{n}-\mathrm{TiO}_{2} / \mathrm{G}$ and $\mathrm{nt}-\mathrm{TiO}_{2} / \mathrm{G}$ (non-hot-pressed) may be related to the presence of phosphoric acid in the membrane electrode assembly.

As shown in Fig. $3 b$ and $3 c$, the $\mathrm{Ti} 2 \mathrm{p}$ core level and the valence band edges of $\mathrm{TiO}_{2}$, respectively, in the hot-pressed samples are shifted towards higher binding energies as compared with the non-hot-pressed samples and pure $\mathrm{TiO}_{2}$. The same result is seen in the $\mathrm{O} 1 \mathrm{~s}$ spectra also. These shifts are not seen for peaks not associated with $\mathrm{TiO}_{2}$ - peaks from organics in Fig. $3 \mathrm{c}$ and $\mathrm{F}$ 1s peaks (not shown) for example. In the case of insulating samples requiring charge compensation, it is known that the binding energy level that an emitted photoelectron originates from depends on the sample work function according to equation 1 below [34]

$\mathrm{BE}_{\mathrm{F} \text { sample }}=\mathrm{h} v-\mathrm{KE}+\mathrm{E}_{\mathrm{e}}-\Phi_{\text {sample }}$

where $\mathrm{BE}$ is the binding energy with respect to the Fermi level $\left(\mathrm{E}_{\mathrm{F}}\right), \mathrm{h} v$ is the excitation energy, $\mathrm{KE}$ is the measured kinetic energy, $\mathrm{E}_{\mathrm{e}}$ is the charge neutralising contribution to surface potential and $\Phi_{\text {sample }}$ is the work function of the sample. The shift of the peaks associated with $\mathrm{TiO}_{2}(\mathrm{Ti}$ $2 \mathrm{p}, \mathrm{O} 1 \mathrm{~s}$ and the valence band) to higher binding energies for $\mathrm{n}-\mathrm{TiO}_{2} / \mathrm{C}$ and nt- $\mathrm{TiO}_{2} / \mathrm{C}$ imply that the work function of the $\mathrm{TiO}_{2}$ particles in them is less than that of $\mathrm{TiO}_{2}$ in nt- $\mathrm{TiO}_{2} / \mathrm{G}, \mathrm{n}$ $\mathrm{TiO}_{2} / \mathrm{G}$ and of pure $\mathrm{TiO}_{2}$.

\footnotetext{
${ }^{*}$ The supporting information for manuscript IV is deposited in the appendix.
} 
The reduction in work function (shift of $\mathrm{E}_{\mathrm{F}}$ towards the vacuum level) may have contribution from the presence of organic molecules around $\mathrm{TiO}_{2}$. However, n- $\mathrm{TiO}_{2} / \mathrm{G}$ and nt- $\mathrm{TiO}_{2} / \mathrm{G}$ which have organics around them do not show any shifts in binding energy. The hot-pressed samples, the non-hot-pressed ones and pure $\mathrm{TiO}_{2}$ have similar X-ray diffraction patterns (Fig. S2 in the supporting information). Therefore, the reduction in work function of the hot-pressed samples can be related to the shift of the absorption edge of $\mathrm{TiO}_{2}$ as seen in the optical studies. This may be due to introduction of surface defect levels near the conduction band, as a result of enhanced interfacial interaction of the hydrophilic part of $\mathrm{Nafion}^{\circledR}$ with $\mathrm{TiO}_{2}$ under the hot-pressing conditions.
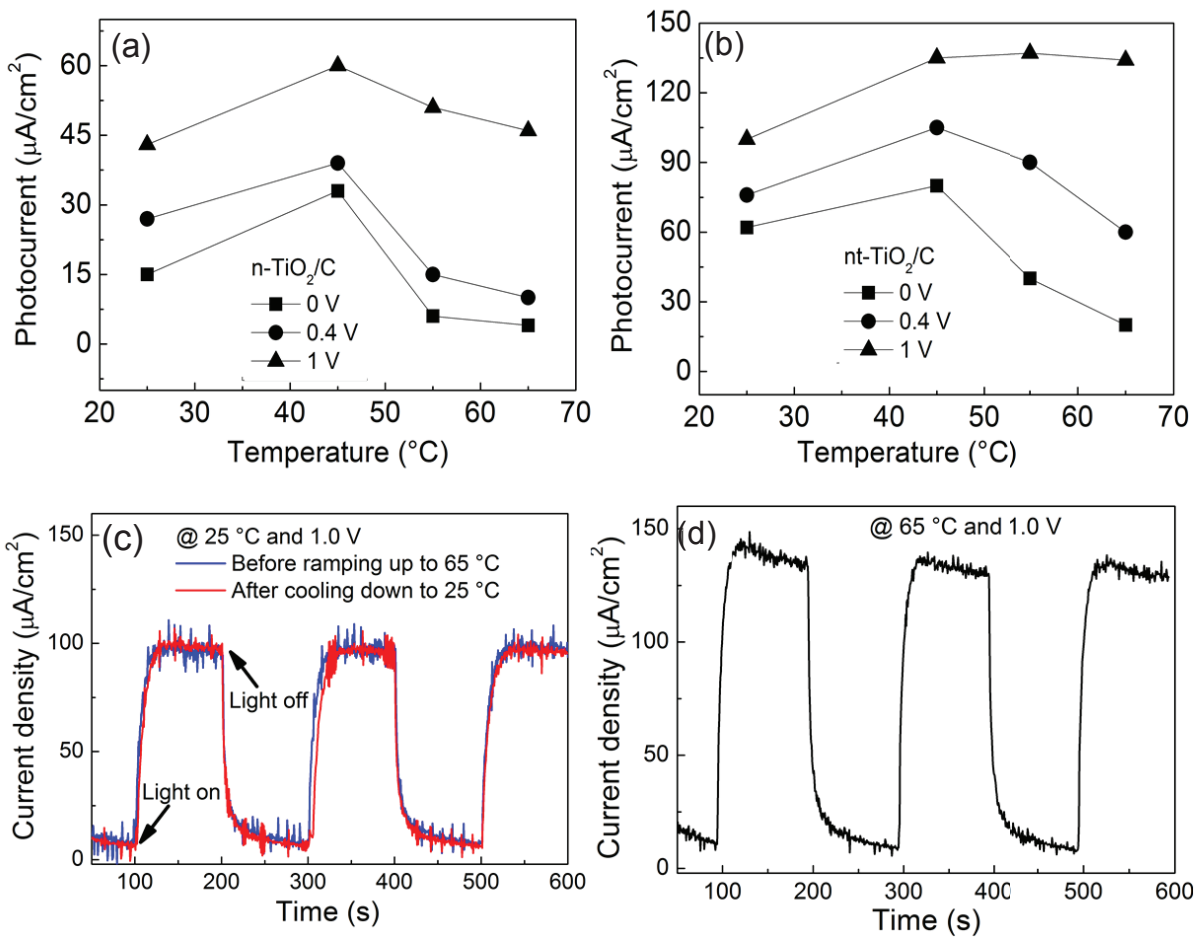

Fig. 4: Photocurrents vs. temperature for PEC cells: (a) $\mathrm{n}-\mathrm{TiO}_{2} / \mathrm{C}$, and (b) $\mathrm{nt}-\mathrm{TiO}_{2} / \mathrm{C}$; current-time plots for nt- $\mathrm{TiO}_{2} / \mathrm{C}$ at $25^{\circ} \mathrm{C}$ (c) and $65^{\circ} \mathrm{C}$ (d). The results were obtained with $\mathrm{Ar}+\mathrm{H}_{2} \mathrm{O}+\mathrm{CH}_{3} \mathrm{OH}$. 


\subsection{Photoelectrochemical characterisation}

Photocurrents for the PEC cell with n- $\mathrm{TiO}_{2} / \mathrm{C}$ and $\mathrm{nt}-\mathrm{TiO}_{2} / \mathrm{C}$ anodes recorded while supplying $\mathrm{Ar}+\mathrm{H}_{2} \mathrm{O}+\mathrm{CH}_{3} \mathrm{OH}$ to the anode side $\left(\mathrm{Ar}=97.50 \%, \mathrm{H}_{2} \mathrm{O}=2.27 \%\right.$, and $\mathrm{CH}_{3} \mathrm{OH}=0.23 \%$, ) are shown in Fig. 4a-b. Photocurrents increase for both cells from room temperature to $45^{\circ} \mathrm{C}$ and then drop off, except for nt- $\mathrm{TiO}_{2} / \mathrm{C}$ at $1.0 \mathrm{~V}$ which appears to remain stable. In general, nt$\mathrm{TiO}_{2} / \mathrm{C}$ photocurrents are two to four times higher than those of $\mathrm{n}-\mathrm{TiO}_{2} / \mathrm{C}$. Figure $4 \mathrm{c}-\mathrm{d}$ show the observed current densities for nt- $\mathrm{TiO}_{2} / \mathrm{C}$ at $25{ }^{\circ} \mathrm{C}$ (before ramping up to $65{ }^{\circ} \mathrm{C}$ ) and $65{ }^{\circ} \mathrm{C}$ respectively, when periodically turning the light source on and off at an applied cell voltage of 1 $\mathrm{V}$. The response at $1.0 \mathrm{~V}$ after cooling down to $25{ }^{\circ} \mathrm{C}$ is also given in Figure $4 \mathrm{c}$. The photocurrent densities before and after ramping up temperature are basically the same, with similar results obtained at 0 and $0.4 \mathrm{~V}$ and also for $\mathrm{n}-\mathrm{TiO}_{2} / \mathrm{C}$. This indicates that the PEC cell is stable and that the drop off in photocurrent of the cells at higher temperature is not due to an irreversible process.
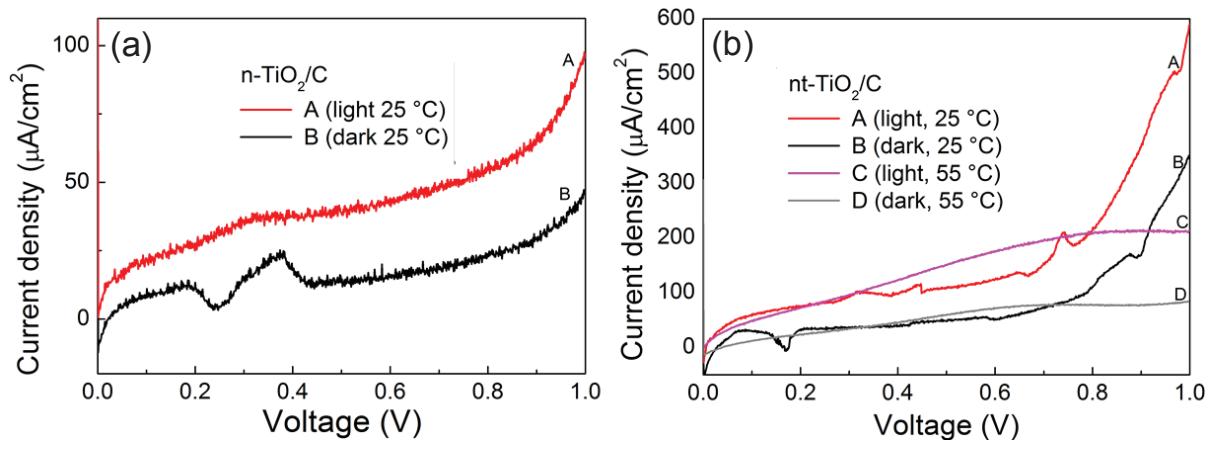

Fig. 5: Linear sweep voltammograms for (a) $\mathrm{n}-\mathrm{TiO}_{2} / \mathrm{C}$, and (b) $n t-\mathrm{TiO}_{2} / \mathrm{C}$, obtained with $\mathrm{Ar}+\mathrm{H}_{2} \mathrm{O}+\mathrm{CH}_{3} \mathrm{OH}$ going from 0 and up to $1 \mathrm{~V}$ at a sweep rate of $50 \mathrm{mV} \mathrm{s}^{-1}$.

Linear sweep voltammograms for the two cells at $25{ }^{\circ} \mathrm{C}$, with $\mathrm{Ar}+\mathrm{H}_{2} \mathrm{O}+\mathrm{CH}_{3} \mathrm{OH}$ supplied to the anode side, are shown in Fig. 5a-b. They indicate an open circuit photogenerated voltage (OCPV) of about $0 \mathrm{~V}$, which is positively shifted in comparison with the $-0.4 \mathrm{~V}$ value earlier obtained by us in a recent work for a PEC hydrogen generating cell assembled by a wet chemistry method [14]. The OCPV depends on not just the amount of photogenerated electron hole pairs, but on how fast the photogenerated holes can be consumed by water at the 
photoanode surface. The consumption of holes is significantly enhanced in the presence of methanol, leading to a negative shift in OCPV [10]. In the current cells under study, lower hydration means that the photogenerated holes are not quickly snapped up, leading to higher recombination rate of photogenerated electron hole pairs, a positive shift in OCPV, and of course lower photocurrents. The peaks seen in the voltammograms are difficult to explain because their positions and intensities varied with subsequent experiments; however, they were largely absent at higher temperatures.

The voltammograms also provide additional insight into the reason for the drop-off in photocurrents at higher temperatures. As also shown in Fig. $5 \mathrm{~b}$ for $\mathrm{nt}-\mathrm{TiO}_{2} / \mathrm{C}$, the shapes of the curves at $25{ }^{\circ} \mathrm{C}$ and at $55{ }^{\circ} \mathrm{C}$ are different. Unlike the result at $25{ }^{\circ} \mathrm{C}$, both the dark and photo currents reach a limiting current density at about $0.7 \mathrm{~V}$ for $55^{\circ} \mathrm{C}$, and afterwards drop off (no exponential increase). Similar results are seen for $\mathrm{n}-\mathrm{TiO}_{2} / \mathrm{C}$. This phenomenon has been identified in a PEM electrolyser run with water vapour - using Ar as carrier gas - and was attributed to the water level in the feed gas stream being unable to sustain water electrolysis at higher applied voltage[35]. Therefore the drop off in photocurrent (Fig.4a-b) at above $45^{\circ} \mathrm{C}$ can be ascribed to dehydration of the cells, which also explains the degradation of photocurrent with time and cycle number as shown in Fig.4d, and the fact that the photocurrent levels at $25{ }^{\circ} \mathrm{C}$ before and after ramping up temperature are the same. Considering that the cathode and the membrane are supersaturated with phosphoric acid and that the temperature regime here is still relatively low, we conclude that this dehydration is mainly at the photoanode layers.

To further evaluate the effect of temperature on photocurrent, nt- $\mathrm{TiO}_{2} / \mathrm{C}$ was chosen for currenttime measurements between $25^{\circ} \mathrm{C}$ and $45^{\circ} \mathrm{C}$. A plot of photocurrent vs temperature presented in Fig. 6 shows that photocurrent generation peaked at $35^{\circ} \mathrm{C}$ for biases of 0 and $0.4 \mathrm{~V}$, but at 45 ${ }^{\circ} \mathrm{C}$ for $1 \mathrm{~V}$, indicating that the increased cell overpotential at higher temperatures is offset by the external voltage. 


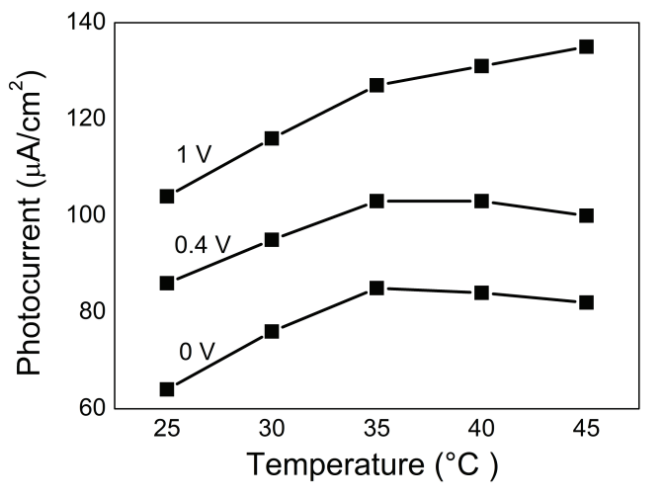

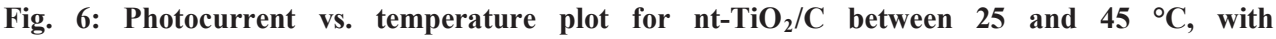
$\mathrm{Ar}+\mathrm{H}_{2} \mathrm{O}+\mathrm{CH}_{3} \mathrm{OH}$ in the anode side.

Since nt- $\mathrm{TiO}_{2} / \mathrm{C}$ and $\mathrm{n}-\mathrm{TiO}_{2} / \mathrm{C}$ have similar XRD, photoluminescence, and XPS characteristics, the difference in their photocurrent levels cannot be attributed to differences in light absorption. The likely reason for higher photocurrent generation in $n t-\mathrm{TiO}_{2} / \mathrm{C}$ can be seen from the TRPL results (Fig. 2c) which show an almost two-fold increase in the lifetime of photogenerated charge carriers in nt- $\mathrm{TiO}_{2}$ compared to $\mathrm{n}-\mathrm{TiO}_{2}$. This is in agreement with the reports that triazole can enhance separation of photogenerated charge carriers and act as a bridge for transfer of photogenerated electrons from a photoactive centre to an electron acceptor [36, 37].

Triazole in triazole + Nafion ${ }^{\circledR}$ blend is said to reside in the nanostructure of the hydrophilic end group of the polymer electrolyte ${ }^{[21]}$. That will make it easily accessible to $\mathrm{TiO}_{2}$ surface when the latter is mixed with the blend. We investigated the interaction of $\mathrm{TiO}_{2}$ and triazole in an acidic environment by Fourier transform infrared spectroscopy (see the supporting information for experimental details). The FT-IR results are shown in Fig.7, indicating the presence of triazole molecules on $\mathrm{TiO}_{2}$ nanoparticles. The $\mathrm{C}-\mathrm{N}$ stretching vibration at $1118 \mathrm{~cm}^{-1}$ is slightly shifted to the right, which means that triazole is probably connected to $\mathrm{TiO}_{2}$ via the carbon or nitrogen centres, or both. The effectiveness of triazole as an electron bridge is dependent on which of its elements connects to a light absorber or electron acceptor, as well as on the use of other organic molecules as linkers (spacers) in the donor-triazole bond[36]. Optimisation of the $\mathrm{TiO}_{2}$-triazole conjugation may present another opportunity for improving the photocurrent of solid state PEC cells. 


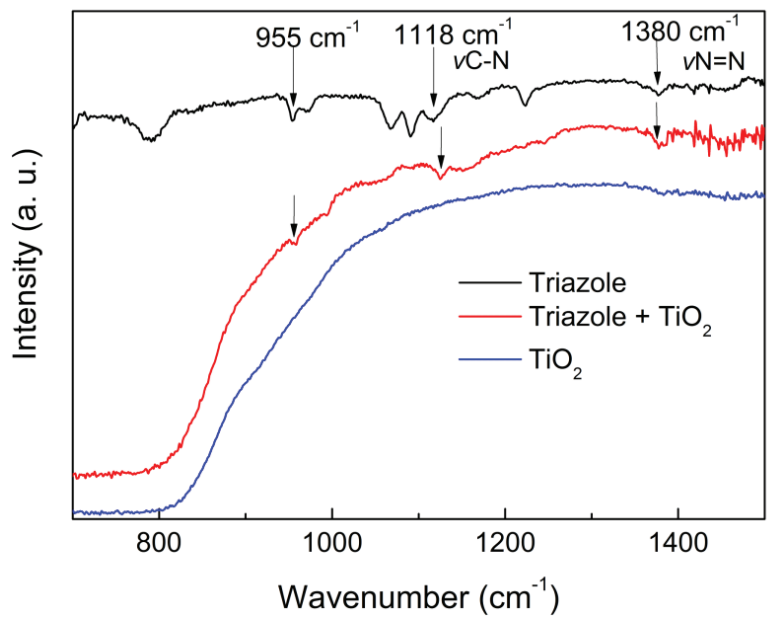

Fig. 7. FT-IR spectra of triazole, triazole $+\mathrm{TiO}_{2}$ and pure $\mathrm{TiO}_{2}$ powder.

\subsubsection{Electrochemical impedance spectroscopy}

EIS experiments were conducted for dark and illuminated conditions at selected voltages with $\mathrm{Ar}+\mathrm{H}_{2} \mathrm{O}+\mathrm{CH}_{3} \mathrm{OH}$ supplied to the anode side. For an ideally polarisable semi-conductor, a series $\mathrm{R}-\mathrm{C}$ equivalent circuit can be used to calculate the space-charge capacitance in the absence of deep-level (sub-band) energy states. When deep-level states are taken into consideration (hence the capacity associated with deep-level states are not negligible as compared with the spacecharge capacitance), one or more R-C series branches are put in parallel to the space-charge capacitance. As shown by Jansen et al, the number of resistor-capacitor pairs that may be detected depends on temperature [38]. It is important to note that since we are dealing with $\mathrm{TiO}_{2}$ nanoparticles of about $25 \mathrm{~nm}$ average diameter, it is possible that the normal semiconductor space-charge layer does not exist or has a very small width, and that separation of photogenerated charge carriers by charge transfer to redox species at the nanoparticles surfaces is either the only available process, or a complimentary process [39, 40].

An equivalent circuit (Fig. 8) representing the semi conductor electrode was employed in this work to model the experimental data. The model includes a parallel combination of the space charge resistance $\left(R_{\mathrm{ss}}\right)$ and space charge capacitance $\left(Q_{\mathrm{ss}}\right)$, as well as one resistance-capacitance 
series branch $\left(R_{\mathrm{d}}-C_{\mathrm{d}}\right)$ put in parallel to account for any deep level state activities within the semiconductor electrode.

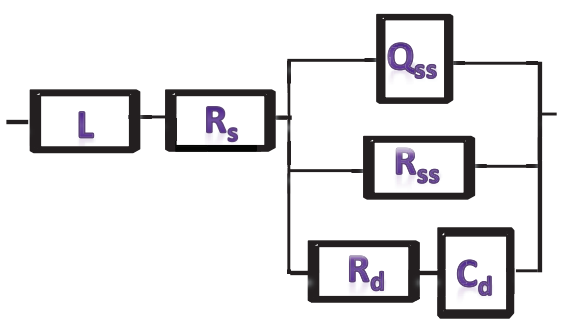

Fig. 8: Circuit model used in fitting impedance data

$R_{\mathrm{S}}$ is included in series to the semi conductor electrode and represents the general ohmic resistance in the circuit as a result of the rather poor ion conductivity in the PBI membrane and interfacial contact resistances. The inductor, $L$, has no physical meaning and was only added to compensate for stray inductances observed for the highest frequencies.

Fig. 9a-b show the dark Nyquist plots obtained with a $\mathrm{DC}$ bias of $1 \mathrm{~V}$ for $\mathrm{n}-\mathrm{TiO}_{2} / \mathrm{C}$ and nt$\mathrm{TiO}_{2} / \mathrm{C}$ cells. One low frequency and one high frequency semi-circle can be seen in the Nyquist spectra indicating at least two relaxation processes in the system. Clearly the circuit parameters and appearance of the impedance spectra depend on temperature, light condition and type of electrode composition. Unfortunately, some of the recorded impedance spectra proved to be difficult to fit without introducing a large error bar on one or more parameters, and any conclusive discussions involving the parameters $R_{\mathrm{ss}}, R_{\mathrm{d}}$ and $C_{\mathrm{d}}$, are therefore avoided. 

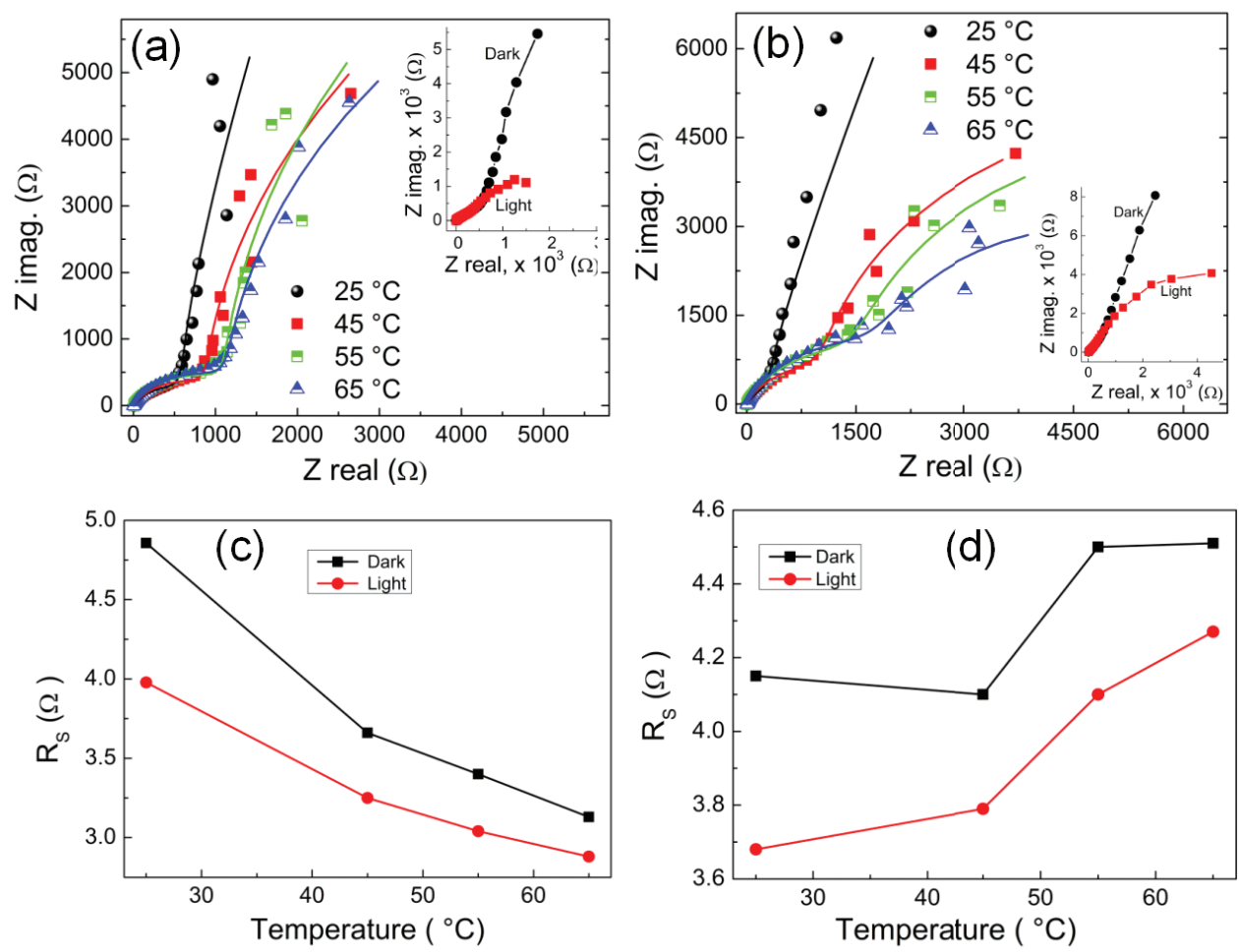

Fig. 9: Dark Nyquist plots of nt- $\mathrm{TiO}_{2} / \mathrm{C}$ (a) and $\mathrm{n}-\mathrm{TiO}_{2} / \mathrm{C}$ (b) and electrolyte resistance vs. temperature plots of $\mathrm{nt}-\mathrm{TiO}_{2} / \mathrm{C}(\mathrm{c})$ and $\mathrm{n}-\mathrm{TiO}_{2} / \mathrm{C}(\mathrm{d})$, all obtained with a $\mathrm{DC}$ bias of $1 \mathrm{~V}$. The insets in (a) and (b) show the plots for dark (black) and illuminated (red) conditions at $25^{\circ} \mathrm{C}$ and $0 \mathrm{~V}$. The anode side gas was $\mathrm{Ar}+\mathrm{H}_{2} \mathrm{O}+\mathrm{CH}_{3} \mathrm{OH}$.

At $25^{\circ} \mathrm{C}$, the dark electrolyte resistances as obtained from the fitting results are $4.15 \pm 0.06$ and $4.86 \pm 0.1 \Omega \mathrm{cm}^{2}$ for $\mathrm{n}-\mathrm{TiO}_{2} / \mathrm{C}$ and $\mathrm{nt}-\mathrm{TiO}_{2} / \mathrm{C}$, respectively. The slightly higher value for the latter could be attributed to reduced proton conductivity in its photoanode region due to a lower Nafion ${ }^{\circledR}$ concentration. As shown in Fig. 9c-d, with increasing temperature, there is a general drop and increase in the electrolyte resistances of $n t-\mathrm{TiO}_{2} / \mathrm{C}$ and $\mathrm{n}-\mathrm{TiO}_{2} / \mathrm{C}$, respectively (except for a slight drop in the dark at $45{ }^{\circ} \mathrm{C}$ for $\mathrm{n}-\mathrm{TiO}_{2} / \mathrm{C}$ ). Similar values and trends were obtained at 0 and $0.4 \mathrm{~V}$ as well. We recall that the photoanode layer in $\mathrm{n}-\mathrm{TiO}_{2} / \mathrm{C}$ contains only water saturated Nafion ${ }^{\circledR}$ electrolyte while that of $\mathrm{nt}-\mathrm{TiO}_{2} / \mathrm{C}$ contains triazole in addition. With increase 
in temperature, the drying of $\mathrm{n}-\mathrm{TiO}_{2} / \mathrm{C}$ should result in reduced proton conductivity while the presence of triazole is expected to mitigate against this in nt- $\mathrm{TiO}_{2} / \mathrm{C}$ [21]. The comparative impact of these results on the photocurrent of the two cells are difficult to ascertain at the moment since, according to our earlier result, better hydration can have a bigger impact on photocurrent than cell resistance, the hot-pressed cells in focus here particularly suffering from a lower hydration level [14].

Furthermore, the electrolyte resistance of both cells at all temperatures and applied bias decrease with illumination, as exemplified in Fig.9c-d. This can be related to enhanced wetability of $\mathrm{TiO}_{2}$ with UV illumination (formation of surface hydroxyl groups) [41], or simply to an increase in the concentration of protons at the photoanode where photogenerated holes oxidise water and methanol to produce protons.

As can be seen from the low frequency part of the impedance spectra in Fig. 9a-b, there appears to be a decrease in the overall polarisation resistance of the cells (zero frequency limit) with increasing temperature at $1 \mathrm{~V}$. The same results are seen with applied voltages of 0 and $0.4 \mathrm{~V}$ (Fig. S3 in the supporting information). With 0 and $0.4 \mathrm{~V}$ biases however, after the initial decrease on moving from 25 to $45^{\circ} \mathrm{C}$, it appears like there is no further decrease on ramping up the temperature even more. Rather high values for $R_{\mathrm{ss}}$ were obtained $\left(10^{4}\right)$ for all spectra. In fact, removing $R_{\mathrm{ss}}$ from the circuit (i.e. excluding any leakage processes [38, 42]) generally improved the fitting, yielding a blocking behaviour in the low frequency region. The general reduction of this low frequency semi circle with increasing temperatures can be attributed to increased space charge/surface kinetics, while any stagnation or increase (at 0 and $0.4 \mathrm{~V}$ ) may indicate drying of the photoanode countering the increased electrode kinetics. In addition, this polarisation resistance decrease at all temperatures with illumination, as exemplified in the insets of Fig. 9a-b. This is attributed to increased concentration of charge carriers at the photoanode with illumination.

\subsubsection{Photocurrents with only gaseous water in the anode compartment}

$\mathrm{Ar}+\mathrm{H}_{2} \mathrm{O}+\mathrm{CH}_{3} \mathrm{OH}$ was replaced with $\mathrm{Ar}+\mathrm{H}_{2} \mathrm{O}\left(97.5 \% \mathrm{Ar}\right.$ and $\left.2.5 \% \mathrm{H}_{2} \mathrm{O}\right)$ and the PEC performance of nt- $\mathrm{TiO}_{2} / \mathrm{C}$ cell studied. Fig. 10a shows the current transients of the cell at $25^{\circ} \mathrm{C}$, indicating photocurrents which are reduced to around $20 \%$ of the values obtained with 
$\mathrm{Ar}+\mathrm{H}_{2} \mathrm{O}+\mathrm{CH}_{3} \mathrm{OH}$. This is around the values reported by Seger and Kamat with a similar Nafion ${ }^{\circledR}$ based PEC cell design fed with aqueous reactants [11]. Experiments at elevated temperatures was made possible by heating the humidification bubbler to $90{ }^{\circ} \mathrm{C}$, supplying an anode gas composition of approximately $93 \% \mathrm{Ar}$ and $7 \% \mathrm{H}_{2} \mathrm{O}$. The gas line from the bubbler to the measurement cell was maintained at $125{ }^{\circ} \mathrm{C}$ in order to avoid condensation. Current time measurements at a cell temperature of $125^{\circ} \mathrm{C}$ (Fig. 10b) show an increase in photocurrents of about three times as compared to the results at $25^{\circ} \mathrm{C}$.

Upon increasing the temperature to $145{ }^{\circ} \mathrm{C}$, photocurrents increased further by up to $30 \%$ of the values at $125{ }^{\circ} \mathrm{C}$ at 0.4 and $1 \mathrm{~V}$ (Fig. 10c), but further experiment was not possible due to a sudden drop in photocurrent and increase in noise level. Upon post-mortem inspection, the anode layer was almost completely detached from the membrane, while the cathode suffered a similar fate but to a lesser extent. This is attributed to deterioration of the membrane catalyst layers interfaces due to excessive hydration [22], and may suggest that the photocurrents obtained at these elevated temperatures could have been higher without this interfacial degradation. However, the photocurrents recorded at $125{ }^{\circ} \mathrm{C}$ and above clearly demonstrate that higher PEC efficiency can be achieved at higher temperature if the hydration level of the cell is properly regulated.
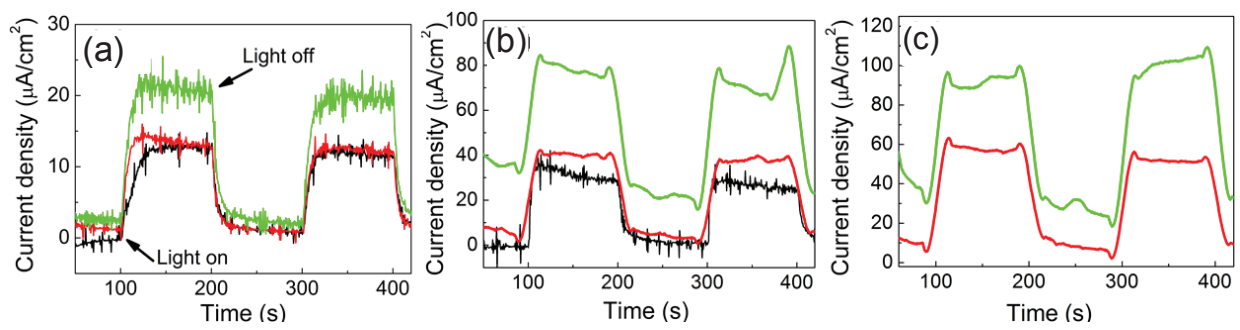

Fig. 10: Current transients for nt- $\mathrm{TiO}_{2} / \mathrm{C}$ with $\mathrm{Ar}+\mathrm{H}_{2} \mathrm{O}$ on the anode side at $25{ }^{\circ} \mathrm{C}$ (a), $125^{\circ} \mathrm{C}$ (b) and $145^{\circ} \mathrm{C}(\mathrm{c})$. The anode feed gas water content is $2.5 \%$ in (a) and $7 \%$ in (b) and (c). Colour code: black $(0 \mathrm{~V})$, red $(0.4 \mathrm{~V})$ and green $(1 \mathrm{~V})$. The plots for 0.4 and $1 \mathrm{~V}$ in $(\mathrm{b})$ and (c) have been smoothened.

\section{Conclusion}

Membrane electrode assembly of a solid-state photoelectrochemical cell by hot-pressing shifts the optical absorption of the $\mathrm{TiO}_{2}$ photoanode to longer wavelength. The photocurrent of the 
solid-state cell operating with gaseous reactants at the anode increases with increasing temperature. In the lower temperature regime, this is shown to be mainly due to improved electrode kinetics. Interaction of the $\mathrm{TiO}_{2}$ photoanode with triazole, an electroactive heterocyclic compound, improved the lifetime of photogenerated charge carriers, and invariably, the performance of the photoelectrochemical cell. Electrolyte resistances of photoelectrochemical cells - with $\mathrm{TiO}_{2}$ or triazole-modified $\mathrm{TiO}_{2}$ - were reduced with illumination. This is attributed to a likely enhancement in hydrophilicity of the photoanode surface.

\section{Acknowledgement}

This work has been funded by the Research Council of Norway (RCN, RENERGI 191080 "Solid-State Photoelectrochemical Production of Hydrogen"). Vonano AS, Norway is acknowledged for providing $\mathrm{P} 25 \mathrm{TiO}_{2}$ nanoparticles.

\section{References}

[1] R. Hinogami, Y. Nakamura, S. Yae, Y. Nakato, Applied Surface Science, 121-122 (1997) 301-304.

[2] R. Hinogami, Y. Nakamura, S. Yae, Y. Nakato, The Journal of Physical Chemistry B, 102 (1998) 974-980.

[3] H. Flaisher, R. Tenne, M. Halmann, Journal of Electroanalytical Chemistry, 402 (1996) $97-$ 105.

[4] W. Kim, T. Seok, W. Choi, Energy \& Environmental Science, (2012).

[5] N.M. Dimitrijevic, B.K. Vijayan, O.G. Poluektov, T. Rajh, K.A. Gray, H. He, P. Zapol, Journal of the American Chemical Society, 133 (2011) 3964-3971.

[6] X. Chen, L. Liu, P.Y. Yu, S.S. Mao, Science, 331 (2011) 746-750.

[7] T.S. Teets, D.G. Nocera, Chemical Communications, 47 (2011) 9268-9274.

[8] A. Kudo, Y. Miseki, Chemical Society Reviews, 38 (2009) 253-278.

[9] R.M. Navarro Yerga, M.C. Álvarez Galván, F. del Valle, J.A. Villoria de la Mano, J.L.G. Fierro, ChemSusChem, 2 (2009) 471-485.

[10] S.K. Mohapatra, K.S. Raja, V.K. Mahajan, M. Misra, The Journal of Physical Chemistry C, 112 (2008) 11007-11012.

[11] B. Seger, P.V. Kamat, The Journal of Physical Chemistry C, 113 (2009) 18946-18952. 
[12] B. Seger, G.Q. Lu, L. Wang, Journal of Materials Chemistry, 22 (2012) 10709-10715.

[13] R. Marschall, C. Klaysom, A. Mukherji, M. Wark, G.Q. Lu, L. Wang, International Journal of Hydrogen Energy, 37 (2012) 4012-4017.

[14] K.O. Iwu, A. Galeckas, A.Y. Kuznetsov, T. Norby, Electrochimica Acta, 97 (2013) 320325.

[15] M.K. Hansen, D. Aili, E. Christensen, C. Pan, S. Eriksen, J.O. Jensen, J.H. von Barner, Q. Li, N.J. Bjerrum, International Journal of Hydrogen Energy, 37 (2012) 10992-11000.

[16] F. Marangio, M. Pagani, M. Santarelli, M. Calì, International Journal of Hydrogen Energy, 36 (2011) 7807-7815.

[17] O.K.V. Craig A. Grimes, Sudhir Ranjan, Springer Science+Business Media, (2008).

[18] C. Ampelli, G. Centi, R. Passalacqua, S. Perathoner, Energy \& Environmental Science, 3 (2010) 292-301.

[19] J. Georgieva, S. Armyanov, I. Poulios, S. Sotiropoulos, Electrochemistry Communications, 11 (2009) 1643-1646.

[20] J. Georgieva, S. Armyanov, I. Poulios, A.D. Jannakoudakis, S. Sotiropoulos, Electrochemical and Solid-State Letters, 13 (2010) P11-P13.

[21] J.-D. Kim, Y. Oba, M. Ohnuma, M.-S. Jun, Y. Tanaka, T. Mori, Y.-W. Choi, Y.-G. Yoon, Journal of The Electrochemical Society, 157 (2010) B1872-B1877.

[22] Q. Li, R. He, J.O. Jensen, N.J. Bjerrum, Chemistry of Materials, 15 (2003) 4896-4915.

[23] F. Seland, T. Berning, B. Børresen, R. Tunold, Journal of Power Sources, 160 (2006) $27-$ 36.

[24] W.F.S. J.F. Moulder, P.E. Sobol and K.D. Bomben, Perkin-Elmer, (1992).

[25] S. Sen, S. Mahanty, S. Roy, O. Heintz, S. Bourgeois, D. Chaumont, Thin Solid Films, 474 (2005) 245-249.

[26] J.-G. Yu, H.-G. Yu, B. Cheng, X.-J. Zhao, J.C. Yu, W.-K. Ho, The Journal of Physical Chemistry B, 107 (2003) 13871-13879.

[27] K.-T. Jeng, Y.-C. Liu, Y.-F. Leu, Y.-Z. Zeng, J.-C. Chung, T.-Y. Wei, International Journal of Hydrogen Energy, 35 (2010) 10890-10897.

[28] A. Kleiman-Shwarsctein, Y.-S. Hu, A.J. Forman, G.D. Stucky, E.W. McFarland, The Journal of Physical Chemistry C, 112 (2008) 15900-15907.

[29] B.H. Meekins, P.V. Kamat, ACS Nano, 3 (2009) 3437-3446. 
[30] S. Berger, H. Tsuchiya, A. Ghicov, P. Schmuki, Applied Physics Letters, 88 (2006) 203119-203113.

[31] J. Jiang, G. Oberdörster, P. Biswas, Journal of Nanoparticle Research, 11 (2009) 77-89.

[32] Y. Yan, J. Wang, Q. Chang, M. Babikier, H. Wang, H. Li, Q. Yu, S. Gao, S. Jiao, Electrochimica Acta.

[33] X. Ding, S. Zhou, L. Jiang, H. Yang, J Sol-Gel Sci Technol, 58 (2011) 345-354.

[34] D. Briggs, J.T. Grant, Eds., IM Publications and Surface Spectra Ltd, Chichester, 2003.

[35] J.M. Spurgeon, N.S. Lewis, Energy \& Environmental Science, 4 (2011) 2993-2998.

[36] G. de Miguel, M. Wielopolski, D.I. Schuster, M.A. Fazio, O.P. Lee, C.K. Haley, A.L.

Ortiz, L. Echegoyen, T. Clark, D.M. Guldi, Journal of the American Chemical Society, 133 (2011) 13036-13054.

[37] A. Baron, C. Herrero, A. Quaranta, M.-F. Charlot, W. Leibl, B. Vauzeilles, A. Aukauloo, Chemical Communications, 47 (2011) 11011-11013.

[38] A.N. Jansen, P.T. Wojcik, P. Agarwal, M.E. Orazem, Journal of The Electrochemical Society, 143 (1996) 4066-4074.

[39] M. Gratzel, Nature, 414 (2001) 338-344.

[40] P. Zawadzki, A.B. Laursen, K.W. Jacobsen, S. Dahl, J. Rossmeisl, Energy \& Environmental Science, (2012).

[41] S. Wang, X. Feng, J. Yao, L. Jiang, Angewandte Chemie International Edition, 45 (2006) 1264-1267.

[42] D.B. Bonham, M.E. Orazem, Journal of The Electrochemical Society, 139 (1992) 118-126. 


\section{Further results, discussion and outlook}

Whoever climbs the Iroko should gather all he can - firewood, leaves, etc - because it is not often that one climbs the tree.

\section{(An Igbo/West African proverb)}

\subsection{Photoanode selection}

$\mathrm{TiO}_{2}, \mathrm{Fe}_{2} \mathrm{O}_{3}, \mathrm{WO}_{3}, \mathrm{SrTiO}_{3}$ and $\mathrm{SnO}_{2}$ are the most widely studied photoanode materials for PEC $\mathrm{H}_{2}$ generation. Apart from $\mathrm{Fe}_{2} \mathrm{O}_{3}$, and $\mathrm{WO}_{3}$ to a lesser extent, the rest are wide bandgap materials which do not have significant visible light absorption [1]. Due to its resistance to PEC corrosion and very good charge carrier transport properties, $\mathrm{TiO}_{2}$ has been frequently investigated as a photocatalyst and was used as the primary photoanode in this thesis.

$\mathrm{Fe}_{2} \mathrm{O}_{3}$ was initially considered as a second photoanode bearing in mind its significant visible light absorption. However, $\mathrm{Fe}_{2} \mathrm{O}_{3}$ films prepared by pulsed laser deposition showed virtually no photoresponse in aqueous electrolyte based PEC tests ${ }^{*}$. This and the fact that membrane electrode assembly became increasingly focused on the use of highly acidic membrane led to discontinuation of its use, since it is only stable against corrosion in PEC operations at $\mathrm{pH}$ greater than 3 [2], with alkaline electrolyte often employed in its PEC studies. On the other hand, PEC studies on $\mathrm{WO}_{3}$ can be carried out at electrolyte $\mathrm{pH}$ less than 1 [3-5], including a $1 \mathrm{M}$ solution of a superacid $\left(\mathrm{HClO}_{4}\right)$ [5], with no report of instability on the part of $\mathrm{WO}_{3}$. Besides, $\mathrm{WO}_{3}$ has a much better charge transport properties than $\mathrm{Fe}_{2} \mathrm{O}_{3}$, for example, the hole diffusion lengths of $\mathrm{WO}_{3}$ [5] and $\mathrm{Fe}_{2} \mathrm{O}_{3}$ [6] and are reported as 2-4 and $150 \mathrm{~nm}$, respectively. It was therefore chosen as the second photocatalyst.

\subsection{Nafion ${ }^{\circledR}+$ inorganic composite proton conducting membrane}

Composites of polymer electrolytes with hygroscopic inorganic fillers have been used as proton conductors in PEM electrolysis and fuel cells. Examples comprise Nafion ${ }^{\circledR}$ with $\mathrm{WO}_{3}, \mathrm{TiO}_{2}, \mathrm{SiO}_{2}$, and phosphotungstic acid [7,8], with typical inorganic loading between 3 and $14 \mathrm{wt} \%$. The major attraction for their use is to improve the water retention capacity of

\footnotetext{
${ }^{*}$ Liquid electrolyte based PEC system at acidic and near-neutral $\mathrm{pH}$ conditions was used for initial screening of photoanodes.
} 
the membranes when operating at temperatures high enough to partially dehydrate the pure PEM. Composites membranes are usually prepared by the so called recast method which involves evaporating a solution containing the polymer electrolyte and the inorganic component to dryness at low temperatures.

As stated in manuscript III, it was not possible to use a pure PEM or composite membrane with the typical inorganic loading for PEC cell assembly by wet chemistry Nafion ${ }^{\circledR}$ adhesion because of excessive curling up of the extremely flexible membranes. Increasing the solid loading up to $30-40 \mathrm{wt} \%$ (silica and phosphotungstic acid) gave membranes which were more rigid but too brittle for practical use. With $\mathrm{Mo}_{0.5} \mathrm{~W}_{0.5} \mathrm{O}_{3} \cdot 1 / 3 \mathrm{H}_{2} \mathrm{O}$, it was possible to obtain a sufficiently rigid and flexible composite membrane at $80 \mathrm{wt} \%$ of the oxide hydrate. This is perhaps due to the large amount of chemisorbed/adsorbed water associated with the surface of the oxide hydrate which could make for a stronger bonding between it and Nafion ${ }^{\circledR}$ - through hydrogen bonds for example.
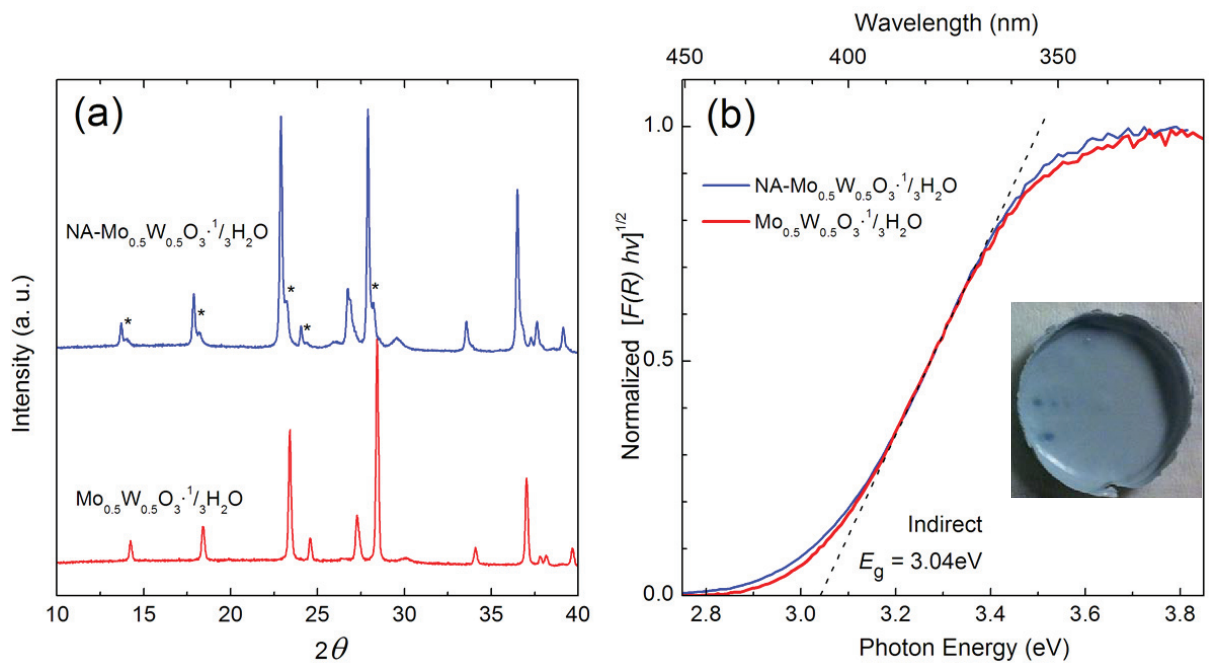

Fig. 6.1: XRD patterns (a) and Tauc plot (b) of $\mathrm{Mo}_{0.5} \mathrm{~W}_{0.5} \mathrm{O}_{3} \cdot 1 / \frac{1}{3} \mathrm{H}_{2} \mathrm{O}$ and NA$\mathrm{Mo}_{0.5} \mathrm{~W}_{0.5} \mathrm{O}_{3} \cdot 1 / 3 \mathrm{H}_{2} \mathrm{O}$. New peaks in the XRD of $\mathrm{NA}-\mathrm{Mo}_{0.5} \mathrm{~W}_{0.5} \mathrm{O}_{3} \cdot 1 / 3 \mathrm{H}_{2} \mathrm{O}$ are marked with asterisk. The inset in (b) is an image of the composite membrane (diameter is $20 \mathrm{~mm}$ ).

The XRD patterns of $\mathrm{Mo}_{0.5} \mathrm{~W}_{0.5} \mathrm{O}_{3} \cdot 1 / 3 \mathrm{H}_{2} \mathrm{O}$ and the composite membrane (NA$\mathrm{Mo}_{0.5} \mathrm{~W}_{0.5} \mathrm{O}_{3} \cdot 1 / 3 \mathrm{H}_{2} \mathrm{O}$ ) shown in Figure 6.1 a are similar, except for a shift in peaks positions to lower $2 \theta$ and appearance of a few peaks (shoulders). These new peaks cannot be indexed to any known phase of $\mathrm{WO}_{3}$ or its hydrate and so are attributed to interaction of 
$\mathrm{Mo}_{0.5} \mathrm{~W}_{0.5} \mathrm{O}_{3} \cdot 1 / 3 \mathrm{H}_{2} \mathrm{O}$ with Nafion ${ }^{\circledR}$. The shift in peak positions is also seen for pure oxide hydrate dried at $50{ }^{\circ} \mathrm{C}$, and is therefore attributed to the effect of heat. The clear presence of the signal at about $2 \theta \approx 18$ in NA- $\mathrm{Mo}_{0.5} \mathrm{~W}_{0.5} \mathrm{O}_{3} \cdot 1 / 3 \mathrm{H}_{2} \mathrm{O}$ indicates that $\mathrm{Mo}_{0.5} \mathrm{~W}_{0.5} \mathrm{O}_{3} \cdot 1 / 3 \mathrm{H}_{2} \mathrm{O}$ maintained its structure in the composite, including the usual large layers of chemisorbed water around the structural unit of $\mathrm{WO}_{3} \cdot 1 / 3 \mathrm{H}_{2} \mathrm{O}[9,10]$. These water molecules are expected to help in proton conductivity. The Tauc plots of $\mathrm{Mo}_{0.5} \mathrm{~W}_{0.5} \mathrm{O}_{3} \cdot 1 / 3 \mathrm{H}_{2} \mathrm{O}$ and NA$\mathrm{Mo}_{0.5} \mathrm{~W}_{0.5} \mathrm{O}_{3} \cdot 1 / 3 \mathrm{H}_{2} \mathrm{O}$ (Figure $6.1 \mathrm{~b}$ ) derived from analysis of the diffuse reflectance spectra show that $\mathrm{Mo}_{0.5} \mathrm{~W}_{0.5} \mathrm{O}_{3} \cdot 1 / 3 \mathrm{H}_{2} \mathrm{O}$ maintain its optical band gap in the membrane, further indicating that its structure is maintained after embedding in Nafion ${ }^{\circledR}$. An image of the membrane is shown in the inset of Figure $6.1 \mathrm{~b}$.

\subsection{Carbon paper versus titanium-covered carbon paper}

We showed in manuscript III that the photocurrent of a solid state PEC cell with NA$\mathrm{Mo}_{0.5} \mathrm{~W}_{0.5} \mathrm{O}_{3} \cdot 1 / 3 \mathrm{H}_{2} \mathrm{O}$ proton conducting membrane and $\mathrm{TiO}_{2}$ photoanode $\left(\mathrm{TiO}_{2} / \mathrm{C}\right.$-wet, referred to as $\mathrm{TiO}_{2} / \mathrm{C}$ in this chapter for the sake of simplicity) is limited at positive bias by the availability of photogenerated charge carriers and that photocurrent generation and trapping of photogenerated electrons in the $\mathrm{TiO}_{2}$ defect sites are two competing processes.

A general requirement for efficient electron transfer from a photoanode to a current collecting substrate is that the work function of the substrate should be lower than that of the photoanode, allowing for the formation of an ohmic contact at the photoanode/current collector interface [11]. It therefore follows that a better ohmic contact at the $\mathrm{TiO}_{2} /$ current collector interface in our PEC cell might help improve photocurrent generation. In dye sensitised solar cells (DSSC) ${ }^{\dagger}$, a Ti film substrate has been reported to lead to enhanced efficiency with $\mathrm{TiO}_{2}$ [12] while $\mathrm{Ti}$ film/ZnO interface is said to be superior to a contact formed between $\mathrm{ZnO}$ and other metals or fluorine tin oxide (FTO) [13]. Besides, Ti is a well known photoanode substrate in aqueous electrolyte based PEC cells. Therefore, we deposited a $100 \mathrm{~nm}$ Ti film on carbon paper (Figure 6.2) by electron beam (e-beam) evaporation $*$ and used it to prepare another cell, $\mathrm{TiO}_{2} / \mathrm{Ti}-\mathrm{C}$ in the same manner as $\mathrm{TiO}_{2} / \mathrm{C}$. Its PEC response was also recorded with an irradiance of $62 \mathrm{mw} / \mathrm{cm}^{2}$, just like in manuscript III.

\footnotetext{
${ }^{\dagger}$ A DSSC is a photoelectrochemical cell which converts photogenerated electron hole pairs to electricity, just like a silicon photovoltaic cell.

\$ Deposition done with a Leybold e-beam evaporator operating at a DC rating of 6-12 kV and beam power of 5 $\mathrm{kW}$ at $12 \mathrm{kV}$.
} 


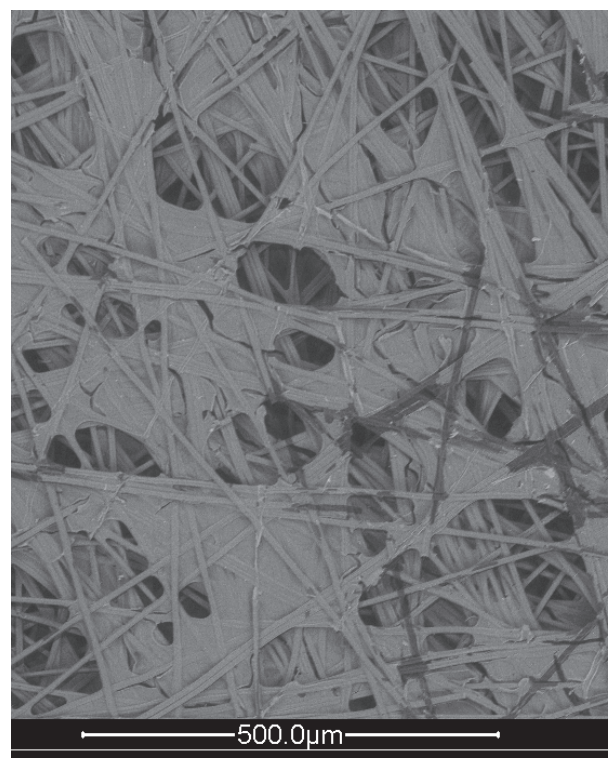

Fig. 6.2: SEM image of a Ti covered carbon paper. The darker points on the mesh are where the paper was scratched, revealing the pure carbon layer.

I-U plots shown in Figure 6.3a indicate that $\mathrm{TiO}_{2} / \mathrm{Ti}-\mathrm{C}$ has a slightly better photocurrent than $\mathrm{TiO}_{2} / \mathrm{C}$ and that its photocurrent exhibited a lesser tendency to saturate at higher applied positive bias. EIS (not shown) indicate that $\mathrm{TiO}_{2} / \mathrm{Ti}-\mathrm{C}$ show the same limitation to photocurrent posed by availability of photogenerated charge carriers as seen in $\mathrm{TiO}_{2} / \mathrm{C}$; the two cells have similar electrolyte resistance and electrode impedance. Regarding the dark I$\mathrm{U}$ curves, $\mathrm{TiO}_{2} / \mathrm{C}$ displays a higher current and correspondingly lower resistance for electrolysis than $\mathrm{TiO}_{2} / \mathrm{Ti}-\mathrm{C}$, which may reflect that the carbon is covered and protected by the Ti and its oxide layers. This variation in the I-U curves indicates that a major part of the resistance of the electrodes resides in the anode, and that the $\mathrm{H}_{2}$-evolving Pt-C cathode has better and not current-limiting kinetics, as is normal in water electrolysis.

The dark currents arising from the discharge of photo-induced capacitance (reversal of the trapping process) of the $\mathrm{TiO}_{2}$-based cells are shown in Figure 6.3b, and generally indicate a higher current density for $\mathrm{TiO}_{2} / \mathrm{Ti}-\mathrm{C}$. At $0 \mathrm{~V}$ for example, the current density of $\mathrm{TiO}_{2} / \mathrm{Ti}-\mathrm{C}$ $\left(\mathrm{TiO}_{2} / \mathrm{Ti}-\mathrm{C}\right.$ "dark") is about twice that of $\mathrm{TiO}_{2} / \mathrm{C}\left(\mathrm{TiO}_{2} / \mathrm{C}\right.$ "dark"). Utilisation of trapped electrons may be in the form of anodic current generation [14], or opposition to anodic current like reduction reaction at the anode and recombination with holes [15]. The extent to 
which the trapped electrons can be used for anodic current generation during their discharge would also be dependent on the photoanode/current collector interface. The Ti work function of $4.33 \mathrm{eV}$ [16] is lower than the 4.6 to $5.16 \mathrm{eV}$ reported for different forms of conducting carbon [17-19]. Anatase $\mathrm{TiO}_{2}$ work function is reported to be $5.23 \mathrm{eV}$, decreasing by more than $0.5 \mathrm{eV}$ on exposure to UV light [20]. The lower work function of Ti may explain its better current collecting property. However, it has been stated that work function difference is not always the only criterion that defines the interfacial contact between a photoanode and its substrate [11].
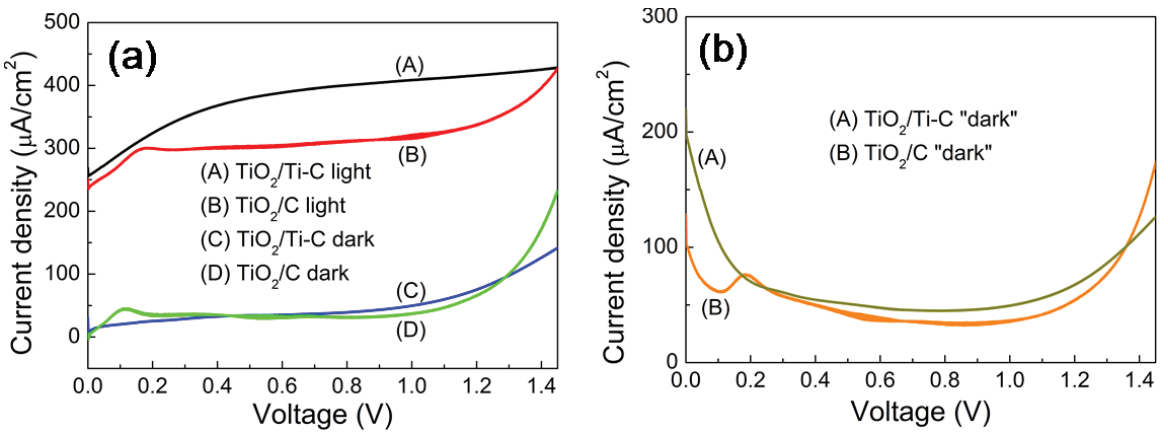

Figure 6.3: (a) I-U responses of PEC cells with and without irradiation, (b) The dark I-U curves obtained after light scan. Measurements were made at $25{ }^{\circ} \mathrm{C}$ and with $\mathrm{Ar}+\mathrm{H}_{2} \mathrm{O}+\mathrm{CH}_{3} \mathrm{OH}$ supplied to the anode compartment. 

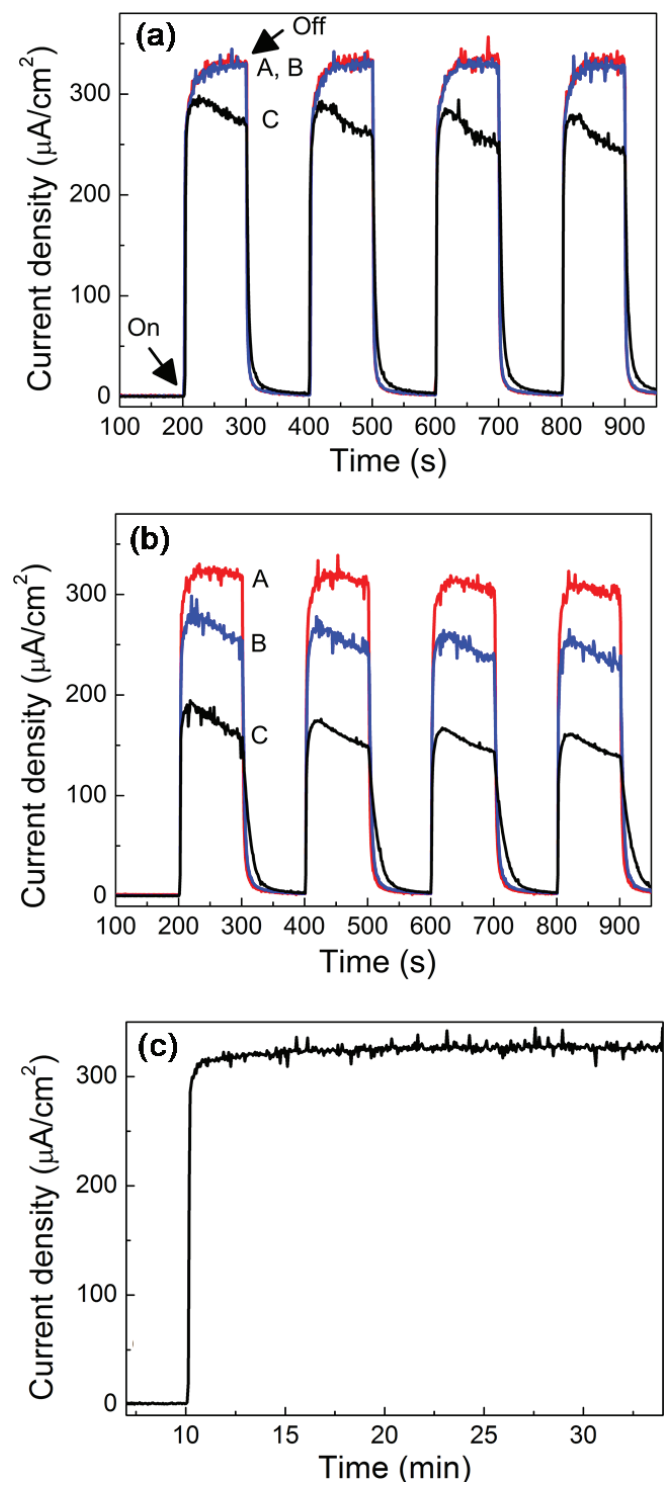

Figure 6.4: I-t plots of $\mathrm{TiO}_{2} / \mathrm{C}$ (a) and $\mathrm{TiO}_{2} / \mathrm{Ti}-\mathrm{C}$ (b) at $0.8 \mathrm{~V}$ (red, A), $0.4 \mathrm{~V}$ (blue, B) and $0 \mathrm{~V}$ (black, C); and (c) I-t plot of $\mathrm{TiO}_{2} / \mathrm{Ti}-\mathrm{C}$ at $0.8 \mathrm{~V} \mathrm{C}$ after the decay of its photocurrent had stopped. Measurements were made at $25^{\circ} \mathrm{C}$ and with $\mathrm{Ar}+\mathrm{H}_{2} \mathrm{O}+\mathrm{CH}_{3} \mathrm{OH}$ supplied to the anode compartment.

The I-t responses of $\mathrm{TiO}_{2} / \mathrm{C}$ and $\mathrm{TiO}_{2} / \mathrm{Ti}-\mathrm{C}$ are shown in Figure 6.4a-b. The magnitude of photocurrents in $\mathrm{TiO}_{2} / \mathrm{Ti}-\mathrm{C}$ are lower than what its $\mathrm{I}-\mathrm{U}$ curve would suggest and also contrary to the I-U results, lower than those of $\mathrm{TiO}_{2} / \mathrm{C}$. It was discovered that the photocurrent of the $\mathrm{TiO}_{2} / \mathrm{Ti}-\mathrm{C}$ decreased with time (in subsequent I-U measurements), which 
explains the lower ${ }^{\S}$ and decaying photocurrents at 0.4 and $0.8 \mathrm{~V}$ in the I-t plots. When photocurrent was monitored at $0.8 \mathrm{~V}$ over a period of 5 minutes, the photocurrent of $\mathrm{TiO}_{2} / \mathrm{Ti}-\mathrm{C}$ decayed by about $15 \%$ while that of $\mathrm{TiO}_{2} / \mathrm{C}$ did not but rather increased by about $10 \%$.

The decay of the photocurrent of $\mathrm{TiO}_{2} / \mathrm{Ti}-\mathrm{C}$ latter ceased as can be seen from Figure $6.4 \mathrm{c}$. We attribute the initial decay to a gradual oxidation of the Ti film which increases the contact resistance between the photoanode and the current collector [13]. A possible explanation for the cessation of the decay is that at some point the oxidation of Ti stopped as a result of exhaustion of the Ti layer or the formation of a buffer layer of oxidised Ti. In spite of this decay, the slightly better photocurrent obtained with $\mathrm{TiO}_{2} / \mathrm{Ti}-\mathrm{C}$ indicates that photocurrent of the PEC cells can be enhanced with an optimised photoanode/conducting substrate interface.

\subsection{Light-to-photocurrent conversion efficiency}

From the I-t plot in figure $6.4 \mathrm{a}$, at $0 \mathrm{~V}, 25{ }^{\circ} \mathrm{C}$, and with an irradiance of $62 \mathrm{~mW} / \mathrm{cm}^{2}$, photocurrent peaked at $294 \mu \mathrm{A} / \mathrm{cm}^{2}$ for $\mathrm{TiO}_{2} / \mathrm{C}$. That amounts to light-to-photocurrent conversion efficiency, $\eta$, of $0.6 \%$. Similarly, the hot-pressed cell (with triazole) in manuscript IV gave a photocurrent of $62 \mu \mathrm{A} / \mathrm{cm}^{2}$ with a higher irradiance of $85 \mathrm{~mW} / \mathrm{cm}^{2}$, translating to $\eta$ of $0.1 \%$. These values will definitely be higher if the actual percentage of the UV-visible irradiance that falls within the absorption profile of the photoanodes is taken into consideration.

The non-hot-pressed cell conversion efficiency appears comparable with the $0.5 \%$ conversion efficiency recorded for an aqueous, acidic electrolyte PEC cell with similar design as ours (Nafion ${ }^{\circledR}$ membrane was used to separate the cathode and photoanode but the system was still fed with aqueous electrolyte) [21]. Unfortunately, there was no information on the spectral characteristics of the light source in the PEC cell utilising aqueous electrolyte, making a more direct comparison of $\eta$ difficult. Another PEM-like cell with $\mathrm{TiO}_{2}$ nanotubes and aqueous alkaline electrolyte yielded $580 \mu \mathrm{A} / \mathrm{cm}^{2}$ of photocurrent at 0.6 $\mathrm{V}$ applied bias and $70 \mathrm{~mW} / \mathrm{cm}^{2}$ irradiance, which equates to about $0.5 \%$ ๆ. However, UV light of $365 \pm 15 \mathrm{~nm}$ wavelength was used as the illumination source. A solid state PEC cell utilising $\mathrm{TiO}_{2}$ nanotubes and the vapour of $10 \%$ ethanol in water produced a photocurrent of

\footnotetext{
$\S$ The I-t measurements were made after the I-U ones.
} 
$335 \mu \mathrm{A} / \mathrm{cm}^{2}$ at $0 \mathrm{~V}$. The efficiency of this system could not be determined because there was no information on the irradiance of the xenon-arc lamp used. Moreover, the photoanode was loaded with $0.5 \mathrm{wt} \% \mathrm{Pt}$, without which it was said to show very low photoactivity [22]. These light-to-photocurrent conversion values suggest that efficiencies of PEM-like PEC cells are still low at the moment in comparison to PEC cells with aqueous electrolyte separating the photoanode and cathode. For the latter, $\eta$ of $1.6 \%$ (simulated sunlight, AM 1.5 ) and $8 \%$ (365 nm light, $10.5 \mathrm{~mW} / \mathrm{cm}^{2}$ ) have been demonstrated with $\mathrm{TiO}_{2}$ nanowire [23] and nanotube [24], respectively (the latter used 5 vol \% ethylene glycol solution to enhance efficiency by about $40 \%$ ).

\subsection{Substituting $\mathrm{TiO}_{2}$ with $\mathrm{WO}_{3}$}

$\mathrm{WO}_{3}$ was used to replace $\mathrm{TiO}_{2}$ in the PEC cell assembly. This was done in order to utilise the visible component of the light source and also to see if the photocurrent limitation at positive bias and the light induced capacitance charging are limited to a particular type of photoanode. Using mon- $\mathrm{WO}_{3}$ nanostructures prepared by combustion synthesis involving peroxotungstic acid and thiourea [25] and precipitation from peroxotungstic acid solution (ensuring no organic contamination) gave PEC cells with rapidly decaying photocurrent in I$\mathrm{t}$ run (see appendix), and so their use was discontinued. These $m$ - $\mathrm{WO}_{3}$ samples were annealed in air between 400 and $450{ }^{\circ} \mathrm{C}$. A stable $\mathrm{WO}_{3}$ based PEC cell (hex-WO$/ \mathrm{C}$ ) was obtained with the phase pure hex $\mathrm{WO}_{3}$ nanorods (3.0 eV band gap) reported in manuscript $\mathrm{I}^{* *}$.

The dark and light I-U curves of hex- $\mathrm{WO}_{3} / \mathrm{C}$ shown in Figure $6.5 \mathrm{a}$ are similar to those of $\mathrm{TiO}_{2} / \mathrm{C}$, with photocurrent peaking around $60 \mu \mathrm{A} / \mathrm{cm}^{2}$, just above $0 \mathrm{~V}$, and remaining more or less stable before exponential increase at above $1.0 \mathrm{~V}$. It is interesting that hex- $\mathrm{WO}_{3} / \mathrm{C}$ shows some photocurrent because, in general, PEC cell with $\mathrm{WO}_{3}$ photoanode usually involves mon- $\mathrm{WO}_{3}$ prepared at higher temperatures of 450 to $600{ }^{\circ} \mathrm{C}$ [26-29] (compared to $180{ }^{\circ} \mathrm{C}$ used for the preparation of our hex $\left.-\mathrm{WO}_{3}\right)$. C. A. Grimes et al. reported that mon$\mathrm{WO}_{3}$ (nanoflakes, $2.5 \mathrm{eV}$ band gap) and hex- $\mathrm{WO}_{3}$ (nanowires, $3.1 \mathrm{eV}$ band gap) photoanodes prepared at $180{ }^{\circ} \mathrm{C}$ by hydrothermal process showed almost zero photocurrents with applied bias and a solar (AM 1.5) irradiance of $100 \mathrm{~mW} / \mathrm{cm}^{2}$. After annealing at $500{ }^{\circ} \mathrm{C}$ in air and at a bias of $1.1 \mathrm{~V}$, the hex $-\mathrm{WO}_{3}$ and $m-\mathrm{WO}_{3}$ photocurrents increased to about 700

\footnotetext{
** The solid loading of $\mathrm{WO}_{3}$ was estimated to be about $0.8 \mathrm{mg} / \mathrm{cm}^{2}$, less than the $1.3 \mathrm{mg}$ of $\mathrm{TiO}_{2}$ used in $\mathrm{TiO}_{2} / \mathrm{C}$. This was because the dropcast suspension of $\mathrm{Nafion}^{\mathbb{B}}$ and $\mathrm{WO}_{3}$ nanostructures drained out easily through the carbon paper.
} 
and $1430 \mu \mathrm{A} / \mathrm{cm}^{2}$, respectively [30]. They attributed this improvement to better crystallisation. Attempts to anneal our hex $-\mathrm{WO}_{3}$ nanorods at $450{ }^{\circ} \mathrm{C}$ and lower was not successful because the nanorods transformed into near-spherical particles.
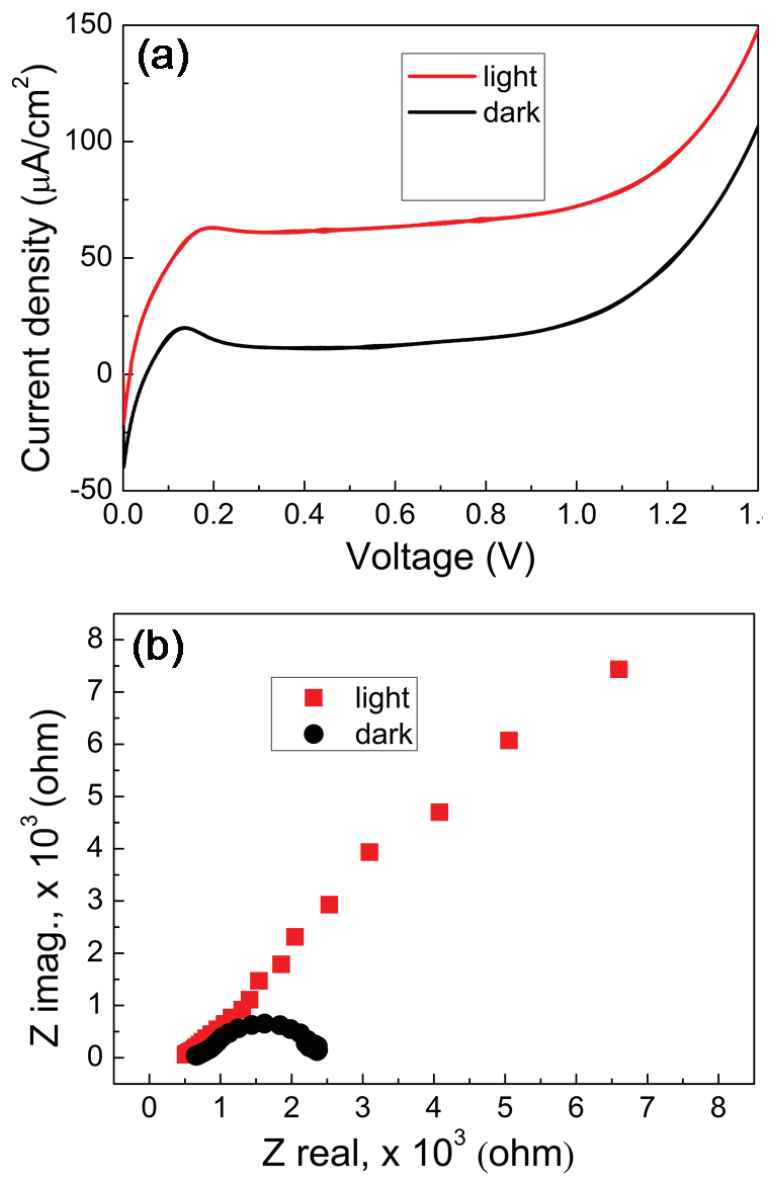

Figure 6.5: (a) I-U curves of $h e x-\mathrm{WO}_{3} / \mathrm{C}$ and (b) EIS spectra of $h e x-\mathrm{WO}_{3} / \mathrm{C}$ obtained at $60 \mu \mathrm{A}$ $\mathrm{DC}$ bias and $5 \mu \mathrm{A} \mathrm{AC}$ amplitude. All measurements were conducted at $25^{\circ} \mathrm{C}$ while supplying the anode compartment with $\mathrm{Ar}+\mathrm{H}_{2} \mathrm{O}+\mathrm{CH}_{3} \mathrm{OH}$.

By imposing a DC bias in the flat photocurrent region of the I-U curve $\left(60 \mu \mathrm{A} / \mathrm{cm}^{2}\right)$, EIS spectrum obtained under illumination (Figure 6.5b) indicates the presence of the Warburg type electrode impedance reported for $\mathrm{TiO}_{2} / \mathrm{C}$. The dark EIS spectrum at the same bias (which lies in the electrolysis region in the dark I-U plot) shows an electrolyte resistance of around $600 \Omega \mathrm{cm}^{2}$, also similar to the value for $\mathrm{TiO}_{2} / \mathrm{C}$. This indicates that the lower 
photocurrent of hex- $\mathrm{WO}_{3} / \mathrm{C}$ and OCPV of about $0 \mathrm{~V}$ - compared to about $-0.4 \mathrm{~V}$ for $\mathrm{TiO}_{2} / \mathrm{C}$ - is due to less availability of photogenerated charge carriers in this cell.

The I-t responses of hex- $\mathrm{WO}_{3} / \mathrm{C}$ are presented in Figure 6.6, indicating well defined light on and off responses. The slow decay of current after light off, which is more pronounced at 0 $\mathrm{V}$, is an indication of the discharge of photo induced capacitance of $\mathrm{WO}_{3}$. The magnitudes of current remaining after 100 seconds of "light off" (in the first cycle of the respective I-t plots) are about 1 and $20 \%$ for $\mathrm{TiO}_{2} / \mathrm{C}$ and hex $-\mathrm{WO}_{3} / \mathrm{C}$, respectively. This can be related to a better capacity of hex $-\mathrm{WO}_{3}$ for electron trapping and cation intercalation or simply to a difference in the electrical contact between carbon paper and the two photoanodes.

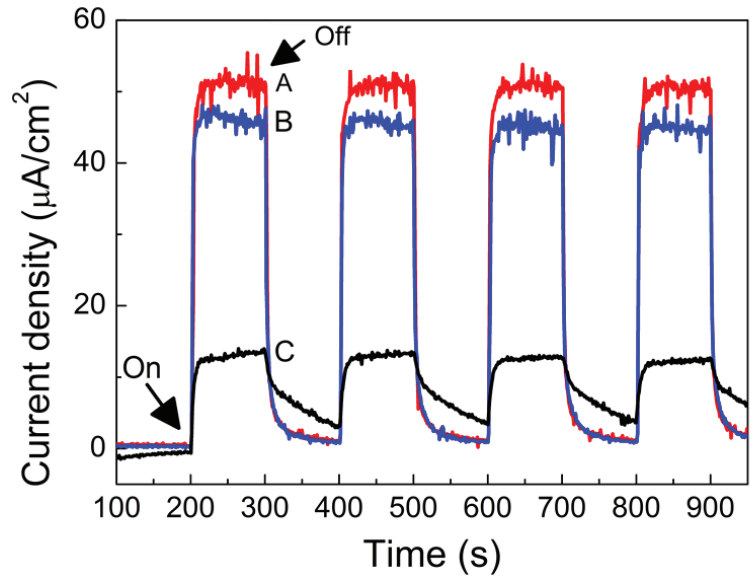

Figure 6.6: I-t plots of hex- $\mathrm{WO}_{3} / \mathrm{C}$ at $0.8 \mathrm{~V}$ (red, A), $0.4 \mathrm{~V}$ (blue, B) and $0 \mathrm{~V}$ (black, C). All measurements were conducted at $25{ }^{\circ} \mathrm{C}$ while supplying the anode compartment with $\mathrm{Ar}+\mathrm{H}_{2} \mathrm{O}+\mathrm{CH}_{3} \mathrm{OH}$.

Severe decay of photocurrent with $m-\mathrm{WO}_{3}$ samples was also noticed by Choi and Seabold in $\mathrm{WO}_{3}$ prepared at $500{ }^{\circ} \mathrm{C}$ [31]. It was attributed to the formation of peroxo species on the photoanode surface after illumination - the species are formed by the oxidation of water or hydroxyl groups and are in competition with oxygen evolution for the photogenerated holes. They were able to employ a cobalt-based oxygen evolution catalyst to stop the photocurrent decay, with stable photocurrent demonstrated for several hours in a $\mathrm{pH} 7$ electrolyte. This catalyst is not stable in acidic environment and so could not be employed in this work. 


\subsection{Photoanode/electrolyte/reactant triple phase boundary}

The lower incident light-to-current conversion efficiency of the hot-pressed cells in comparison to the non-hot-pressed ones mentioned in manuscripts III and IV has been attributed to a reduced concentration of reacting water and methanol molecules. A more intimate mixing of the photoanode with $\mathrm{Nafion}^{\circledR}$ is therefore important in order to ensure sufficient hydration of the photoanode surface. Another important function of this mixing is to facilitate the quick transport of protons produced by the oxidation of the reactants towards the proton conducting membrane. This electrode/electrolyte/reactant triple phase boundary (TPB) is considered a key area that needs to be optimised in order to enhance the efficiency of PEM fuel cells [32, 33]. In this thesis, a fourth component, light, is added to the mix.

SEM images of non-hot-pressed $\mathrm{TiO}_{2}$ and hex $-\mathrm{WO}_{3}$, and hot-pressed $\mathrm{TiO}_{2}$ are shown in Figure 6.7. It is evident that the non-hot-pressed cell with hex- $\mathrm{WO}_{3}$ anode has a significant portion of the carbon paper current collector not covered by the photoanode, which implies that the current densities shown in Figure 6.6 above for this cell could be higher when the actual PEC active area of the cell is considered. One dimensional nanostructures such as nanorods and nanotubes are of interest because they offer less resistance to the transport of photogenerated electrons. This is because electron transport through an assembly of nanoparticles of a certain average diameter will entail more encounter of the usually less conducting nanoparticle grain boundaries compared with travel along rods of same diameter but with lengths of hundreds of nanometres. 

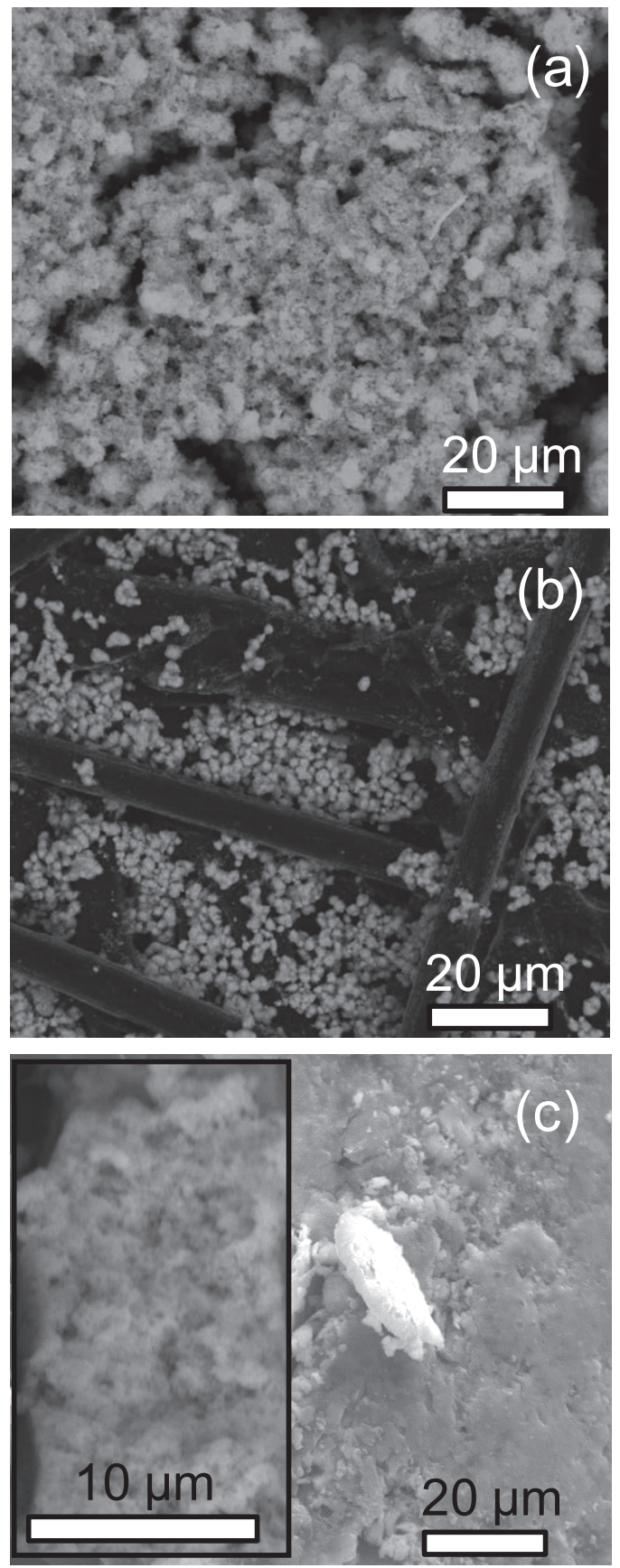

Figure 6.7: $\mathrm{SEM}$ images of non hot pressed $\mathrm{TiO}_{2}$ (a) and $h e x-\mathrm{WO}_{3}(\mathrm{~b})$, and hot pressed $\mathrm{TiO}_{2}$ (c) on carbon paper. Unlike the others, the carbon paper could be seen in (b), implying an incomplete coverage of its surface. The inset in (c) is an edge image, indicating that the hot pressed $\mathrm{TiO}_{2}$ is also porous. 
Comparing the images of the hot-pressed and non-hot-pressed $\mathrm{TiO}_{2}$ photoanode, it can be seen that the non-hot-pressed one is more porous. Therefore it is likely that insufficient gas diffusion in the photoanode of the hot-pressed cell could have been an impediment, thereby also contributing to its lower efficiency. On the other hand, as shown in manuscript III, the electrode resistance of the hot-pressed cell is much lower than that of the non-hot pressed one, which is due to a reduced contact resistance at the grain boundaries of the nanoparticles and between the nanoparticles and carbon paper. In a PEM steam electrolysis in which the membrane electrode assembly is mechanically held together by clamping, prior hot-pressing gave an improvement in cell efficiency [34]. This may imply that gas diffusion in a hotpressed electrode is not hindered or that the gain in reduction of contact resistance of the electrode with hot-pressing outweighs any loss associated with reduced porosity. In light of this and considering that the SEM image of the edge of the hot-pressed $\mathrm{TiO}_{2}$ (inset of Figure 6.7c) shows that it is probably sufficiently porous, it is likely that gas diffusion is not a limiting factor in its performance and that its lower performance is strictly related to the amount of Nafion ${ }^{\circledR}$ in the TPB as argued in manuscripts III and IV.

The arrangement of photocatalyst nanostructures when assembled into a film and the pores or in the film are also vital for enhanced light absorption, for example through enhanced light scattering. Based on the SEM images, it is not yet clear which of the photoanode assembly - hot-pressed and non-hot-pressed - leads to a better utilisation of incident light, though it appears, at face value, that the non-hot-pressed ones might have an edge in this regard.

\subsection{Suggestion for future improvements on solar-to-fuel conversion efficiency}

Maximising light absorption (down to longer wavelengths) and utilisation of photogenerated charge carriers are important for enhancing the efficiency of a PEC cell. $\mathrm{TiO}_{2}$ was mainly used as a photoanode in this thesis. A recent work on black hydrogenated $\mathrm{TiO}_{2}$ showed a significant absorption in the visible and infrared regions (and hence a much improved photocatalytic and $\mathrm{H}_{2}$ generation property) [35]. It will be interesting to see how this particular $\mathrm{TiO}_{2}$ type can improve the photocurrent of our solid-state PEC cell.

Further attempt at improving the visible light response of the solid-state PEC cells can be made by replacing $\mathrm{TiO}_{2}$ with $m o n-\mathrm{WO}_{3}, \mathrm{WO}_{3} / \mathrm{BiVO}_{4}$ bi-layers [36], $\mathrm{WO}_{3} / \mathrm{TiO}_{2}$ bi-layers [37], and $\mathrm{Fe}_{2} \mathrm{O}_{3}$, etc. The latter however will need the use of a solid proton conductor that is 
not acidic. As stated earlier in chapter 2, alkaline membranes with ionic conductivities that are close to the best performing solid proton conductors are not yet available. The use of alkaline proton conducting membrane will also make it possible to deploy the cobalt based co-catalyst developed by Nocera and co workers, which is active in neutral and alkaline environment [38]. This catalyst has been used to enhance the photocurrent of $\mathrm{Fe}_{2} \mathrm{O}_{3}$ by 500 $\%$ at $1.0 \mathrm{~V}$ applied bias with an alkaline electrolyte [39].

The $\mathrm{WO}_{3} / \mathrm{BiVO}_{4}$ bi-layer mentioned above not only enhances visible light utilisation $\left(\mathrm{BiVO}_{4}\right.$ has a band gap of 2.4), but also improves the separation of photogenerated charge carriers in $\mathrm{BiVO}_{4}$. This is accomplished by having $\mathrm{BiVO}_{4}$ inject its photogenerated electrons into the conduction band of $\mathrm{WO}_{3}$ - the latter lies more positive (lower, vs NHE) than the conduction band of $\mathrm{BiVO}_{4}$ [40]. The superior charge transport property of $\mathrm{WO}_{3}$ contributes in making this approach realistic. However the same principle has been applied to $\mathrm{Fe}_{2} \mathrm{O}_{3}$ in a $\mathrm{WO}_{3} / \mathrm{Fe}_{2} \mathrm{O}_{3}$ architecture [41]. Since the conduction band of $\mathrm{Fe}_{2} \mathrm{O}_{3}$ is reported to be more positive than that of $\mathrm{WO}_{3}[42,43]$ (see figure 3.3), it may imply that there is more to the beneficial effect of semiconductor bi-layer than the positions of their individual conduction band edges. In any case, a photoanode bi-layer provides another opportunity for improving charge carrier separation which can be complementary to the role of conjugated organic compounds such as triazole.

The importance of adequate hydration cannot be overemphasised; too little hydration and the resistivity of the cell increases, besides reducing the chances of capturing photogenerated holes at the TPB. On the other hand, too much hydration can damage the cell assembly as shown in manuscript IV, or impede diffusion of product gases. One way to obtain a high enough hydration level without damaging the cell could be the use of mechanical clamping of flow plates, as is done in PEM electrolysis [34] (see Figure 3.3). That means the flow plate on the photoanode side will have to be transparent. The lower electrode resistance in the hot-pressed cells and the higher photocurrent in the wet-chemistry assembled cells show that a combination of both processes is a potential way of preparing a cell with low resistance and good hydration.

The SEM images shown in Figure 6.6 above indicate that some photogenerated electrons would have to travel long distances before reaching the current collector substrate. Incorporation of transparent conducting nanostructures in the photoanode region is a possibility for improving electron conductivity in the PEC cells. 


\section{Conclusions}

The world is too much with us; late and soon,

Getting and spending, we lay waste our powers:

Little we see in Nature that is ours...

William Wordsworth

(In: The world is too much with us)

In order to ensure the availability of enough energy to an increasing world population in the future, it has become important to diversify the available sources of energy, away from the current situation dominated by fossil fuels. Tapping into renewable energy sources has become an important part of this goal. However, there is no gainsaying the fact that a lot more research effort - and of course political will - needs to be ploughed into renewable energy development in order to achieve this.

This work has dealt with hydrogen and photocurrent generation in an all-solid-state PEC cell with gaseous anode reactants. Increase in the amount of photocurrent has been promoted by increasing operating temperature and the use of an electro-active organic molecule to promote a better utilisation of photogenerated charge carriers.

Nanostructured $\mathrm{WO}_{3}$ and $\mathrm{WO}_{3} \cdot 1 / 3 \mathrm{H}_{2} \mathrm{O}$ were prepared and characterised by a variety of techniques in manuscripts I and II. An interesting observation on the nature of the positively charged defects - which charge compensated defect electrons - was noted: oxygen vacancies were responsible for the defect electrons in $\mathrm{WO}_{3}$, while defect protons were the primary reason or contribute significantly to those in the hydrated oxide. This combination of ionic and electronic defects makes both the oxide and its hydrate interesting for gas sensing (e.g. $\mathrm{H}_{2}$ ) and electrochromic applications, especially the hydrated oxide. In addition, the mixed ionic and electronic conductivity may find application in hydrogen separation/purification membrane.

Furthermore, it was possible to synthesise $\mathrm{WO}_{3}$ nanorods from a hydrothermal pot containing no other metal ion other than tungsten in less than a day, compared to a previously reported 7-day synthesis. A reduction in the optical absorption edge of hex- $\mathrm{WO}_{3}$ was accompanied by a simultaneous elimination of an impurity monoclinic phase. Even though the reason for this red-shift in absorption was not clarified, the development is still 
significant and may offer future insights into extending the optical absorption of the oxide further into the visible spectrum. This will be particularly important for the application of $m o n-\mathrm{WO}_{3}$, whose band gap has been reported to be as low as $2.5 \mathrm{eV} ; m o n-\mathrm{WO}_{3}$ is the most used phase of the oxide in PEC applications. Comparisons of the optical properties of two hydrothermal $\mathrm{WO}_{3} \cdot 1 / 3 \mathrm{H}_{2} \mathrm{O}$ samples prepared in different ways, and also a $50 \% \mathrm{Mo}$ substituted version of the oxide hydrate indicated that the same type of defect states are active in them. This was further narrowed down to defect protons by the analysis of deuterised sample of the hydrated oxide, in confirmation of earlier results. The peculiar nature of this hydrated oxide - stability of its structural water up to above $300{ }^{\circ} \mathrm{C}$ and presence of large number of chemisorbed and adsorbed water molecules - may have been responsible for the successful development of $\mathrm{NA}-\mathrm{Mo}_{0.5} \mathrm{~W}_{0.5} \mathrm{O}_{3} \cdot 1 / 3 \mathrm{H}_{2} \mathrm{O}$ composite proton conducting membrane.

To assemble a working solid-state PEC device, two approaches were employed. One was using concentrated Nafion ${ }^{\circledR}$ solution as adhesive for binding the catalyst layers onto the proton conducting membrane. This was made possible by the composite membrane of Nafion ${ }^{\circledR}$ and $\mathrm{Mo}_{0.5} \mathrm{~W}_{0.5} \mathrm{O}_{3} \cdot 1 / 3 \mathrm{H}_{2} \mathrm{O}$, as composites with some other commonly used inorganic materials were shown to be fairly rigid but brittle. It was important to have a membrane that was not only rigid but also flexible (not break during handling) in order to avoid excessive curling up of the membrane during the wet chemistry device assembly. Solid state PEC cell assembled by the wet chemistry adhesion (non-hot pressed) method yielded photocurrent that was up to 15 times better than that of a cell assembled by the classical hot-pressing approach, as shown in manuscript III. This was in spite of the fact that the non-hot-pressed cell has a total cell resistance that was up to 5 times more than that of the hot-pressed one. The reason for the better performance in the non-hot-pressed cell was - at least partially attributed to a better hydration of the photoanode occasioned by the surrounding Nafion ${ }^{\circledR}$ molecules.

It was also observed that the pseudo-capacitance of the $\mathrm{TiO}_{2}$ photoanode in the non-hotpressed cell was charged with illumination, simultaneously increasing with photocurrent with increasing irradiance. The implication being that charge intercalation in the $\mathrm{TiO}_{2}$ defect sites was in competition with photocurrent generation for photogenerated charged species protons and electrons. One way to counter this is to electrochemically fill the trapping sites prior to PEC operation, as pointed out earlier in section 3.4. That approach could not be 
implemented in our PEC cell yet. We however theorised that, given a more efficient $\mathrm{TiO}_{2} /$ current collector interface, (photo)current generation can be made to dominate over the capacitance build-up and its associated effect on anodic current generation. This appeared to be confirmed by the general increase in current density when the carbon paper used as anode current collector was first coated with a thin film of titanium before deposition of $\mathrm{TiO}_{2}$.

$\mathrm{WO}_{3}$ was used in place of $\mathrm{TiO}_{2}$ in the non-hot-pressed cell as a way of extending the response of the PEC cell towards visible light. $m o n-\mathrm{WO}_{3}$ from two different preparative routes gave rapidly decaying photocurrents. A PEC cell with a far more stable photocurrent was prepared using the hex- $\mathrm{WO}_{3}$ reported in manuscript $\mathrm{I}$. The reason for the difference in behaviour of the PEC cells with the two phases of $\mathrm{WO}_{3}$ is not totally clear but may have to do with the surface and electronic properties of the oxides being different. The photocurrents from the cell with hex- $\mathrm{WO}_{3}$ were much lower than that with $\mathrm{TiO}_{2}-$ up to 8 times less with a bias of $0.4 \mathrm{~V}$ for example. However, the solid loading of hex $-\mathrm{WO}_{3}$ in its $\mathrm{PEC}$ device was lower than that of $\mathrm{TiO}_{2}$ by almost a factor of two.

Operation of solid-state PEC hydrogen generating devices at higher temperatures was mainly restricted to the hot-pressed cells because increasing temperature led to a decrease in the photocurrent of non-hot-pressed cell. This was due to dehydration having a more dominant effect on photocurrent than temperature. Photocurrent was seen to increase with increasing temperature for the hot-pressed cells, limited eventually at higher temperature by stronger dehydration. It was shown by EIS that the increase in photocurrent with temperature is due to improved electrode kinetics while the electrolyte resistance decreased slightly with increasing temperature (likely due to drying of the anode layer). Thermodynamic analysis e.g. determination of activation energies - was therefore difficult to make due to this problem of dehydration.

Furthermore, it was possible to significantly increase the photocurrent of the hot-pressed cell by incorporating triazole, a conjugated heterocyclic compound, into the photoanode layer. This increase was attributed to an enhanced efficiency in the separation of photogenerated charge carriers at the $\mathrm{TiO}_{2}$ surface, based on TRPL studies. Triazole, which has been demonstrated to help in the proton conductivity of PEM in anhydrous environment, also served to mitigate against the slight decrease in electrolyte resistance with increasing temperature. An interesting observation that illumination decreased the electrolyte resistance of the hot-pressed cells was made. This may be understood as having to do with enhanced 
hydrophilicity of the photoanode surface due to formation of hydroxyl groups following light irradiation, or increase in the concentration of protons with illumination. In addition, the hotpressing process was shown to induce a red-shift in the optical absorption of the $\mathrm{TiO}_{2}$ photoanode, which is in agreement with the observation from XPS that the valence band maximum of the photoanode shifted to higher binding energy.

Part of the objectives of this thesis was to run PEC experiments with solid oxide proton conducting membranes, in order to take further advantage of the favourable thermodynamics and improved electrode kinetics at temperatures beyond the operational range of PEM. The major problem encountered with PEC cells based on solid oxide proton conductors was the difficulty in obtaining a high enough concentration of the photoanode/electrolyte/reactant TPB. Only an insignificant $1.3 \mu \mathrm{A} / \mathrm{cm}^{2}$ of photocurrent was obtained with such a device at $400{ }^{\circ} \mathrm{C}$ and $0.8 \mathrm{~V}$. It will be interesting to see what future improvement can be made to this design in order to enhance its efficiency.

Central to the quest for greater utilisation of renewable energy sources is materials science and technology, and this is especially true for PEC systems where a photoelectrode is expected to be a good semiconductor, with low recombination rate of photogenerated charge carriers, and at the same time, have appreciable charge transport properties. In addition, the photoelectrode has to be combined with a conducting substrate, an electrolyte and an electrocatalyst or another photoelectrode to form a functional cell. In such a system, as in many device assemblies in general, finding compatibility among different components is often a challenge. In this thesis, attempts have been made to prepare or select appropriate (nanostructured) materials and assemble them into a working device in the face of some challenges having to do with material stability, component integrity, and utilisation of photogenerated charge carriers. 


\section{References for chapters 1-4 and 6}

1. 2010 Survey of Energy Resources Executive Summary. World energy council, 2010.

2. Chapter 1 Why Hydrogen Energy?, in Hydrogen Energy: Challenges and Prospects. 2008, The Royal Society of Chemistry. p. 1-33.

3. Ramachandran, R. and R.K. Menon, An overview of industrial uses of hydrogen. International Journal of Hydrogen Energy, 1998. 23(7): p. 593-598.

4. Craig A. Grimes, O.K.V., Sudhir Ranjan, Light, Water, Hydrogen

The Solar Generation of Hydrogen by Water Photoelectrolysis. Springer Science+Business Media, 2008.

5. Yoon, S., et al., Self-sustained operation of a kWe-class kerosene-reforming processor for solid oxide fuel cells. Journal of Power Sources, 2009. 192(2): p. 360366.

6. Yoon, S., I. Kang, and J. Bae, Suppression of ethylene-induced carbon deposition in diesel autothermal reforming. International Journal of Hydrogen Energy, 2009. 34(4): p. 1844-1851.

7. Baykara, S.Z., Experimental solar water thermolysis. International Journal of Hydrogen Energy, 2004. 29(14): p. 1459-1469.

8. LeRoy, R.L., C.T. Bowen, and D.J. LeRoy, The Thermodynamics of Aqueous Water Electrolysis. Journal of The Electrochemical Society, 1980. 127(9): p. 1954-1962.

9. Hansen, M.K., et al., PEM steam electrolysis at $130^{\circ} \mathrm{C}$ using a phosphoric acid doped short side chain PFSA membrane. International Journal of Hydrogen Energy, 2012. 37(15): p. 10992-11000.

10. Leng, Y., et al., Solid-State Water Electrolysis with an Alkaline Membrane. Journal of the American Chemical Society, 2012. 134(22): p. 9054-9057.

11. Marangio, F., et al., Concept of a high pressure PEM electrolyser prototype. International Journal of Hydrogen Energy, 2011. 36(13): p. 7807-7815.

12. Hauch, A., et al., Highly efficient high temperature electrolysis. Journal of Materials Chemistry, 2008. 18(20): p. 2331-2340.

13. Kreuter, W. and H. Hofmann, Electrolysis: The important energy transformer in a world of sustainable energy. International Journal of Hydrogen Energy, 1998. 23(8): p. 661-666.

14. Miles, M.H., et al., Effect of Temperature on Electrode Kinetic Parameters for Hydrogen and Oxygen Evolution Reactions on Nickel Electrodes in Alkaline Solutions. Journal of The Electrochemical Society, 1976. 123(3): p. 332-336.

15. Tom, S. PEM water electrolysis - present status of research and development. in 18 th World Hydrogen Energy Conference 2010, . 2010. Essen, Germany: http://www.sintef.no/project/nexpel/pdf/HP-3d PEMelectrolysis smo\%5B1\%5D.pdf (accessed on 18/03/2013).

16. Mazúr, P., et al., Non-conductive TiO2 as the anode catalyst support for PEM water electrolysis. International Journal of Hydrogen Energy, 2012. 37(17): p. 1208112088.

17. Xiao, L., et al., First implementation of alkaline polymer electrolyte water electrolysis working only with pure water. Energy \& Environmental Science, 2012. 5(7): p. 7869-7871.

18. Laguna-Bercero, M.A., S.J. Skinner, and J.A. Kilner, Performance of solid oxide electrolysis cells based on scandia stabilised zirconia. Journal of Power Sources, 2009. 192(1): p. 126-131. 
19. Kim-Lohsoontorn, P., N. Laosiripojana, and J. Bae, Performance of solid oxide electrolysis cell having bi-layered electrolyte during steam electrolysis and carbon dioxide electrolysis. Current Applied Physics, 2011. 11(1, Supplement): p. S223S228.

20. Schefold, J., A. Brisse, and F. Tietz, Nine Thousand Hours of Operation of a Solid Oxide Cell in Steam Electrolysis Mode. Journal of The Electrochemical Society, 2012. 159(2): p. A137-A144.

21. Gan, Y., et al., Composite Oxygen Electrode Based on LSCM for Steam Electrolysis in a Proton Conducting Solid Oxide Electrolyzer. Journal of The Electrochemical Society, 2012. 159(11): p. F763-F767.

22. Li, S. and K. Xie, Composite Oxygen Electrode Based on LSCF and BSCF for Steam Electrolysis in a Proton-Conducting Solid Oxide Electrolyzer. Journal of The Electrochemical Society, 2013. 160(2): p. F224-F233.

23. Haugsrud, R. and T. Norby, Proton conduction in rare-earth ortho-niobates and ortho-tantalates. Nat Mater, 2006. 5(3): p. 193-196.

24. Norby, T., Proton Conductivity in Perovskite Oxides, in Perovskite Oxide for Solid Oxide Fuel Cells, T. Ishihara, Editor. 2009, Springer US. p. 217-241.

25. Currao, A., Photoelectrochemical Water Splitting. CHIMIA International Journal for Chemistry, 2007. 61(12): p. 815-819.

26. van de Krol, R., Y. Liang, and J. Schoonman, Solar hydrogen production with nanostructured metal oxides. Journal of Materials Chemistry, 2008. 18(20): p. 23112320 .

27. Kelly, N.A. and T.L. Gibson, Design and characterization of a robust photoelectrochemical device to generate hydrogen using solar water splitting. International Journal of Hydrogen Energy, 2006. 31(12): p. 1658-1673.

28. Miller, E.L., R.E. Rocheleau, and X.M. Deng, Design considerations for a hybrid amorphous silicon/photoelectrochemical multijunction cell for hydrogen production. International Journal of Hydrogen Energy, 2003. 28(6): p. 615-623.

29. Gratzel, M., Photoelectrochemical cells. Nature, 2001. 414(6861): p. 338-344.

30. Kleiman-Shwarsctein, A., et al., Electrodeposition of $\alpha-\mathrm{Fe} 2 \mathrm{O} 3$ Doped with $\mathrm{Mo}$ or $\mathrm{Cr}$ as Photoanodes for Photocatalytic Water Splitting. The Journal of Physical Chemistry C, 2008. 112(40): p. 15900-15907.

31. Sivula, K., F.L. Formal, and M. Grätzel, WO3-Fe2O3 Photoanodes for Water Splitting: A Host Scaffold, Guest Absorber Approach. Chemistry of Materials, 2009. 21(13): p. 2862-2867.

32. Kay, A., I. Cesar, and M. Grätzel, New Benchmark for Water Photooxidation by Nanostructured $\alpha-\mathrm{Fe} 2 \mathrm{O} 3$ Films. Journal of the American Chemical Society, 2006. 128(49): p. 15714-15721.

33. Jang, J.S., et al., Development of a Potential Fe2O3-Based Photocatalyst Thin Film for Water Oxidation by Scanning Electrochemical Microscopy: Effects of $\mathrm{Ag}-\mathrm{Fe} 2 \mathrm{O} 3$ Nanocomposite and Sn Doping. Chemistry of Materials, 2009. 21(20): p. 4803-4810.

34. Mohapatra, S.K., et al., Water Photooxidation by Smooth and Ultrathin $\alpha-F e 2 O 3$ Nanotube Arrays. Chemistry of Materials, 2009. 21(14): p. 3048-3055.

35. Yang, B., et al., Enhanced Photoelectrochemical Activity of Sol-Gel Tungsten Trioxide Films through Textural Control. Chemistry of Materials, 2007. 19(23): p. 5664-5672.

36. Xu, Y.a.S., A. A. Martin, The absolute energy positions of conduction and valence bands of selected semiconducting minerals. American Mineralogist, 2000. 85: p. 543556. 
37. Bott, W.A., Electrochemistry of Semiconductors. Current separations, 1998. 17(3): p. 87-91.

38. Garnett, E. and P. Yang, Light Trapping in Silicon Nanowire Solar Cells. Nano Letters, 2010. 10(3): p. 1082-1087.

39. Spinelli, P., et al., Plasmonic light trapping in thin-film Si solar cells. Journal of Optics, 2012. 14(2): p. 024002.

40. Ulmann, M., N.R. De Tacconi, and J. Augustynski, Behavior of surface peroxo species in the photoreactions at titanium dioxide. The Journal of Physical Chemistry, 1986. 90(24): p. 6523-6530.

41. Seabold, J.A. and K.-S. Choi, Effect of a Cobalt-Based Oxygen Evolution Catalyst on the Stability and the Selectivity of Photo-Oxidation Reactions of a WO3 Photoanode. Chemistry of Materials, 2011. 23(5): p. 1105-1112.

42. Meekins, B.H. and P.V. Kamat, Got TiO2 Nanotubes? Lithium Ion Intercalation Can Boost Their Photoelectrochemical Performance. ACS Nano, 2009. 3(11): p. 34373446.

43. $\mathrm{Ng}, \mathrm{C}$, et al., Visible light-induced charge storage, on-demand release and selfphotorechargeability of WO3 film. Physical Chemistry Chemical Physics, 2011. 13(29): p. 13421-13426.

44. Tatsuma, T., et al., TiO2-WO3 Photoelectrochemical Anticorrosion System with an Energy Storage Ability. Chemistry of Materials, 2001. 13(9): p. 2838-2842.

45. Kanan, M.W. and D.G. Nocera, In Situ Formation of an Oxygen-Evolving Catalyst in Neutral Water Containing Phosphate and Co2+. Science, 2008. 321(5892): p. 10721075.

46. Steinmiller, E.M.P. and K.-S. Choi, Photochemical deposition of cobalt-based oxygen evolving catalyst on a semiconductor photoanode for solar oxygen production. Proceedings of the National Academy of Sciences, 2009. 106(49): p. 20633-20636.

47. Zhong, D.K. and D.R. Gamelin, Photoelectrochemical Water Oxidation by Cobalt Catalyst ("Co-Pi")/ $/ \mathrm{-Fe} 2 \mathrm{O} 3$ Composite Photoanodes: Oxygen Evolution and Resolution of a Kinetic Bottleneck. Journal of the American Chemical Society, 2010. 132(12): p. 4202-4207.

48. Zhong, D.K., et al., Photo-assisted electrodeposition of cobalt-phosphate (Co-Pi) catalyst on hematite photoanodes for solar water oxidation. Energy \& Environmental Science, 2011. 4(5): p. 1759-1764.

49. Mohapatra, S.K., et al., Efficient Photoelectrolysis of Water using TiO2 Nanotube Arrays by Minimizing Recombination Losses with Organic Additives. The Journal of Physical Chemistry C, 2008. 112(29): p. 11007-11012.

50. Wahl, A., et al., Photoelectrochemical studies pertaining to the activity of TiO2 towards photodegradation of organic compounds. Journal of Electroanalytical Chemistry, 1995. 396(1-2): p. 41-51.

51. Morand, R., et al., Photoelectrochemical Behavior in Low-Conductivity Media of Nanostructured TiO2 Films Deposited on Interdigitated Microelectrode Arrays. The Journal of Physical Chemistry B, 2002. 106(29): p. 7218-7224.

52. Poznyak, S.K., A.I. Kokorin, and A.I. Kulak, Effect of electron and hole acceptors on the photoelectrochemical behaviour of nanocrystalline microporous TiO2 electrodes. Journal of Electroanalytical Chemistry, 1998. 442(1-2): p. 99-105.

53. Seger, B. and P.V. Kamat, Fuel Cell Geared in Reverse: Photocatalytic Hydrogen Production Using a TiO2/Nafion/Pt Membrane Assembly with No Applied Bias. The Journal of Physical Chemistry C, 2009. 113(43): p. 18946-18952. 
54. Seger, B., G.Q. Lu, and L. Wang, Electrical power and hydrogen production from a photo-fuel cell using formic acid and other single-carbon organics. Journal of Materials Chemistry, 2012. 22(21): p. 10709-10715.

55. Drew, K., et al., Boosting Fuel Cell Performance with a Semiconductor Photocatalyst: TiO2/Pt-Ru Hybrid Catalyst for Methanol Oxidation. The Journal of Physical Chemistry B, 2005. 109(24): p. 11851-11857.

56. Anh Tuan, P. and S. Toshio, Efficient Hydrogen Production from Aqueous Methanol in a Proton Exchange Membrane Electrolyzer with Porous Metal Flow Fields. International Journal of Automotive Engineering, 2012. 3: p. 125-130.

57. Blasse, G and Grabmaier, B. C., Luminescent Materials. Springer, Verlag Berlin Heidelberg, 1994.

58. Blasse, G., Interaction between optical centers and their surroundings: An inorganic chemist's approach. Advances in inorganic chemistry, vol. 35.

59. Shalav, A., et al., Application of NaYF [sub 4]:Er[sup 3+] up-converting phosphors for enhanced near-infrared silicon solar cell response. Applied Physics Letters, 2005. 86(1): p. 013505-3.

60. Gillet, M., et al., The role of surface oxygen vacancies upon WO3 conductivity. Surface Science, 2003. 532-535: p. 519-525.

61. Cox, S.F.J., et al., Oxide muonics: A new compendium. Physica B: Condensed Matter, 2006. 374-375(0): p. 379-382.

62. Karazhanov, S.Z., et al., Resonant defect states and strong lattice relaxation of oxygen vacancies in WO_\{3\}. Physical Review B, 2003. 68(23): p. 233204.

63. van Dijken, A., et al., The Kinetics of the Radiative and Nonradiative Processes in Nanocrystalline ZnO Particles upon Photoexcitation. The Journal of Physical Chemistry B, 2000. 104(8): p. 1715-1723.

64. Lee, K., W.S. Seo, and J.T. Park, Synthesis and Optical Properties of Colloidal Tungsten Oxide Nanorods. Journal of the American Chemical Society, 2003. 125(12): p. 3408-3409.

65. Luo, J.Y., et al., Ultraviolet-visible emission from three-dimensional WO[sub 3 - x] nanowire networks. Applied Physics Letters, 2007. 91(9): p. 093124-3.

66. Gfroerer T.H., Photoluminescence in Analysis of Surfaces and Interfaces. Encyclopedia of Analytical Chemistry, John Wiley \& Sons Ltd.

67. Khanna, V.K., Physical understanding and technological control of carrier lifetimes in semiconductor materials and devices: A critique of conceptual development, state of the art and applications. Progress in Quantum Electronics, 2005. 29(2): p. 59-163.

68. Marschall, R., et al., Composite proton-conducting polymer membranes for clean hydrogen production with solar light in a simple photoelectrochemical compartment cell. International Journal of Hydrogen Energy, 2012. 37(5): p. 4012-4017.

69. Jeng, K.-T., et al., Membrane electrode assembly-based photoelectrochemical cell for hydrogen generation. International Journal of Hydrogen Energy, 2010. 35(20): p. 10890-10897.

70. Ampelli, C., et al., Synthesis of solar fuels by a novel photoelectrocatalytic approach. Energy \& Environmental Science, 2010. 3(3): p. 292-301.

71. Georgieva, J., et al., An all-solid photoelectrochemical cell for the photooxidation of organic vapours under ultraviolet and visible light illumination. Electrochemistry Communications, 2009. 11(8): p. 1643-1646.

72. Georgieva, J., et al., Bi-component semiconductor oxide photoanodes for the photoelectrocatalytic oxidation of organic solutes and vapours: A short review with emphasis to TiO2-WO3 photoanodes. Journal of Hazardous Materials, 2012. 211212(0): p. 30-46. 
73. Georgieva, J., et al., Gas Phase Photoelectrochemistry in a Polymer Electrolyte Cell with a Titanium Dioxide/Carbon/Nafion Photoanode. Electrochemical and SolidState Letters, 2010. 13(10): p. P11-P13.

74. Licht, S., Solar Water Splitting To Generate Hydrogen Fuel: Photothermal Electrochemical Analysis. The Journal of Physical Chemistry B, 2003. 107(18): p. 4253-4260.

75. Licht, S., Solar water splitting to generate hydrogen fuel-a photothermal electrochemical analysis. International Journal of Hydrogen Energy, 2005. 30(5): p. 459-470.

76. Katakis, D., C. Mitsopoulou, and E. Vrachnou, Photocatalytic splitting of water: increase in conversion and energy storage efficiency. Journal of Photochemistry and Photobiology A: Chemistry, 1994. 81(2): p. 103-106.

77. Bell, S.J., The effect of light intensity and temperature on photocatalytic water splitting, in Doctoral thesis, Queensland University of Technology. 2011.

78. Orazem, M.E. and B. Tribollet, in Electrochemical Impedance Spectroscopy. 2008, John Wiley \& Sons, Inc.

79. Park, S.-M. and J.-S. Yoo, Peer Reviewed: Electrochemical Impedance Spectroscopy for Better Electrochemical Measurements. Analytical Chemistry, 2003. 75(21): p. 455 A-461 A.

80. T. Jacobsen, B.Z.-C., L. Bay, S. Skaarup, Proc. 17th. Risø International Symposium on Materials Science: High Temperature Electrochemistry: Ceramics and Metals, Roskilde, Denmark, 1996: p. 29.

81. Aiming, M., et al., Hematite modified tungsten trioxide nanoparticle photoanode for solar water oxidation. J. Power Sources, 2012. 210: p. 32-37.

82. Shinde, P.S., G.H. Go, and W.J. Lee, Multilayered large-area WO3 films on sheet and mesh-type stainless steel substrates for photoelectrochemical hydrogen generation. International Journal of Energy Research, 2013. 37(4): p. 323-330.

83. Esposito, D.V., et al., Photoelectrochemical reforming of glucose for hydrogen production using a WO3-based tandem cell device. Energy \& Environmental Science, 2012. 5(10): p. 9091-9099.

84. Lee, W.J., et al., Ag grid induced photocurrent enhancement in WO3 photoanodes and their scale-up performance toward photoelectrochemical H2 generation. International Journal of Hydrogen Energy, 2011. 36(9): p. 5262-5270.

85. Kennedy, J.H. and K.W. Frese, Photooxidation of Water at $\alpha-F e 2 O 3$ Electrodes. Journal of The Electrochemical Society, 1978. 125(5): p. 709-714.

86. Shao, Z.-G., et al., Hybrid Nafion-inorganic oxides membrane doped with heteropolyacids for high temperature operation of proton exchange membrane fuel cell. Solid State Ionics, 2006. 177(7-8): p. 779-785.

87. Baglio, V., et al., Solid Polymer Electrolyte Water Electrolyser Based on NafionTiO2 Composite Membrane for High Temperature Operation. Fuel Cells, 2009. 9(3): p. 247-252.

88. Daniel, M.F., et al., Infrared and Raman study of WO3 tungsten trioxides and WO3, xH2O tungsten trioxide tydrates. Journal of Solid State Chemistry, 1987. 67(2): p. 235-247.

89. Iwu, K.O., et al., One-dimensional WO3 and its hydrate: One-step synthesis, structural and spectroscopic characterization. Journal of Solid State Chemistry, 2012. 185(0): p. 245-252.

90. Roel, v.d.K., Photoelectrochemical measurements, in Photoelectrochemical hydrogen production, v.d.K. Roel and G. Michael, Editors. 2012, Springer Science+Business Media,. p. 69-120. 
91. Wang, D., et al., Fiber-shaped all-solid state dye sensitized solar cell with remarkably enhanced performance via substrate surface engineering and TiO2 film modification. Journal of Materials Chemistry, 2011. 21(17): p. 6383-6388.

92. Kyaw, A.K.K., et al., Top-illuminated dye-sensitized solar cells with a roomtemperature-processed $\mathrm{ZnO}$ photoanode on metal substrates and a Pt-coated Gadoped $\mathrm{ZnO}$ counter electrode. Journal of Physics D: Applied Physics, 2011. 44(4): p. 045102 .

93. Skriver, H.L. and N.M. Rosengaard, Surface energy and work function of elemental metals. Physical Review B, 1992. 46(11): p. 7157-7168.

94. Song, S.M., et al., Determination of Work Function of Graphene under a Metal Electrode and Its Role in Contact Resistance. Nano Letters, 2012. 12(8): p. 38873892.

95. Shiraishi, M. and M. Ata, Work function of carbon nanotubes. Carbon, 2001. 39(12): p. 1913-1917.

96. Yu, Y.-J., et al., Tuning the Graphene Work Function by Electric Field Effect. Nano Letters, 2009. 9(10): p. 3430-3434.

97. Gutmann, S., et al., Effect of ultraviolet and $x$-ray radiation on the work function of TiO[sub 2] surfaces. Journal of Applied Physics, 2010. 107(10): p. 103705-8.

98. Wang, G., et al., Hydrogen-Treated TiO2 Nanowire Arrays for Photoelectrochemical Water Splitting. Nano Letters, 2011. 11(7): p. 3026-3033.

99. Liu, Z., et al., 3-D vertical arrays of TiO2 nanotubes on Ti meshes: Efficient photoanodes for water photoelectrolysis. Journal of Materials Chemistry, 2011. 21(28): p. 10354-10358.

100. Morales, W., et al., Combustion Synthesis and Characterization of Nanocrystalline WO3. Journal of the American Chemical Society, 2008. 130(20): p. 6318-6319.

101. Santato, C., et al., Crystallographically Oriented Mesoporous WO3 Films: Synthesis, Characterization, and Applications. Journal of the American Chemical Society, 2001. 123(43): p. 10639-10649.

102. Amano, F., D. Li, and B. Ohtani, Fabrication and photoelectrochemical property of tungsten(vi) oxide films with a flake-wall structure. Chemical Communications, 2010. 46(16): p. 2769-2771.

103. Sun, Y., et al., Photoelectrochemical and structural characterization of carbondoped WO3 films prepared via spray pyrolysis. International Journal of Hydrogen Energy, 2009. 34(20): p. 8476-8484.

104. Su, J., et al., Vertically Aligned WO3 Nanowire Arrays Grown Directly on Transparent Conducting Oxide Coated Glass: Synthesis and Photoelectrochemical Properties. Nano Letters, 2010. 11(1): p. 203-208.

105. Makharia, R., M.F. Mathias, and D.R. Baker, Measurement of Catalyst Layer Electrolyte Resistance in PEFCs Using Electrochemical Impedance Spectroscopy. Journal of The Electrochemical Society, 2005. 152(5): p. A970-A977.

106. O'Hayre, R. and F.B. Prinz, The Air/Platinum/Nafion Triple-Phase Boundary: Characteristics, Scaling, and Implications for Fuel Cells. Journal of The Electrochemical Society, 2004. 151(5): p. A756-A762.

107. Chen, X., et al., Increasing Solar Absorption for Photocatalysis with Black Hydrogenated Titanium Dioxide Nanocrystals. Science, 2011. 331(6018): p. 746750.

108. Su, J., et al., Nanostructured WO3/BiVO4 Heterojunction Films for Efficient Photoelectrochemical Water Splitting. Nano Letters, 2011. 11(5): p. 1928-1933. 
109. Chatchai, P., et al., Efficient photocatalytic activity of water oxidation over WO3/BiVO4 composite under visible light irradiation. Electrochimica Acta, 2009. 54(3): p. 1147-1152.

110. Matsumoto, Y., Energy Positions of Oxide Semiconductors and Photocatalysis with Iron Complex Oxides. Journal of Solid State Chemistry, 1996. 126(2): p. 227-234. 


\section{Definitions and acronyms}

RES - Renewable energy source

OER - Oxygen evolution reaction

HER - Hydrogen evolution reaction

PEM - Polymer electrolyte membrane

PEC - Photoelectrochemical

AM 1.5 - A definition of the typical solar irradiance (taken to be $100 \mathrm{~mW} / \mathrm{cm}^{2}$ ) reaching the surface of the earth in temperate latitudes. It is used as a standard in testing solar devices.

$\eta$ - Light (solar)-to-current (chemical) conversion efficiency

$\mathrm{E}_{\mathrm{F}}-$ Fermi level

SCR - Space charge region, also known as accumulation or depletion region

$\mathrm{E}_{\mathrm{C}}-$ Conduction band edge

$\mathrm{E}_{\mathrm{V}}-$ Valence band edge

$\mathrm{V}_{\mathrm{fb}}$ - Flat band potential

SOM - Small organic molecules

PL - Photoluminescence

GS - Ground state

ES - Excited state

TRPL - Time-resolved photoluminescence

EIS - Electrochemical impedance spectroscopy

CPE - Constant phase element

$h-\mathrm{WO}_{3}-$ Hexagonal $\mathrm{WO}_{3}$

$m-\mathrm{WO}_{3}-$ Monoclinic $\mathrm{WO}_{3}$

$o-\mathrm{WO}_{3} \cdot 1 / 3 \mathrm{H}_{2} \mathrm{O}$ - Orthorhombic $\mathrm{WO}_{3} \cdot 1 / 3 \mathrm{H}_{2} \mathrm{O}$

ac- $\mathrm{WO}_{3} \cdot 1 / 3 \mathrm{H}_{2} \mathrm{O}$ - Orthorhombic $\mathrm{WO}_{3} \cdot 1 / 3 \mathrm{H}_{2} \mathrm{O}$ prepared from a solution containing acetic acid and urea.

$\mathrm{g}-\mathrm{WO}_{3} \cdot 1 / 3 \mathrm{H}_{2} \mathrm{O}-$ Orthorhombic $\mathrm{WO}_{3} \cdot 1 / 3 \mathrm{H}_{2} \mathrm{O}$ prepared from a green solution, with no additives.

1D - One dimensional

DRS - Diffuse reflectance spectroscopy

DRIFTS - Diffuse reflectance infrared Fourier transform spectroscopy

HRTEM - High Resolution transmission electron microscopy 
SAED - Selected area electron diffraction

XPS - X-ray photoelectron spectroscopy

Pt-C - Platinum coated carbon particles

NA- $\mathrm{Mo}_{0.5} \mathrm{~W}_{0.5} \mathrm{O}_{3} \cdot 1 / 3 \mathrm{H}_{2} \mathrm{O}$ - A composite membrane of Nafion ${ }^{\circledR}$ and $\mathrm{Mo}_{0.5} \mathrm{~W}_{0.5} \mathrm{O}_{3} \cdot 1 / 3 \mathrm{H}_{2} \mathrm{O}$ with

a 4:1 weight ratio in favour of the oxide hydrate.

$\mathrm{TiO}_{2} / \mathrm{C}$-wet $\left(\mathrm{TiO}_{2} / \mathrm{C}\right)$ - A PEC cell assembled with Nafion ${ }^{\circledR}$ as adhesive.

$\mathrm{TiO}_{2} / \mathrm{Ti}-\mathrm{C}-$ Similar to $\mathrm{TiO}_{2} / \mathrm{C}$-wet above but with the anode carbon paper covered with titanium film.

n- $\mathrm{TiO}_{2} / \mathrm{C}-$ Similar to $\mathrm{TiO}_{2} / \mathrm{C}$-wet, but with membrane/electrode assembly made by hot-pressing.

nt- $\mathrm{TiO}_{2} / \mathrm{C}-\mathrm{A}$ PEC cell assembled by hot-pressing but containing triazole in the photoanode layer.

$\mathrm{Ar}+\mathrm{H}_{2} \mathrm{O}+\mathrm{CH}_{3} \mathrm{OH}-\mathrm{A}$ gas mixture of $97.5 \% \mathrm{Ar}, 2.27 \% \mathrm{H}_{2} \mathrm{O}$ and $0.23 \% \mathrm{CH}_{3} \mathrm{OH}$.

I-U - Current vs. voltage

I-t - Current vs. time

OCPV - Open circuit photogenerated voltage

PBI - Polybenzimidazole

TPB - Triple phase boundary

NHE - Normal hydrogen electrode 


\section{Appendix}

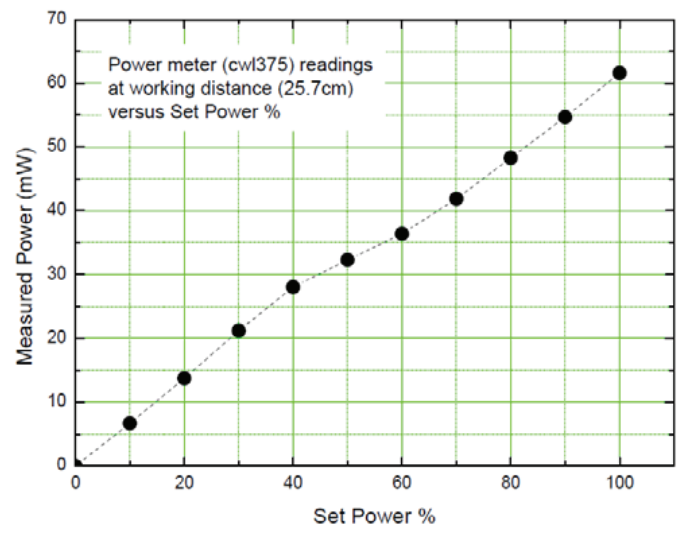

The measured irradiance (measured power, integrated intensity from 300 to $500 \mathrm{~nm}$ ) versus the set power of the Omnicure S2000 lamp. The irradiated area was $1 \mathbf{c m}^{2}$ area and was set at a distance of $25.7 \mathrm{~cm}$ from the tip of the light guide. The irradiance measurements were made with Ocean Optics USB4000 and HR4000 spectrophotometers, both with detection range of 200 to $1100 \mathrm{~nm}^{\dagger \dagger}$.

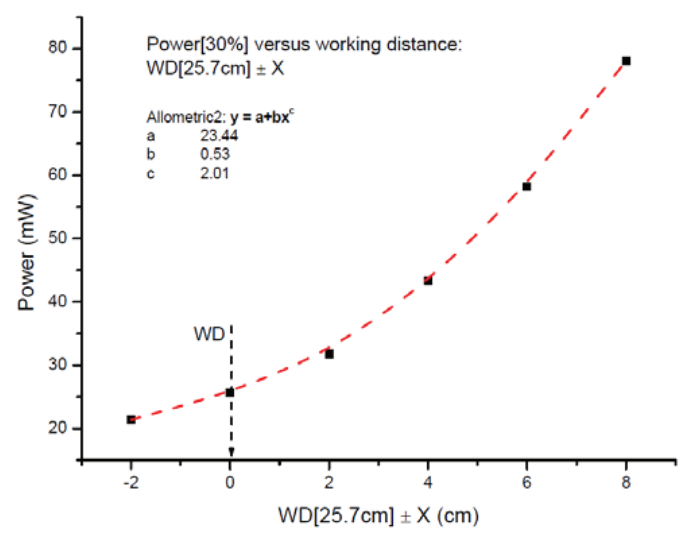

Plot of irradiance vs deviation from $25.7 \mathrm{~cm}$ light guide-to-sample distance (WD). On the $\mathrm{x}$ axis, 0 corresponds to $25.7 \mathrm{~cm}$ and positive values denotes decreasing WD while negative values denotes increasing WD. This plot was used to determine the irradiance on deviating from WD $=25.7 \mathrm{~cm}^{\text {㳯. }}$.

\footnotetext{
\$ Measurements courtesy of Dr Augustinas Galeckas.
} 


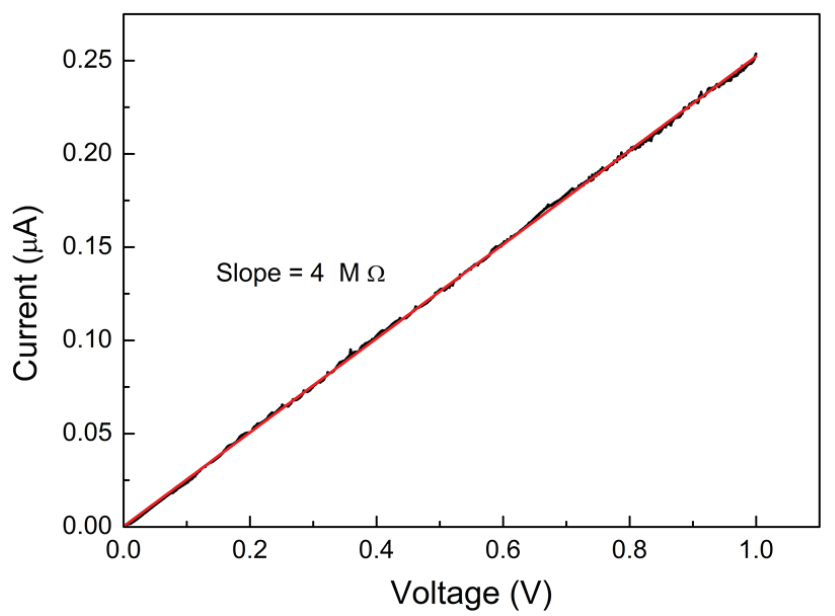

Current vs. voltage plot of a $4 \mathrm{M} \Omega$ resistor run to ascertain the reliability of the potentiostat in a 2 electrode set-up (black line is measured data while the red is the linear fit).

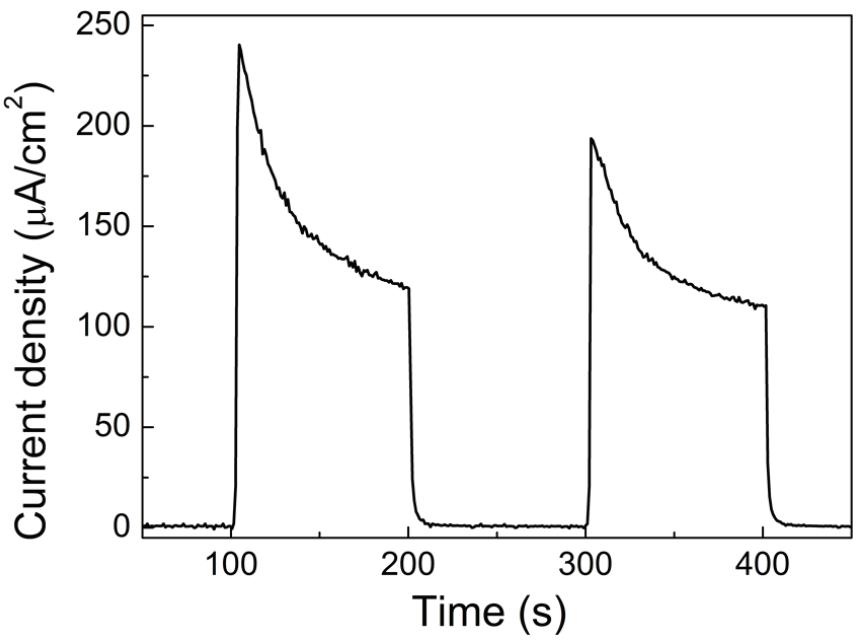

Current vs. time plot of a non-hot-pressed $m o n-\mathrm{WO}_{3} / \mathrm{C} \mathrm{PEC}$ cell at $25^{\circ} \mathrm{C}$ and $0.8 \mathrm{~V}$ applied voltage. The fast decay is also seen at other bias voltages and $0 \mathrm{~V}$ also. The anode gas was $\mathrm{Ar}+\mathrm{H}_{2} \mathrm{O}+\mathrm{CH}_{3} \mathrm{OH}$. 


\section{Supporting information for manuscript IV}

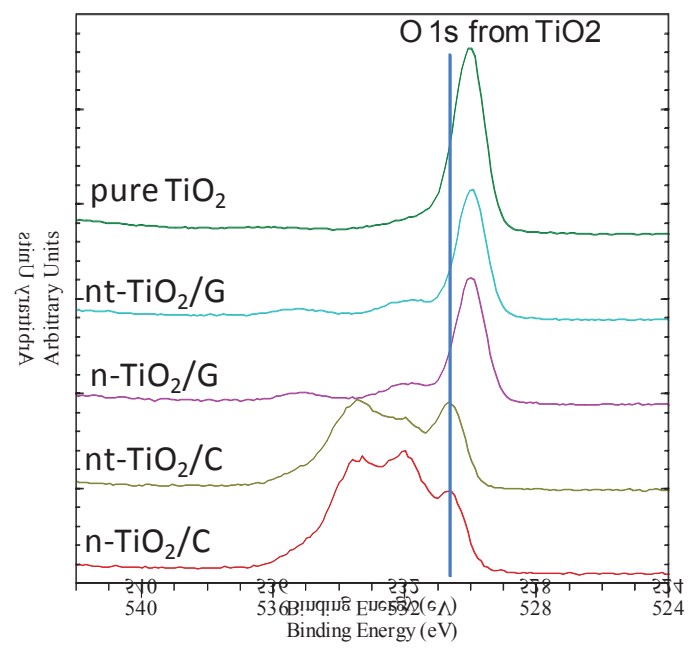

Fig. S1: High resolution spectra of $O$ 1s peaks. The binding energies of $O 1$ s from the photoanode are shifted to higher $\mathrm{eV}$.

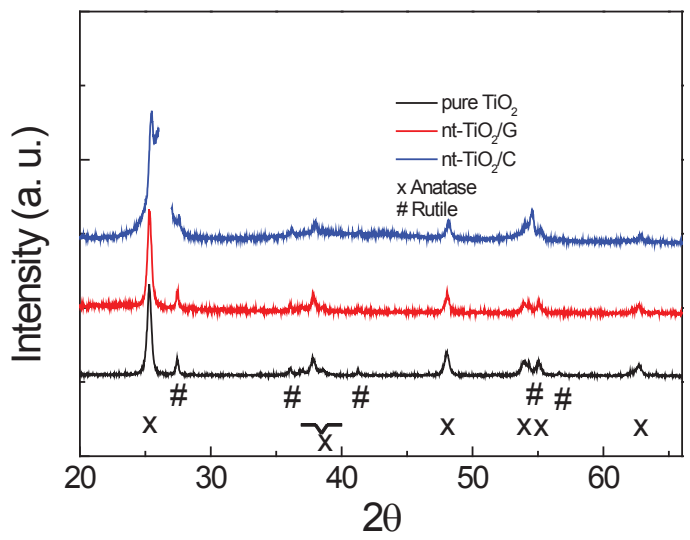

Fig. S2: XRD of representative samples. The diffractofram for nt- $\mathrm{TiO}_{2} / \mathrm{C}$ and $\mathrm{nt}-\mathrm{TiO}_{2} / \mathrm{G}$ are representative of $\mathrm{n}-\mathrm{TiO}_{2} / \mathrm{C}$ and $\mathrm{n}-\mathrm{TiO}_{2} / \mathrm{G}$ respectively. The cut portion in $\mathrm{nt}-\mathrm{TiO}_{2} / \mathrm{C}$ is ascribed to graphite-2H from the carbon paper (JCPDS 041-1487) 


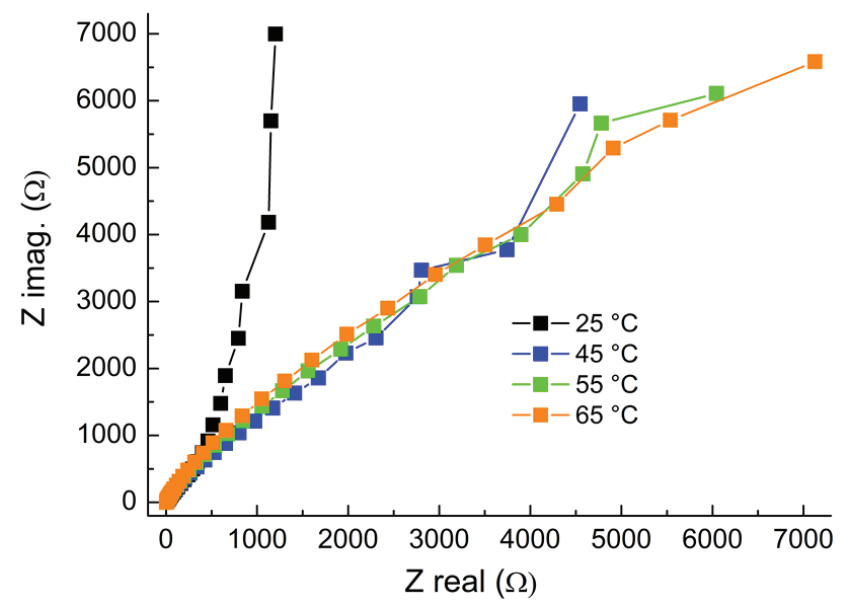

Fig. S3: Dark Nyquist plots of $n-\mathrm{TiO}_{2} / \mathrm{C}$ obtained with a $\mathrm{DC}$ bias of $0.4 \mathrm{~V}$ at various temperatures. The plot at $\mathrm{O} \mathrm{V}$ and those for $\mathrm{nt}-\mathrm{TiO}_{2} / \mathrm{C}$ follow the same trend.

\section{Preparation of samples for FT-IR}

Triazole $+\mathrm{TiO}_{2}$ conjugate was prepared by first dispersing $15 \mathrm{mg} \mathrm{TiO} 2$ in $1 \mathrm{M} \mathrm{H}_{2} \mathrm{SO}_{4}$ solution, followed by stirring for 10 mins. Thereafter the nanoparticles were centrifuged and washed three times with deionised water. The acidified $\mathrm{TiO}_{2}$ was then dispersed in deionised water and $5 \mathrm{mg}$ triazole (in isopropanol) added, followed by incubation for $5 \mathrm{mins}$ (with stirring). The conjugate was separated by centrifugation and washed with deionised water and isopropanol. Nafion ${ }^{\circledR}$ was excluded in order not to obscure the signals from triazole. The samples were dispersed in $\mathrm{KBr}$ at concentration of $0.8-1.5 \mathrm{wt} \%$. 